\title{
1 Das römische Oratorium im Spiegel der Annales Ecclesiastici
}

\begin{abstract}
Divino plane consilo factum est, ut nostra aetate, ante annos triginta, ad eiusmodi Apostolici conventus formam magna ex parte, et potissimum quae ad audientium aedificationem ex rerum divinarum sermonibus comparata, ad profectum Ecclesiae peragi mandavit Apostolus, in Urbe fuerint instituta opera in primis R. P. Philippi Nerii Fiorentini.
\end{abstract}

Baronius, Ann. Ecc., I, S. 477

Im ersten Band seiner Annales Ecclesiastici fügte der aus Sora stammende Cesare Baronio eine Passage ein, in welcher die Funktion einer seit seiner Ankunft in Rom 1557 zuerst privaten und ab $1575 \mathrm{zu}$ einer Kongregation angewachsenen Versammlung von Laien und Priestern beschrieben wird. Diese Zusammenkünfte wurden bereits seit ihrem Gründungsjahr vom engsten Kreis des später zum Heiligen gesprochenen Filippo Neri, der im Zentrum jener Versammlungen stand, als Oratorium bezeichnet. Die Kongregation des Oratoriums, die im Zusammenhang mit den Gründungen neuer Bruderschaften im Jubeljahr 1550 entstand, sollte ein Treffpunkt und Ort des gemeinsamen Gebetes von Menschen aus allen Gesellschaftsschichten Roms sein. Bis zu ihrer endgültigen Etablierung als eigenständige Kongregation, die schliesslich im Jahr 1575 durch ein päpstliches Gutachten Gregors XIII. Boncompagni bestätigt wurde, war diese vom Florentiner Neri gegründete Versammlung noch fest in ein dichtes Netzwerk karitativer Bruderschaften des römischen Stadtraumes eingebunden. Anlässlich des Jubeljahres 1550 boten die Hospitäler geeignete Unterkünfte für die nach Rom strömenden Pilger. Folgt man der Lebensbeschreibung des ersten Biographen Filippo Neris, Antonio Gallonio, hatte jener schon früher eine solche Bruderschaft samt Hospital gegründet, die als Vorbild der späteren Kongregation des Oratoriums betrachtet werden kann. Die Gründung karitativer Bruderschaften zielte nach der Eröffnung des Konzils von Trient im Jahr 1545 darauf ab, eine angemessene Verwaltung der Sakramente und der Spende im liturgischen officium zu bewerkstelligen. Dadurch rückte vor allem die Messzelebration mit den quarant'ore verstärkt in den Mittelpunkt des Interesses solcher Bruderschaften:

Desiderando sempre Filippo fare cosa, che à Dio piacesse, volle insieme col P. Persiano Rosa Sacerdote [...] suo padre spirituale, che habitava in San Girolamo della Charità, [...] dar principio ad uno Spedale, dove si ricevessero poveri pellegrini, che venivano per visitare i santi luoghi di Roma. [...] S’adunavano costro insieme nella Chiesa [San Salvatore in Campo] [...], e quivi erano con affetto grande di charità ministrati loro i Santissimi Sagramenti. Facevasi nel medesimo luogo ogni prima Domenica del mese d'ordine del B. Padre l'oratione delle quaranta hore, nel qual tempo ragionava egli di Dio con frutto grande degli uditori, incitando tutti alla divotione colle parole [...] ne si partiva di Chiesa infino che l'orationi non erano finite. ${ }^{31}$

31 Gallonio, Vita, 29-30. Vgl. zur Gründung der Confraternita della SS. Trinità, die dann im Jahr 1578 als Erzbruderschaft bezeichnet wurde, v. a. Delcroix 2011, S. 68-70; Cistellini 1970, S. 3-23

Ә Open Access. () 2022 Filip Malesevic, publiziert von De Gruyter. (c) BY-NC-ND Dieses Werk ist lizenziert unter einer Creative Commons Namensnennung - Nicht-kommerziell - Keine Bearbeitung 4.0 International Lizenz. https://doi.org/10.1515/9783110741117-002 
Die karitativen Tätigkeiten der am 16. August 1548 gegründeten Bruderschaft der Santissima Trinità dei Pellegrini e Convalescenti konzentrierten sich insbesondere auf die Unterstützung der Pilger während des Jubeljahres: ungefähr 20.000 von ihnen wurde eine Herberge angeboten. Die quarant'ore bildeten in Bezug auf die Verehrung sowie auf den Empfang der heiligen Sakramente das Zentrum der liturgischen Zelebration dieser Confraternità, in der durch ein über vierzig Stunden kontinuierlich andauerndes Gebet vor dem heiligen Sakrament der Eucharistie der Zeit Christi im Grab gedacht wurde. Der Mailänder Erzbischof Carlo Borromeo (15641584) war sich der Wirkung eucharistischer Frömmigkeitspraktiken angesichts der protestantischen Häresie bewusst. Er wollte in jeder Diözese Mailands eine sakramentale Bruderschaft gründen, um den Laienstand über die ordentliche Verehrung des heiligen Sakramentes der Eucharistie zu unterrichten, durch das er ,gegen alle Sünden und bösartiges Verhalten beschützt[e]“ werde. Borromeo verfasste 1575 schliesslich seine Regeln, durch welche die Zelebration der darin beschriebenen quarant'ore festgelegt wurde. Der Kontrast zu den heiligen Prozessionen und zur eucharistischen Verehrung diente ihm dazu, die „,weltlichen Vergnügen des Karnevals“ $\mathrm{zu}$ verurteilen. ${ }^{32}$ Diese besondere Art der Förderung eucharistischer Andacht, die bei der Bruderschaft der Santissima Trinità dei Pellegrini besonders ausgeprägt war, entstand in der Compagnia di San Girolamo della Carità. Der Florentiner Neri pflegte um die Mitte des 16. Jahrhunderts eine besondere Beziehung zu den beiden wichtigsten Gestalten der Tridentiner Reform, nämlich dem Priester Bonsignore Cacciaguerra und dem Dominikaner Ambrogio Catarino Politi.

Diese Erwähnung der Kongregation des Oratoriums muss innerhalb von Baronios Annales besonders berücksichtigt werden, da sie auch in Baronios Abhandlung des frühen Christentums angeführt wird. Deshalb hatte die bisherige Forschung die Wechselwirkung zwischen der eucharistischen Verehrung, wie sie in den Feiern der quarant'ore hervortrat, und einer liturgischen Messzelebration innerhalb derselben

und idem 1989, Bd. 1, S. 42-45. Filippo Neri wurde mit 36 Jahren am 23. Mai des Jahres 1551 in San Tommaso Parione zum Priester ordiniert, so dass in der hier wiedergegebenen Passage mit dem „B. (eato) Padre“ Persiano Rosa gemeint sein muss. Rosa wurde in Genazzano geboren. In Rom wurde er dann später zum Kaplan der Kirche von San Girolamo della Carità berufen. Zu seiner Bekanntschaft mit Neri vgl. v. a. Marangoni, Vita, App., S. 24-26: „Fu dei rimi sacerdoti, ch' entrarano e vissero in questa casa con fiori di gran virtù e bontà. Fu di costumi così illibati, e di purità così grande, che meritò di esser favorito da Dio con molte grazie singolarissime, trà le quali, meritatamente annoversari quella di avergli dato in custodia quel candidissimo giglio di purità Filippo Neri, fino alla sua giovent'ù guidandolo sicuramente per la via dello Spirito. Sì che poi l'istesso padre attestò, che il Santo era vergine, sapendo egli tutti gli arcani, e segreti dei lui cuore“. Vgl. hierzu auch Bella 2006, S. 76-83, 182.

32 Seine Avvertenze sind in AEM, II, Sp. 1927-1930, abgedruckt. Zu den quarant'ore vgl. weiter Weil 1974, S. 223; idem 1992; Petersen 2012, S. 115-120 sowie jüngst Stewart 2015, S. 138. Die Wechselwirkung zwischen quarant'ore und den cinquecentesken Bruderschaften Roms hatte bereits Black 1989, S. 99-100, angesprochen. 
Kongregation vernachlässigt. Eine solche Betrachtungsweise der erwähnten Passage aus den Annales bietet sich daher besonders an, um die starke Einflussnahme der Tridentiner Debatten auf die eucharistische Verehrung sowie die Messefeier während Baronios ersten Jahren in Rom nachzuzeichnen. ${ }^{33}$ Der folgende Abschnitt wird daher sowohl die Entstehung und Datierung von Baronios De origine Oratori eingehend beleuchten als auch seinen Beitritt in das frühe Oratorium Neris neu bewerten. ${ }^{34}$ Baronio zeichnet darin in groben Zügen die Ursprünge des Oratoriums anhand dreier Kirchengebäude - San Girolamo della Carità, San Giovanni dei Fiorentini und Santa Maria in Vallicella - nach. Baronios Feststellung, dass es vor der Gründung der Kirche von Santa Maria in Vallicella und den damit verbundenen Ablässen durch Papst Eugen III. „,in Rom kein Gedenken an die Geburt der Gottesgebärerin gäbe“, deutet auf eine Verbindung zwischen eucharistischer Andacht und der innerhalb des Oratoriums gepflegten Verehrung der Gottesmutter hin. Im Folgenden wird aber nicht nur auf die Bedeutung der Verehrung des heiligen Sakramentes der Eucharistie einzugehen sein. Ebenso soll die vielfach vernachlässigte Frage, aus welchem Anlass Baronio seinen Traktat verfasst habe, beantwortet werden.

\subsection{Entstehungsnarrative des Oratoriums}

Im ersten Band seiner Annales Ecclesiastici, der von der Vatikanischen Druckerei 1588 herausgegeben wurde, beschreibt Baronio die Entwicklung des frühen Christentums. Bereits in der Vorrede dieses Bandes, in der die Widmung an den Peretti-Papst Sixtus V. enthalten ist, findet die Kongregation des Oratoriums eine erste, bedeutende

33 Die offiziellen, vom Tridentinum promulgierten Dekrete zur Eucharistie wurden während der 13. Sitzung am 11. Oktober 1551 beschlossen, diejenigen zur Messfeier während der 22. Sitzung am 17. September 1562. Hierbei ist es entscheidend anzumerken, dass diese beiden Dekrete aus zwei verschiedenen und im Abstand von 10 Jahren liegenden Pontifikaten, nämlich demjenigen Julius“ III. und dem Pius‘ IV., verfasst wurden. Zu den Dekreten zuletzt O’Malley 2013, S. 147-149, 189-195. Vgl. auch CT, VII/1, S. 144-146, 208-212 sowie eadem, VIII, S. 402-463.

34 Baronios Traktat galt seit über 200 Jahre als verschollen, bis P. Antonio Bellucci dieses im Archiv des Oratoriums in Neapel unter der Signatur ACN, XXI.1 wiederfand. Das Konvolut enthält vor allem Miszellaneen mit dem Titel Liber historiae Congregationis Oratorii, woraus Bellucci 1927 den transkribierten Text Baronios veröffentlichte: Bellucci 1927. Zuletzt zu Baronios Text, begleitet von einer deutschen Übersetzung vgl. Wodrazka 2012, S. 115-122. Falls nicht anders vermerkt, werden sich die folgenden Ausführungen auf Wodrazkas Übersetzung stützen. Der Text wurde ebenfalls in englischer Sprache bei Finnegan 2008, S. 29-38, übersetzt. Erstmals wird der Traktat bei Marciano, Memorie historiche, I, S. 3-4, 12, 13-14, 31, 44-49, 51 erwähnt. Mit der Zuschreibung der Autorschaft dieser Schrift an Baronio, haben Ponnelle/Bordet 1958, XXVII, Anm. 2, dann argumentiert, dass das darin enthaltene „blumige und umgelenkte Latein [...] typisch für den Stil Baronios“ sei. Zur italienischen Edition des Textes vgl. Cesare Baronio, „Alle Origini dell’ Oratorio filippino“, in: Memorie Oratoriane. Quaderni di storia e spiritualità oratoriana 17 (1995), S. 110-115. Zu Baronios Traktat i. Allg. vgl. Cerrato 2009, S. 78-83. 
Erwähnung. ${ }^{35}$ Baronio reagierte damit - wie sich aus seiner Briefkorrespondenz mit dem Vorsitzenden der neapolitanischen Oratorianerfiliale, Antonio Talpa, rekonstruieren lässt - auf den durch seine Mitbrüder im römischen Oratorium auf ihn ausgeübten Druck. Aufgrund eines auf den 19. Februar 1588 datierten Schreibens an Talpa lässt sich schliessen, dass Baronio das Oratorium und dessen karitative Tätigkeiten ursprünglich nicht im ersten Band seiner Annales zu erwähnen beabsichtigte, da er in den Jahren davor einen Verfall der römischen Kongregation festgestellt hatte. Bereits in einem früheren Brief vom 30. Oktober 1587 an denselben Talpa erwähnt Baronio, dass das Oratorium bereits im Widmungsschreiben an den Papst eine honorevol mentione erhalten habe, weshalb er eine wiederholte Erwähnung als überflüssig erachte. ${ }^{36}$ Darüber hinaus waren Baronio und Talpa sich einig, dass die Predigten des Oratoriums zum Zeitpunkt der Drucklegung von Baronios Annales bereits von ihrer ursprünglichen Gestalt abgewichen waren. In einem Schreiben an Filippo Neri bekundet Talpa seine Freude über die „Reinheit“ und „Einfachheit“ der frühen Versammlungen, die nicht mehr länger zu finden seien:

Hoggi il Padre messer Francesco Maria (Tarugi) ha ragionato in sul libro familiarmente, et è stato il primo, e di poi ha ragionato messer Giovenale (Ancina) Io ne ho sentita tanta consolatione che non potrei dir di più, parendomi di veder l'Oratorio in quella purità e semplicità che soleva essere in San Girolamo [...] Si conservarà la forma di ragionare propria dell'Oratorio et si trasmetterà in posteros, chè altrimenti si perderebbe, ch' è quanto bene ha la nostra Congregazione. ${ }^{37}$

35 Ann. Ecc., I, n. p. (Widmung an Sixtus V.): „Nota est Sanctitati vestrae vetus consuetudo Oratorii nostri; in quo singulis diebus, pomeridianis horis, panis verbi Dei, sic paruulis frangitur, ut non illo sublimi dicendi genere, quod in sacris concionibus adhiberi solet, sed aliquanto submissiore, ac magis familiari, verum ad permovendos audientium animos [...] valde accomodato, res cominus, quasi ex aequo loco cum unoquoque agi videatur. Quam ob causam inter alia ex variis diversisq (ue) sanctorum Patrum scriptis ad mores optimos instituendos accepta, Sanctorum vitae, \& ecclesiastica gesta narrantur, quod ad virtutis \& pietatis stadium in auditorium animis excitandum, exempla magnam vim habeant“.

36 ACN, X.2, f. 342r: „Scrivo la presente in contratularmi della commune gratia fattaci dal Sig.re della sua convalescentia: per la quale ottenne, equi si è affatigato assai, et al fine concessaci dalla Santissima Madre: alla quale tanto siamo obligati. Benedetto sia il Signore qui vulnerat et medetur. Dirrete al R. P. Ms. Francesco Maria [Tarugi], che si farrà honorevol mentione nell'epistola dedicatoria a S. S.tà de nostro Oratorio, et ne remanerà satisfatto“. Auch zit. in Testimonianze, S. 204. Vgl. dann ebenfalls das vom Februar 1588 wiederum an Talpa adressierte Schreiben in ACN, II.1, f. 40v-41r; Memorie, S. 103 und Alberici, Epistolae et opuscula, III, S. 19-21, hier 20.

37 Zit. n. Cistellini 1975, S. 5-12. Der Brief Talpas an Neri ist auf den 9. Dezember 1588 datiert. Der Oratorianer Gigli hatte ebenfalls in einem an Talpa adressierten und sich in ACR, XIII.1, f. $157 r$ befindenden Schreiben die frühe Entstehung des Oratoriums folgendermassen festgehalten: „Le dico che hanno preso allegrezza il Padre e li altri deputati et sacerdoti quando hanno inteso che Vostra Reverenza ha parlato costì sopra il libro, conforme all' antico costume dell' Oratorio, quando in spiritu et veritate et simplicitate cordis si ragionava (=predicava), dando campo allo Spirito Santo che infundesse le sue virtù in bocca a chi parlava, senza che ci si mettesse profundo et premeditato 
Demnach wünschte sich Talpa, dass das Oratorium wieder zu seiner ursprünglichen Gestalt der ersten Jahre seit der Gründung in San Girolamo della Carità zurückgeführt würde. Talpa kritisierte vor allem die nun festzustellende Abkehr der confratelli von ihren durch die eucharistische Andacht motivierten Versammlungen. ${ }^{38}$ Nichtsdestotrotz setzte Baronio das Oratorium in seinen Annales mit einer „apostolische[n] Gemeinschaft“ gleich. ${ }^{39}$ Diese Einbindung der Kongregation Neris in die Annales bedarf daher im Zusammenhang mit seinem oben erwähnten Traktat De origine Oratori einer genaueren Erläuterung.

Cesare Baronio erklärt in diesem Traktat die Entstehung des Oratoriums mittels einer vom Kirchenvater Hieronymus überlieferten Metapher. Als dieser zusammen mit einem „Weltklerus“ in einem neuen Betlehem weilte, spendete er den Hungernden mit dem „Brot des Lebens“ die Heilige Eucharistie. Mit der Beschreibungder karitativen Tätigkeit des Kirchenvaters gewann Baronio gleichsam einen Einblick in die Verwaltungspraxis der Eucharistie und ihrer Spende:

Wie sehr die, die danach trachten Seelen zu gewinnen, der Stadt nützen, dafür ist die Welt Zeuge und für diejenigen, die, als ob sie mit dem heiligen Hieronymus zusammen in einem neuen Betlehem weilten, aus diesem das Brot des Lebens reichlicher den danach Hungernden spendeten. Damals lernte Rom nach diesem eifriger Hunger zu haben und reichlicher davon gesättigt zu werden. Daher wurde der häufige Empfang der heiligen Eucharistie wieder eingeführt, der schon seit langem außer Gebrauch gekommen war. Die Väter übten das in Worten und Schriften, und erzielten damit sofort einen Zustrom, als ob Hieronymus selbst aus der Wüste nach Rom hierher zurück gekommen sei [...] und die übrigen sich an ihn wandten, um mit dem Brot von Betlehem gesättigt zu werden, um in seine Worte eingeführt und mit seinen Bräuchen vertraut zu werden [...]. ${ }^{40}$

diuturno studio et revolutione di libri et di diversi autori et scholastici [...] Et se qualcuno dicesse: non è più quel tempo della simplicità, hoggi si cammina coi piedi più tersi; io certo di questo non me ne intendo [...] ma bene il posso dire che a me pare che quel tempo della simplicità non recava minor frutto che si faccia al presente [...] Et io dico che allora ci era maggior fuoco nelle lingue di chi ragionava, et perciò si palpavano le conversioni, si empievano le religioni il che oggi è raro. Che bisogna? Fuoco, fede, ferro. Fuoco per accendere il cuore di chi ragiona, fede per sperare che chi dava spirito allhora lo darà ancora di presente, ferro per tagliare la nostra propria volontà et stabilirsi nella santa obbedienza di chi anni et anni ci ha guidati, et sia pregato il Signore che anni et anni ancora ci guidi“. Vgl. diesbezüglich auch Talpa, Institutio, S. 8-9: „[...] il cotidiano e familiare esercizio de la Parola di Dio per introdurre et mantenere vivi li altri due mezzi, cioè la frequentia de' Sacramenti e l'esercizio dell' oratione“.

38 Talpa, Institutio, S. 8-9: „[...] il cotidiano e familiar esercizio de la Parola di Dio [...] per introdurre et mantenere vivi li altri due mezzi, cioè la frequentia de' Sacramenti e l' esercizio dell' oratione“.

39 Ann. Ecc., I, S. 477.

40 Baronio, De origine Oratori, S. 110: „Hi qui lucro tantummode animarum inhiantes, quantum profecerint Urbi testis est orbis, qui una velut cum Hieronimo in nova Bethlehem commorantes, panem vitae abundantius exurientibus ex ea ministrabat. Didicit tunc Roma hunc avidius exurire et uberius satiari; illic frequens sacrae Eucharistiae usus iam vetustate dimissus, est restitutus. Egere id patris verbis, egere et scriptis, qualis illuc statim factus concursus dixisses ipsum Hieronimum 
Während somit die anfänglichen Versammlungen des Oratoriums noch eine lose Gruppierung in San Girolamo della Carità waren, mussten diese vor allem von der Verehrung sowie Spende des Eucharistie-Sakraments angeregt worden sein. Die Zusammenkünfte Neris und seiner Mitbrüder wiesen insbesondere bei der Messzelebration Ähnlichkeiten mit der Zusammenkunft Jesu und seiner Jünger beim letzten Abendmahl auf. Die Gedenkfeiern zum letzten Abendmahl waren allerdings auch ausserhalb der Messe im Oratorium stark verankert, insbesondere während denjenigen Mahlzeiten, die nach den regelmässigen Veranstaltungen stattfanden..$^{41}$ Damit zeigte Baronio in seinem Traktat das problematische Verhältnis zwischen liturgischer Ordnung und einer weniger regulierten und daher weit offeneren Organisation auf, die sich ab den 1580er Jahren allmählich zu manifestieren begann. Diese Feststellung spricht für eine Datierung von Baronios Traktats auf die Zeit des Pontifikats Sixtus' V. und nicht, wie die Forschung bislang meinte, in die Ära des vorhergehenden Boncompagni-Pontifikats Gregors XIII. In Baronios Auslegungen ist eine besondere Verwandtschaft mit den Bestrebungen des Peretti-Papstes zu erkennen, die am 22. Januar 1588 in der Papstbulle Immensa aeterni Dei festgehalten wurden. Das Kardinalskollegium wurde damit einer systematischen Neuordnung unterzogen, die mit einer ebenso neuen Strukturierung der Kongregationen einherging.

Baronios De origine Oratorii weist mehrere Gemeinsamkeiten mit dieser Bulle auf. Darüber hinaus kann sie sogar als eigentlicher Anlass für das Verfassen des Traktats betrachtet werden. Die Konstitution leitet mit einer Ausführung über die wunderbare Harmonie der Schöpfung Gottes ein und führt weiter aus, dass im Himmlischen Jerusalem der „Baumeister aller Dinge“ die Geister der Seligen in verschiedene Ordnungen einteile. Diese Ränge waren hierarchisch strukturiert. Die Pläne der göttlichen Vorsehung liessen sich somit von den höheren auf die niederen Ränge überführen. Der Körper der Ecclesia militans erscheint dadurch als Abbild der Ecclesia triumphans und ist ebenfalls in verschiedene Stufen eingeteilt, die „durch das Band der Liebe zusammengefügt und verbunden sind“. Sowohl die Erhaltung als auch das Heil dieses Körpers basieren demgemäss auf der gemeinsamen Unterstützung der Hierarchien der Ecclesia militans. ${ }^{42}$ Der römische Bischof, der als sichtbares Haupt dieses Kirchenkörpers aufgefasst wird, ruft seine Gehilfen dazu auf, die Riten mit derselben Sorgfalt, die er dabei walten liess, in allen Kirchen des Erdkreises auszuüben. Die Bulle richtete sich damit nicht nur an alle Bischöfe, sondern auch an die Kardinäle, die ,als die edelsten Glieder ganz nahe mit dem Haupte zusammenhängend, wie Christus dem Herrn die Apostel,

ex haeremo Romam postlimino reversum et illic ad eum properare [...] ipsum adire, ut bethlehemitico pane satiarentur, verbis instruerentur et moribus imbuerentur [...]“.

41 Ibid., S. 111: „[...] ipsum adierunt et eadem mox ibi fuerint repetita instituta, consuetae epulae, dixisses ipsam Spientiam solitam apposuisse mensam, mox cunctos invitasse, panem et vinum miscuisse, nam et sapienter cuncta suo ordine fuerunt disposita“.

42 Bull. dipl. rom., VIII, S. 985. Die deutschen Übersetzungen der Bulle sind Pastor 1891-1933, Bd. 10, S. 181-182 entlehnt. 
stets zur Seite stehen“. Dies sollte hauptsächlich dem Papst dazu dienen, die „gewaltige Last seiner Sorgen und Geschäfte“ an die übrigen Behörden der römischen Kurie übergeben zu können. ${ }^{43}$ Die Einleitung der Bulle schliesst mit der Einsetzung von fünfzehn Kongregationen ab, von welchen sechs sich der Verantwortung des Kirchenstaates annehmen sollten. Die übrigen waren mit „geistlichen Angelegenheiten“ beauftragt. Eine dieser fünfzehn Kongregationen war die Congregatio pro sacri ritibus et caeremoniis, der die Kardinäle Niccolò Sfondrato, Agostino Valier, Vincenzo Laureo und der Mailänder Federico Borromeo angehörten und welche mit der Verwaltung der Sakramente und der Überwachung des öffentlichen Gottesdienstes beauftragt wurde. Der Kardinal und spätere Erzbischof von Neapel, Alfonso Gesualdo, wurde zum Vorsteher dieser Kongregation berufen. Gemäss dem Text der Bulle sollten die Kardinäle dieser Kongregation dafür Sorge tragen, dass die ,alten christlichen Bräuche überall, in allen Kirchen Roms und des Erdkreises bei der Messe, dem heiligen Offizium, sowie bei der Verwaltung der Sakramente wiederhergestellt und wieder verbessert werden“. ${ }^{44}$ Sixtus V. beauftragte den Vorsteher der Riten- und Zeremonienkongregation bereits im Frühjahr 1588 damit, sich zu erkundigen, inwieweit die von Papst Pius V. herausgegebenen liturgischen Bücher, nämlich das Breviarum und das Missale Romanum, einer Verbesserung bedurften. Dafür holte sich Gesualdo bei gelehrten Ordensleuten, wie den Theatinern in Neapel und den Oratorianern in Rom, Gutachten ein, die Verbesserungsvorschläge zu diesen liturgischen Büchern beinhalteten. Vom 27. August 1588 liegt ein schriftliches Fragment von Cesare Baronio selbst vor, das den Beschluss der Kongregation festhält, die Kapitel, Evangelien, Homilien und Predigten für die drei im Breviarum festgehaltenen lectiones zu zitieren. In demselben Fragment wird auch erwähnt, dass bei denjenigen Lektionen, die aus der Heiligen Schrift entnommen sind, die zitierten Bücher aus dem Neuen und Alten Testament am Rande des Breviarium anzugeben seien. ${ }^{45}$

Durch den Vergleich jener lectiones mit Baronios De origine Oratori fällt insbesondere auf, dass der Traktat die Entwicklung des Oratoriums anhand dessen Rezitationen

43 Bull. dipl. rom., VIII, S. 986: „[...] multos sibi [...] adiutores advocat atque adsciscit, cum venerabiles episcopos fratres suos, quos toto terrarum orbe ad singulos greges pascendos mittit, tum amplissimum ordinem S. R. E. cardinalium, qui tamquam nobilissima mebra capiti propius cohaerentia, eidem summo Pontifici, sicut Christo Domino apostoli, semper assistunt, quique primi laborum et consiliorum socii sunt et participes, ut partita inter eos aliosque Romanae Curiae magistratus ingenti curarum negociorumque mole [...]“.

44 Ibid., S. 989: „[...] praecipue cura incumbere debeat ut veteres tirus sacri ubivis locorum, in omnibus Urbis orbisque ecclesiis, etiam in capella nostra pontificia, in missis, divinis officiis, sacramentorum administratione, ceterisque ad divinum cultum pertinentibus, a quibusvis personis diligenter observentur [...]“. Zur Auseinandersetzung Sixtus' V. mit liturgischen Fragen vgl. infra, Kap. 4.2.2. Zur Riten- und Zeremonienkongregation vgl. jüngst Parigi 2012, S. 32-39.

45 Das Fragment hält auch die weiteren Beschlüsse während der am 10. September und 25. Oktober abgehaltenen Sitzungen fest und wird in BVR, G. 83, aufbewahrt. Es bleibt weiterhin innerhalb der 
des liturgischen Stundengebets nacherzählt, das den im Breviarum festgehaltenen Lektionen entnommen wurde. Nach den Vorbereitungen zur Mahlzeit wurde innerhalb des Oratoriums als Nachahmung der „Zusammenkunft der alten Väter“ (antiquorum patrum collationibus) einem der Brüder ein Buch zum Vorlesen vorgelegt. Dieser las daraus entweder eine Abhandlung zu den Tugenden (virtutes) oder zur „Geschichte der Heiligen“ vor. Ein anderer Bruder setzte das Thema fort, indem er entweder das Vorgelesene ausführlicher erläuterte oder durch genauere Darlegungen erweiterte. Daraufhin wurden in einer vorbereiteten Ansprache Beispiele aus den Heiligenleben „bewährter Autoren“ (probatis auctoribus) vorgetragen. Die Kirchengeschichte (ecclesiastica historia) diente als Kontrast zu den ausgewählten Heiligenleben. Sie behandelte die Vergänglichkeit des Lebens im Diesseits und erzählte von den Qualen der göttlichen Strafe sowie von den Belohnungen des Lebens. In dem von Baronio verfassten Fragment, das die Beschlüsse der Sitzung vom 27. August 1588 festhält, findet sich die Bestimmung der Kongregation, dass es bezüglich der Heiligengeschichten zum Nutzen derer, die sich mit der Reform des Breviers beschäftigten, notwendig sei, die Autoren, aus denen sie entnommen wurden, entsprechend zu zitieren. Innerhalb des Commune Sanctorum sollten demgemäss so viele Lektionen eingesetzt werden, dass sie für eine Lesung über alle Oktaven genügten. ${ }^{46}$ Der englische Pilger Gregory Martin, der sich nach dem Heiligen Jahr 1575 in Rom aufhielt und sehr wahrscheinlich damals auch das römische Oratorium besuchte, hielt in seinem Tagebuch die in der Kirche von Santa Maria in Vallicella gehaltenen Versammlungen fest:

[...] after dinner also every day in the weeke at a knowen hower they beginne, and two houres they continew a goodly kinde of spiritual exhortation in this maner as foloweth. Four of them at lest, one after an other, during the sayd two hoires, not in pulpet, but upon a benche somewhat higher then the audience, sitting as it were among them, make familiar discourses every one of diverse godly matters in great varietie of utterance and wittes, but one divine spirit moving al their tonges to winne infinite soules to life everlasting. Neither are they curious in this case or solemne, but every one as he seeth cause, taketh this text of Scripture or that, this Ecclesiastical storie or that, the life \& example of this Sainte or that: every one a diverse thing, and many of them every day play their part with singular grace, amiable speaches, Zelous spirit, often inculcating Confession, Receaving, Visiting prisons, visiting Hospitals, and serving also the sicke and sore, which in Rome is no rare thing. There is also one present before the

Forschung unbemerkt, dass Sixtus V. ein reges Interesse an der Reform des Breviarum Romanum zeigte, zu welcher Baronio einen bislang unbeachtet gebliebenen Beitrag leistete. Folgende Akten darüber liegen ebenfalls in BVR, G 79, vor, dessen handschriftliches Material hier erstmals betreffend Baronios Beitrag untersucht wird: infra, Kap. 4.2.1. Zur Brevierreform unter Sixtus V. vgl. zuletzt Bäumer 1895, S. 485-486.

46 BVR, G. 83, f. 160r. Zu den Versammlungen der Oratorianer vgl. Baronio, De origine Oratori, S. 112: „Utque post haec auditores aliquantulum allevarentur consultum fuit ut alter fratrum ecclesiasticas reteret historias, a Christi adventu sumens exordium, quodque per annos singulos utiliter gestum fuit ex probatis scriptoribus referret. Aderat postremo qui alicuius sancti vitam, ex probato auctore, paraphrastice magna audientium utilitate enarraret. Haecque diu per trium horarum spatium ad minus absque audientium tedio explebantur“. 
houre, who to supplie the time and to feede the auditors that are coming in by litle and litle an houre before, readeth a spiritual booke [...] and so filleth up al voyde time with blessed matter of meditation and exhortation. To these exhortations come in the weeke dayes men of good calling both spiritual and temporal such as have not other necessarie businesse of office or occupation to withhold them. But upon the Sundayes and holy dayes this exercise is so increased by the thicke assemble openly in a garden [...]. ${ }^{47}$

Für Martin standen die karitativen Tätigkeiten, wofür das Oratorium innerhalb der römischen Stadtgesellschaft bekannt war, im Vordergrund. Baronio sah hingegen in diesen Versammlungen einen organischen Aufbau, der sich aus der Erzählung der Entwicklung der römischen Kirche seit dem Frühen Christentum in Hinblick auf ihre „Nützlichkeit“ (utiliter), aus der Rezitation ausgewählter Heiligenviten in Hinblick auf ihre spirituelle Bedeutung (spiritualiter) und schliesslich aus Fragen der religiösen Moral (moraliter) zusammensetzte. ${ }^{48}$ Baronios Ausführungen zur Entstehung und Wirkung des Oratoriums vermitteln eine besondere Auffassung darüber, wie sich der Einfluss der Kurie auf die römische Stadttopographie auswirkte. Derselbe Stadtraum schöpft seine heilswirksame Einheit aus dessen Verschmelzung mit einer seitens der Kurie gesteuerten liturgischen Ordnung. Dadurch weist der urbane Stadtraum Roms für Baronio eine spezifische Affinität zur Reform des römischen Ritus auf. Galt bislang die Kongregation des Oratoriums seitens der Forschung als eine von der komplexen und diskontinuierlichen Landschaft von Frömmigkeitsbewegungen der römischen Kirche dislozierte Entität, so wurde ihre vom römischen Kurienapparat unabhängige Entstehung auch in Baronios Traktat angenommen. ${ }^{49}$ Es soll zunächst nur im Rahmen von De origine Oratori gezeigt werden, inwieweit Baronio das Oratorium als einen verlängerten Arm des kurialen Kongregationswesens betrachtete, indem er die liturgisch-zeremonielle Ordnung, wie sie die Riten- und Zeremonien-

47 Martin, Roma Sancta, S. 73-74. Die erhöhte Anzahl an Zuhörern anlässlich von Festtagen bestätigt Baronio, De origine Oratori, S. 112: „Diebus tamen festis ad verspetinum officium usque trahebantur sermones, post quos ad divinas laudes dimittebatur populus et ad audiendas aliorum lectiones, nec tantum apud eos vel loqui vel audire in proposito erat, sed praecipue ipsa operum exhibitio, quandoquidem per singulos dies iidem summo vesperi ibidem conveniebant ad orationem quae pro unius horae spatio explebatur, et ibidem ter in hebdomade se flagellis caedebant; diebus singulis nonnulli infirmantium hospitalia visitabant ac iisdem ministrabant; diebus tamen festis tanta erat talium ministrantium numerositas, ut diu publicorum hospitalium Romae existentium ministerio satis essent, quae pia ministeria non nobilis vel quivis sericis indutus erubescebat, sed quisque illorum gloriabatur in humilitate sui“.

48 Letzteres wurde auf der Grundlage kirchenväterlicher Schriften, wie Ambrosius` Officiis oder Gregors d. Gr. Moralia, debattiert und vorgetragen: Baronio, De origine Oratori, S. 111-112. Einen ähnlichen Aufbau hatten die bereits in der noch unter Papst Pius V. herausgegebenen Edition des Breviarum Romanum enthaltenen lectiones. Die ersten beiden wurden aus dem Alten und Neuen Testament entnommen, während diejenigen Lektionen dritten Ranges aus den Heiligenleben und der Patristik stammten. 49 Zuccari 1981a, S. 77; idem 1981b, S. 171-175. Zur politischen Kultur der Kongregation des Oratoriums und ihrer Entwicklung seit ihren Anfängen in San Girolamo della Carità vgl. zuletzt Russo 2001 sowie Zen 1996. 
kongregation ausarbeitete, als Bezugspunkt für Neris Kongregation sah. In der römischen Oratorianerfiliale hätten sich, gemäss Baronios Vorstellungen, die kurialen Kongregationen abbilden lassen können, um eine allgemeingültige Eintracht des gesamten Kirchenkörpers vom Priestertum bis zum Kardinalsbischof zu erlangen. Der Gründervater des Oratoriums war aber, wie im Übrigen auch seine engsten Mitbrüder, entschieden gegen eine solche Ausgestaltung seiner Kongregation. Zu einem späteren Zeitpunkt soll auf die Konstellation der römischen Bruderschaften innerhalb des Stadtraumes eingegangen werden. In dieser Gesamtlage der Bruderschaften war nämlich das Oratorium während seiner ersten Jahre fest eingebunden. Aus dieser engen Verwandtschaft mit den Bruderschaften Roms soll die kuriale Einflussnahme auf Neris Kongregation ableitbar sein, von welcher sich das Oratorium allmählich zu distanzieren begann. Diese Entwicklung des Oratoriums zu einer von der Kurie unabhängigen und autonomen Priesterversammlung, die bereits um die Mitte des Cinquecento einsetzte, ist fester Bestandteil einer vom späteren, aber gleichzeitig mit Baronio zum Kardinal erhobenen Oratorianer Francesco Maria Tarugi verfassten und an Carlo Borromeo adressierten memoria. Tarugis Memorialschrift zeichnet im Vergleich mit Baronios De origine Oratori ein geradezu entgegengesetztes Bild des Oratoriums:

[...] è libero à tutti di venire, sedere et partirsi à piacer loro [...]. Ed è da osservare, che piu frutto si vede nascere da ragionamenti fatti all' improviso sopra quelle materie che impreparatamente s' offeriscono, che non si fa nelle cose pensate. [...] Ma questi due primi, che parlano impensatamente sopra il libro, del qual libro non sono avisati lor prima, ma il lettore prende quale piu li piace, di molti che li sono dati boni et approvati per questo esercitio, bisogna che havendo à ragionare all' improviso sieno huomini molto versati, si che possino sopra ogni materia parlare [...] Et non è da disprezzare questo ricordo ancora per coloro, ch' hanno talento, et offitio di ragionare, che quando si studia da questi tali con animo di dire ad altri quello, che studiano, sempre la dottrina scorre come acqua per canale; ma se principalmente per noi studiano per poterci et saperci humiliare, et vincer con la gratia di Dio le male inclinationi, le passioni, et infinite tentationi [...] et se nel studio della divina scrittura cerchiamo con purità et humiltà di cuore lo Spirito Santo per inamorarci di Gesù Christo [...]. Et vedendo che à vecchi, à fanciulli, à Donne ha dato spirito et fortezza; par che spronino le parole et l' opere de sant ad entrare et correre la via de comandamenti et de consigli di Christo Nostro Signore piu ardentemente. Oltre che si vede l' antiquita del monachismo, et le laudabili osservantie de voti et d' altri riti di santa Chiesa, molto opportuni da raccontarsi à questi nostri miseri tempi [...]. ${ }^{50}$

Tarugi betont darin die entscheidende Rolle der freien Interpretation und Improvisation während der einzelnen Stunden innerhalb desjenigen Oratoriums, welches der römischen Gesellschaft zugänglich war und damit als „offen“ bezeichnet wurde. In dieser Offenheit gegenüber allen Gesellschaftsschichten Roms erkannte Baronio aber gerade eine besondere Gefahr. Er beruft sich in seinem De origine Oratori auf die

50 Zit. n. Callenzio, Vita, S. 134-137. Diese memoria musste Tarugi um 1578 verfasst haben, da es vor allem das sogenannte Oratorio grande, oder secolare, würdigte. Zu diesem, der römischen Gesellschaft offen zugänglichem Oratorium vgl. Cistellini 1989, Bd. 1, S. 79-82; Zuccari 1981a, S. 81-82; Fanucci, Trattato, S. 141; Marangoni, Vita, S. 74; Gallonio, Vita, S. 88 und Primo Processo, I, $19,28$. 
Schwierigkeiten und Verfolgungen, denen der vicarius Urbis Papst Pauls IV., Virgilio Rosario, das frühere Oratorium aussetzte und die Neris Priesterversammlung zu bewältigen hatte:

Nach längerer Zeit kam es aber dazu, dass die frommen Übungen des Oratoriums selbst an ein neues Oratorium übertragen werden mussten, das dort erst kürzlich errichtet wurde. Denn durch die betlehemitische Enge beschränkt, war der zahlreiche Besuch des Volkes kaum länger zu fassen. Deshalb und weil alle ein Herz und eine Seele (Apg. 4, 32) waren, versuchte der Satan uns zu durchsieben, indem er einen von jenen, der nach den anderen dorthin gekommen war, gegen den Vater und die Brüder aufhetzte, der, weil dieser sich nicht in die gemeinsame Ordnung einfügen wollte und deshalb vom Vater getadelt wurde, ihm ins Angesicht Widerstand leistete und gegen eben diesen seine Ferse erhob und als er trotzig darauf bestand und den Weisungen des Vaters nicht folgen wollte, verdiente er es, aus dem Kreis der Brüder ausgeschlossen zu werden. Der von der Gemeinschaft der Mitbrüder Getrennte bewegte nun Meer und Land gegen sie und die Florentiner und erdichtete Lügen und wiegelte die anderen gegen sie auf. In häufigen Zusammenkünften beschlossen sie nun ihrerseits auch alle auszuschließen, die ihn ausgeschlossen hätten. ${ }^{51}$

Im Gegensatz zu Tarugi beruft sich Baronio in dieser Passage seines Traktats auf eine innerhalb des Oratoriums früh etablierte „Ordnung“, die vor allem während der 1580er Jahre vermehrt von Seiten seiner Mitbrüder bestritten wurde und von welcher sich die Kongregation bald distanzierte. Die Kontroverse um die Entstehung gipfelte in Camillo Fanuccis Trattato di tutte l' opere pie di Roma, das dieser

51 Baronio, De origine Oratori, S. 113: „Contigit et post diu ut ipsae Oratorii exercitationes in novum Oratorium illic noviter constructum transferrentur, nam angustiis bethlehemiticis frequens accessus populi arctatus vix diutius continebatur. Haec cum ita se haberent et omnium essent cor unum et anima una, expetivit satanas ut cribraret nos, suscitans adversum Patrem et fratres unum ex illis qui post alios illuc advenerat, qui cum ob id quod inordinate ambularet corriperetur a Patre, restitit in faciem eius et adversus eundem movit calcaneum suum, cumque contumax persisteret iussis $\mathrm{Pa}$ tris obedire vellet, meruit e coetu fratrum expelli, qui fratrum consortio segregatus movit mare et arida adversus eosdem et florentinos quibusque effictis commentis in eosdem concitavit, actumque inter eos crebris conventibus ut omnes pellerentur, qui illum eiecissent“. Der Kardinalvikar Rosario hatte sowohl die Übungen des Oratoriums als auch das Wirken Filippo Neris skeptisch beobachtet. Vgl. hierzu Del Re 1991, S. 155-166. Noch unter dem Carafa-Pontifikat Pauls IV. wurde Neri verboten, die sieben Kirchen zu besuchen und die Beichte abzunehmen. Es wurde ihm vorgeworfen, diesen Besuch als Anlass für ausgelassene Feiern missbraucht zu haben, zu denen sich Neri mit seinen Mitbrüdern „mit sieben Eseln“ begeben habe, die „mit Kuchen beladen“ worden waren. Nach dem Tod Rosarios schickte Paul IV. einen Boten zum Oratorium, der zwei grosse Kerzen von Lichtmess als Geschenk überbrachte, mit der Erlaubnis, alle dessen Tätigkeiten wieder aufnehmen zu dürfen. Im Jahr 1567, unter Pius V., wurde die Rechtsgläubigkeit der Predigten im Oratorium wieder in Frage gestellt, woraufhin der Ghislieri-Papst zwei Dominikanermönche in das Oratorium schickte, um die dortigen Vorgänge zu beobachten und ihm zu berichten: Primo processo, I, S. 383 und ibid., III, S. 144. Vgl. auch Baronio, De origine Oratori, S. 112. Betreffend des Verbots des Besuchs der sieben Kirchen und zum Konflikt mit Papst Pius V. vgl. zuletzt Del Re 2000, S. 96-98 sowie Ponnelle/ Bordet 1928, S. 176. 
fast ein halbes Jahrhundert nach dem Aufkommen der regelmässigen Versammlungen des Oratoriums in S. Girolamo della Carità verfasste und worin er als Gründer des Oratoriums den aus Siena stammenden Prediger Bonsignore Cacciaguerra annahm. ${ }^{52}$ Er begründete diese Annahme mit dem Hinweis auf die besonderen Predigten Cacciaguerras. Dabei berief sich Fanucci auf das Gründungsjahr 1557 als Anfang der Exerzitien Cacciaguerras innerhalb des Oratoriums. In diesem Jahr hatten sich die Versammlungen allmählich in grössere Räume innerhalb von San Girolamo della Carità verlegt. Auf diese Kontroverse um die Entstehung des Oratoriums ging ein von Antonio Talpa im Jahr 1591 verfasster Traktat ein. Talpa hebt darin besonders den Umstand hervor, dass die Entstehung des Oratoriums als Filippo Neris eigene Erfindung zu betrachten und unabhängig von Cacciaguerras Einfluss zu verstehen sei. Weit bedeutsamer sei die Gründung des Oratoriums nämlich für die „praktische [...] Anwendung der Sakramente, sowie [die] spirituellen Übungen für die universelle Wiederherstellung des Geistes durch dessen Institution“. ${ }^{53}$ Aus diesem Grund muss Baronios Traktat vor der Publikation von Talpas Schrift erschienen sein, da in diesem ein besonderes Augenmerk auf die Verehrung des Heiligen Sakramentes der Eucharistie gelegt wird. Zudem reflektiert Baronio seine Pflichten gegenüber dem Oratorium. Ab 1581 hatte Baronio allmählich damit begonnen, seine Verpflichtungen innerhalb der Kongregation zu reduzieren, um commodamente seinen „Kirchengeschichten“ (Historie ecclesiastice) nachgehen zu können, während sich andere Mitglieder wie Tommaso Bozio oder Neris erster Biograph Gallonio sowohl um das Bestehen der Kongregation als auch um ihre pastoralen Tätigkeiten innerhalb der Kongregation kümmerten. ${ }^{54}$ Cesare Baronios allmähliche Distanzierung vom Oratorium kann wiederum aus seiner Briefkorrespondenz mit Talpa, Tarugi sowie Giovenale Ancina abgeleitet werden. In einem am 26. Juni 1588 verfassten Brief an Ancina schreibt Baronio, dass er vor allem die Arbeiten an seinen Annales Ecclesiastici vorantreiben wolle, von denen der erste Band bis dahin noch nicht erschienen

52 Fanucci, Opere pie, S. 138; vgl. De Maio 1965, S. 8-9 sowie Bondadonna Russo 2001, S. 7.

53 Talpa, Institutio Oratori, S. 37: „[...] applicatione pratica de sacramenti, e degl' essercitj spirituali all' universale rinovatione dello spirito col mezo del suo Istituto [...]“. Zwei Jahrhunderte später ordnete Cacciaguerras Biograph, Giuseppe Marangoni, dieser Persönlichkeit die Form und das Bestehen des Oratoriums zu. Marangoni, Vita, S. 76: „,...] tutta la forma e l'essere dell' Oratorio a quelli principii che amendue col medesimo spirito avevano gettato in questa casa“. Dabei lag Cacciaguerras Augenmerkt auf die Verehrung des Heiligen Sakraments der Eucharistie. Tatsächlich versuchte die Kongregation des Oratoriums später die Herausgabe von Marangonis Vita zu verbieten, allerdings ohne Erfolg. Vgl. hierzu das am 2. September 1712 verabschiedete Dekret in ACR, C.I.9, f. 304r. 54 Cistellini 1989, Bd. 2, S. 790-792; Calenzio, Vita, S. 299-307; Bonadonna Russo 2000, S. 81-82. Tommaso Bozio übernahm Baronios Amt als Pfarrer innerhalb der Kongregation, während Gallonio sich desjenigen des Beichtvaters widmete, wie Paolo Aringhi es in seiner Vita Gallonios festhält: BVR, Q 58, f. $363 v$. 
war. ${ }^{55}$ In einem weiteren Brief an Tarugi vom 22. Mai 1589 bat Baronio den Adressaten darum, die Entbindung von seinen Pflichten als Beichtvater innerhalb der Kongregation sicherzustellen:

[...] se è a core alla Congregatione nostra, che io conduchi a perfettione l' opera cominciata, sarà necessario sequestrarmi dal Confessionale, qual non solo mi toglie la mattina, ma va ancora con le facende a questo officio congiunte: come visitar infermi, trattar paci, andar per gli tribunali, \& carceri, \& altre simili, quali mi tengono talmente occupato, \& distratto, che mi togliono la gran parte del tempo. [...] Onde spesso ho pregato Iddio, gli piaccia, se è servitio suo da ciò esentarmi. Io da me non lo faria, nè lo richercheria mai per via straordinaria, come sarebbe farmelo commandare da Sua Santità, il che potrei fare ogni volta, che io volessi [...]. Se Dio vorrà, lo ispirirà a chi tocca per officio il governarmi. [...] molti homini di bontà di vita singolare mi hanno fatto scrupolo, che io attendi ad altro, che a questo. [...] il mio P. M. Filippo, il quale sin hora non mi dice altro. Onde impensatamente provocato dalle due parole, che V. R. nel principio della sua dice: Hò coscientia di occuparvi, mi è parso scrivere quattro versi in questa materia. ${ }^{56}$

Die sich anbahnende Distanzierung Baronios vom Oratorium fällt mit der Niederschrift der ersten offiziellen Statuten zusammen. Sie hätten vor allen Dingen den Versammlungen einen stärker institutionellen und damit einen der römischen Kurie affinen Charakter verleihen sollen. Vorreiter einer solchen gesetzlichen Regelung der vita comunitaria des Oratoriums war die Papstbulle Gregors XIII. Copiosus in misericordia Dominus, mit welcher am 15. Juli 1575 das Oratorium offiziell als Kongregation anerkannt und diesem die Kirche von Santa Maria in Vallicella zugeteilt wurde. ${ }^{57}$ Ein zentraler Beweggrund, der zur Entscheidung führte, dass den Versammlungen eine institutionelle und damit gemäss kanonischem Recht anerkannte Form der Praxis der Seelsorge verliehen werden sollte, war die Suche der Oratorianer nach einem ständigen Kirchenraum für ihre Versammlungen. Das Kirchengebäude sollte auch über einen Annexbau verfügen, der als Wohnsitz der Mitbrüder dienen sollte. An dieser Suche, die in Gallonios Lebensbeschreibung Filippo Neris zum hagiographischen Charakterzug stilisiert wird, nahm der Orden der Barnabiten teil, da sich Neri selbst schon früh an einer Einsetzung der Barnabiten im römischen Stadtraum beteiligt hatte. Es war daher auch nicht überraschend, dass derselbe Neri kurz vor dem Jubel-

55 Alberici, Epistolae et opuscula., III, S. 29.

56 Ibid., S. 41-42. Vgl. auch den am 9. Juni 1589 verfassten Brief an Talpa in ibid., S. 43: „Attenderò ad eseguire più che sia possibile il lor consiglio di ritirarmi, sebene quelli, che ora si confessano da me non gli posso lassare, perchè confessando una parte \& l' altra nò, causerebbe bisbiglio. Cercarò di non pigliar nove confessioni“.

57 Die Originalfassung der Bulle befindet sich in ACR, A.V.1, f. 1r-v. Erstmals abgedruckt, allerdings unvollständig, bei Calenzio, Vita, S. 905-908 sowie in einer von A. M. Stickler redigierten Fassung in Oratorium 6, 1975, S. 1-2. Für eine vollständige Edition vgl. Collectanea, S. 10-16. Bevor die Bulle herausgegeben wurde, vollzog Papst Gregor XIII. mit einem breve vom 11. Juli desselben Jahres die Schenkung an die Kongregation eines Weinberges vor der Porta San Pancrazio als Unterhalt der Väter: Cistellini 1989, Bd. 1, S. 191-199. 
jahr mit der Möglichkeit eines Zusammenschlusses der Barnabiten mit seinem Oratorium geliebäugelt hatte. ${ }^{58}$ Neben einer solchen Vereinigung mit dem Orden der Barnabiten wurde innerhalb des Oratoriums vor dessen päpstlicher Anerkennung und seiner Umgestaltung zu einer Kongregation sogar eine vollständige Verlegung nach Mailand in Betracht gezogen. Wäre dieser Umzug zu Stande gekommen, wäre das Oratorium in die Obhut Carlo Borromeos gefallen, was es wiederum in ein Abhängigkeitsverhältnis zur kurial-bischöflichen Autorität gebracht hätte. Während seines zweiten Romaufenthalts zwischen 1574 und 1575 hatte Borromeo diesbezüglich Verhandlungen mit Neri aufgenommen, um die Missionstätigkeit der Oratorianer in die Lombardei zu verlegen und seinen langjährigen Familiaren Francesco Maria Tarugi für diese zuständig zu machen. Als Papst Gregor XIII. aber wie auch Baronio - 1574 erkrankte, wies er Neri an, dass keines der Mitglieder des Oratoriums Rom während des Jubeljahres verlassen solle, damit sich die Kongregation ausschliesslich um den Zustrom von Pilgern und deren ordentliche Unterbringung in der Zeit der Spende der Sakramente und der Heiligen Eucharistie kümmern könne. ${ }^{59}$

Drei Jahre nach der Anerkennung des Oratoriums als Priesterkongregation verfasste der Boncompagni-Papst eine weitere Bulle, mit welcher die den Oratorianern zugeteilte Kirche von Santa Maria in Vallicella von ihrer kirchenrechtlichen Anbindung als Filiale von San Lorenzo in Damaso, der Titelkirche des Kardinals Alessandro Farnese, befreit wurde. Aus Sicht des Boncompagni-Papstes war die offizielle Anerkennung sowie die Trennung der Vallicelliana von ihrer administrativen Führung durch das Kapitel von San Lorenzo ein gelungener Schachzug, mit dem sowohl die Verlegung des Oratoriums nach Mailand als auch ein Zusammenschluss mit dem Barnabitenorden geschickt verhindert werden konnte. Die Trennung der Chiesa Nuova von der Titelkirche Farneses erfolgte aus dem Bedürfnis heraus, die alte und sich im Zerfall befindliche Kirche von Santa Maria in Vallicella a Pozzo bi-

58 Premoli 1913, S. 264. Mit einer Bulle vom 1. März 1575 wurde den Barnabiten die Kirche San Biagio all'Anello im rione Regola zugeteilt. Der Ordensbruder Tito degli Alessi aus Vicenza, der am 26. Oktober 1574 als Pilger aus Mailand nach Rom anreiste, schilderte seinem Briefpartner Paolo M. Omodei die Pläne einer möglichen Umsiedlung der Versammlungen mit einer besonderen Betonung der Rolle Filippo Neris: „Il Padre più volte ha detto che desiderava che fossimo prima comodati noi che le Reverenze loro, le quali vogliono pigliarne uno (luogo) che sia libero, perché questi due che hanno, cioè S. Hieronimo et S. Giovanni, tutti e due sono luoghi di compagnia e per questo ne vogliono uno che non sia obbligato ad altri“. Zit. n. Cistellini 1989, Bd. 1, S. 186. Am 24. März feierte Neri zusammen mit demselben degli Alessi die Messe nach der Einnahme der neuen Barnabiten-Kirche.

59 Allerdings hielten die Mailänder gentiluomini, welche zu reger Zahl die Versammlungen des Oratoriums besuchten, an einer Verlegung fest, wie dies ein Schreiben Tarugis an Borromeo vom 2. April 1575 bezeugt. Corrispondenza Tarugi-C. Borromeo, S. 240: „[...] accioché piacendoli, aiutassero poi l'opera con tanto più amore quando s’incomincerà a Milano“. 
ancho zu einem als Unterkunft der Oratorianer geeigneten Beherbergungskomplex umzugestalten, wie Baronio dies ebenfalls in seinem Traktat ausführt:

[...] die Übersiedlung sollte nur um eine kurze Zeit verzögert werden bis sie durch einen kleinen Aufwand für unseren Zweck adaptiert wurde. Es wurde dem Urteil eines klugen Architekten überlassen, der diese genau untersuchte und die Fundamente und das was darunter war, prüfte und dabei herausfand, dass sie wegen des Alters beinahe eingestürzt war und, um sie auszubessern, würden alle Ausgaben verloren sein, wenn sie nicht mit neuen Fundamenten geschützt würde, und dass dies nicht ohne hohe Kosten geschehen könne, die sinnvoller verwendet würden, wenn die Fundamente, die man legen musste, einem neuen und größerem Bau dienten. Die Größe der Ausgaben und die zeitliche Verzögerung schreckte beinahe alle zurück, aber der darüber erschreckte Pater wollte, dass alles nach dem Plan des Architekten durchgeführt werde, da er betete, dass in ihm wie einst in Beleel (Bezalel, gem. Ex. 35,31) der Geist Gottes sei; dieser handelte in frommer Gesinnung, weil er seine ganze Arbeit unentgeltlich machte. ${ }^{60}$

Mit dieser Trennung wurde innerhalb des Oratoriums eine liturgische Ordnung in Bezug auf dessen Versammlungen geschaffen, womit diese Zusammenkünfte dann ab 1575 entsprechend auch kirchenrechtlich reglementiert werden konnten. Die Papstbulle vom September 1578 befreite die Kirche Santa Maria in Vallicella von ihren Verpflichtungen gegenüber dem Kanonikat von San Lorenzo in Damaso und unterstellte die Kongregationsmitglieder direkt dem Schutzpatronat des Apostolischen Stuhls. Diese Trennung hatte somit zur Folge, dass die Pfarrei der Chiesa Nuova nun eine eigenständige liturgische Ordnung erhielt. Allerdings sollte sich diese erst ab 1584 mit der Etablierung ihrer ersten Konstitutionen realisieren lassen. ${ }^{61}$ Hinsichtlich dieser nun eindeutigen Zuordnung der Kongregationsmitglieder

60 Baronio, De origine Oratori, S. 114: „[...] ad modicum tantum tempus dilata migratio quosque scilicet aliqua modica impensa ipsa usui redderetur utilior, sapientis architecti id relictum arbitrio, qui eamdem exacte perlustrans fundamenta atque deorsum inspiciens, eamdem iam prope vetustate collabentem comperiit, utque in eadem resarcienda imnem fore impensam deperditam, nisi novis suffulciretur fundamentis, idque fieri nec posse absque magna impensa, quae et utilius impenderetur si iacenda fundamenta novae structurae amplioris dilatio, sed nec his perterrefactus Pater noluit cuncta consilio ipsius architecti peragi, ut in eodem velut olim in Beleele Spiritum Dei inesse deprecaretur, pie is egit quod omne opus suum gratis exhibuit [...]“.. Auch Talpa hielt in seiner memoria an Kardinal Borromeo fest, dass sich die Mitglieder des Oratoriums gezwungen sahen „die Kirche von ihren Fundamenten aus ganz neu zu bauen“. Zit. n. Memorie Oraotoriane 9 (1982), S. 16: „[...] furono quasi a forza tirati a rifar la chiesa tutta da fondamenta“.

61 Vgl. den Text der Bulle, Messem quidem multam, in Collectanea, S. 17-21, hier S. 18: „[...] quod cum alias ipsam Congregationem perpetuo instituerimus, illique parrochialem Ecclesiam Beatae Mariae Vallicellae Regionis Parionis de Urbe certe tunc expresso modo vacantem cum animarum curam illius parochianorum, et aliis omnibus oneribus, ac illi forsan annexis, nec non omnibus bonis, censibus, jurisdictionibus, fructibus, redditibus et proventibus, aliisque juribus et pertinentiis suis perpetuo concesserimus assignaverimus, itaque liceret ipsi Congregatione nomine Ecclesiae et annexorum ac bonorum huiusmodi corporalem possessionem propria auctoritate libere apprehendere [...]“. Die Trennung von Farneses Titelkirche konnte schliesslich nur durch die Intervention Anna Borromeos, der Schwester des Mailänder Bischofs Carlo und Gattin des Vizekönigs 
unter die Schutzherrschaft des Papstes hatte sich eine bemerkbare Divergenz offenbart: Wem sollte der Verdienst, einen geeigneten Kirchenraum für die Versammlungen des Oratoriums gefunden zu haben, zugesprochen werden - dem Papst oder Neri? Diesbezüglich hebt sich Baronios Traktat von den hagiographischen Lebensbeschreibungen Neris ab, da Baronio besonders die spezifische liturgische Praxis tder Feierlichkeiten zur Geburt der Gottesmutter als eigentliche liturgische Ordnung des Oratoriums hervorhebt. Neris erster Biograph, Antonio Gallonio, betrachtet hingegen die von Papst Gregor XIII. zur Verfügung gestellte Kirche lediglich als sponane Schenkung und deutet sie keineswegs im Zusammenhang mit einem zu praktizierenden liturgischen officium. ${ }^{62}$ Der Hinweis Baronios auf diesen spezifischen Ritus der Marienfrömmigkeit ist eine Andeutung darauf, dass das Oratorium in seiner institutionellen Struktur als Kongregation von Priestern eine von Papst Gregor XIII. selbst ins Leben gerufene Ordensgemeinschaft war, welche sich in erster Linie einer Neujustierung des römischen Ritus gemäss dem Catechesimus und dem Breviarum Romanum widmen sollte.

Im gleichem Absatz, in dem Baronio die Wahl der Kirche von Santa Maria in Vallicella erwähnt, erläutert er, dass es ,in Rom kein Gedenken an die Geburt der Gottesgebärerin gäbe, das älter wäre als [jenes]“:

Gütig nahm ihn der Papst auf, er tröstete den Greis, und war seinen Wünschen geneigt. Diese wählte unter den vielen ihm vorgeschlagenen selbst die Kirche Santa Maria in Vallicella aus, vor allem weil er bedacht war auf Nutzen und Annehmlichkeit des Volkes, dass sie an dieser Stelle der Stadt liege, wo die Leute wohnen und der Zustrom derer, die herbeikamen groß war. Die alte Pfarrkirche ist der Geburt der Gottesmutter Maria geweiht gewesen. Es ist nicht überliefert, dass in Rom eine ältere Kirche der Geburt der Jungfrau geweiht war als jene. In den ältesten Aufzeichnungen, die sich in der Biblioteca Vaticana über die Pfarreien der Stadt befinden, wird diese häufig erwähnt, die auch Eugen III. mit Ablässen augestattet hat und von denen es Beispiele in den päpstlichen Registern gibt. Da sie unter der Patriarchatskirche von

von Sizilien, Fabrizio Colonna, erreicht werden. Vgl. hierzu v. a. die Briefkorrespondenz zwischen Neri und Anna Borromeo in Tacchi Venturi 1904, S. 483-492 sowie die Zeugenaussage Federico Borromeos während Neris Kanonisierungsprozesses in Processo, III, S. 274-275.

62 Baronio, De origine Oratori, S. 113-114: „[...] postque multas in his habitas ad Deum preces adiit ipsum Pontificem gregorium, petiit ab eodem humiliter sibi ac suis liberam concedi ecclesiam. Vgl. dann im Gegesatz hierzu Gallonio, Vita, S. 254: Fervebat opus optimi Principis, ac nonnullorum civium beneficio, quorum tantus fuit erga Beatum Patrem amor, tantaq[ue]; in Deum pietas, ut rem ultro eleemosynis adiuverint: Gregorius in primis spontanea liberalitate ad septe milla ureorum in id aedificium insumpsit: ergo templi aedificatio nunqua[m] intermissa [...]“. Diese Ansicht, dass es vielmehr der Verdienst Neris als derjenige Papst Gregors XIII. war, den Oratorianern einen für ihre Bedürfnisse gerechten Kirchenraum zu geben, fand später in der Formulierung der definitiven Instituta 1612 Eingang, die Paul V. mit der Bulle Christifidelium quorumlibet vom 24. Februar desselben Jahres approbierte. 
San Lorenzo in Damaso steht, hat er sie durch ein motu prorpium enthoben und wollte, dass wir sie als freie haben. ${ }^{63}$

Der Verweis auf die bereits erwähnte Bulle Papst Gregors XIII. vom 1. September 1578 legt nahe, dass sich Baronio in seinem Traktat bezüglich der Gründungsgeschichte des Oratoriums um ein spezifisches Narrativ bemühen wollte, das die rituelle Einbindung der Kongregation in eine liturgische Topographie Roms seit dem Pontifikat Pius' IV. hervorheben würde. Für Baronio gehen die Aufgaben dieser Pfarrei weit über diejenigen Tätigkeiten, die in den zwischen 1580 und 1587 verfassten Dekreten erwähnt wurden, hinaus. ${ }^{64} \mathrm{Zu}$ dieser liturgischen Bedeutung der Kongregation des Oratoriums trug einerseits die Errichtung der ersten Kapellen im Kirchenraum der Chiesa Nuova, welche den misteri della Vergine geweiht waren, bei. Des Weiteren wurden die Oratorianer durch die Bestätigungsbulle Sixtus' V. vom 5. September 1586 mit weiteren Privilegien ausgestattet. Der am 31. März desselben Jahres verfasste päpstliche Erlass anlässlich der Errichtung einer Kapelle zu Ehren der Madonna dei Lumi in San Severino anerkannte die dortige Filiale offiziell als die erste Niederlassung der Kongregation. Das Beispiel von San Severino zeigt unter anderem deutlich, wie ausgeprägt das Bedürfnis nach einer neuen Marienfrömmigkeit des Oratoriums war. Der Peretti-Papst ernannte zudem mit einer weiteren Bulle vom 26. November 1586 den ersten Bischof von San Severino, nämlich den aus Vicenza stammenden Orazio Murzano. ${ }^{65}$ Die vorangehende Bulle vom September 1586 bestätigte ferner das von Papst Pius IV. erlassene breve vom 13. März 1565, mit welchem die Kongregation die Erlaubnis bekam, die Heilige Messe sowohl vor der aurora als auch nachmittags feiern zu dürfen. Zusätzlich zu diesen bereits von Papst Gregor XIII. am 13. März 1576 erlassenen Vorrechten erweiterte der Peretti-Papst diese nun auf alle Mitglieder der Kongregation sowie auf alle Oratorianer in und ausserhalb Roms. Hinsichtlich der Messfeierlichkeiten ergänzte Papst Sixtus

63 Baronio, De origine Oratori, S. 114: „Benigne eum excepit Pontifex, consolatus est senem, annuit votis, qui et inter multas sibi propositas ipsemet elegit ecclesiam S. Mariae in Vallicella, consulens praesertim populi utilitati et commodiati, ut in eo loco Urbis sita ubi est frequentior habitantium multitudo et accedentium occursus. Est ipsa dicata Nataliis Dei Genitricis, antiqua Urbis parochia, nec memoria extat quod antiquior illa Natali Virginis Romae fuerit dicata ecclesia. In vetistissimis dipticis quae habentur in Bibliotheca Vaticana de Urbis parochiis eiusdem crebior habetur mentio, quam et Eugenius III ditavit indulgentiis, extant in registris de iisdem exemplaria, haecque cum esset sub patriarchali ecclesia S. Laurentii in Damaso constituta, motu proprio iterum atque iterum eandem exemit et liberam nos eam habere voluit“.

64 Die sogenannten Decreti di Congregazione verliehen seit deren Niederlegung dem Oratorium eine deutliche institutionelle Ordnung. Deren Einführung beruft sich auf die Gründungsbulle Gregors XIII. aus dem Jahr 1575, in welcher der Kongregation gestattet wurde, ihre regole selbständig erweitern und modifizieren zu dürfen, sowie neue zu erlassen. Die Sammlung der ersten Dekrete der Kongregation, die bis zum Jahr 1587 aufgeführt sind, befinden sich in ACR, C.I.2.

65 Ughelli, Italia sacra, II, S. 765-768. 
V. die Bulle um die Erlaubnis, die nachmittägliche Messe feiern zu dürfen. Dieses Zugeständnis wurde schliesslich vom vicarius Urbis, Giacomo Savelli, bestätigt. ${ }^{66}$

Mit dieser Gewährung von Privilegien im Bereich der liturgischen Messefeier für die Versammlungen des Oratoriums, an welche Baronio in seinem Traktat anknüpft, wenn er vom „häufigen Empfang der Eucharistie“ als einer der grundlegenden liturgischen Einführungen dieser Kongregation berichtet, begann sich die einst aus „Priestern und weltlichen Klerikern“ zusammengesetzte Gemeinschaft zu einer mit dem römischen Ritus konformen Institution zu entwickeln. Auf einen solchen Ausbau berief sich das Oratorium selbst, als Giovanni Francesco Bordini von Borromeo im Sommer 1581 gebeten wurde, dem zwei Jahre zuvor als Herzog von Bayern inthronisierten Wilhelm V. in „kirchliche[n] Zeremonien“ geschulte Priester bereitzustellen. Bordini antwortete ihm, dass es am bayerischen Hof an einer liturgisch korrekten Bestattungspraxis mangelte. Zudem konnten die Oratorianer auch wegen ihres vollen Gehorsams gegenüber dem Papst nicht der Bitte Borromeos nachkommen. ${ }^{67}$ In der Tat war sich Neri selbst bewusst, dass bei einer Niederlassung in Mailand, wie sie um 1575 beinahe realisiert worden wäre, das Oratorium vollständig unter Borromeos Obhut gefallen wäre. Dies hätte zur Folge gehabt, dass sich die Kongregation in ihrer Messpraxis an die ambrosianische Liturgie, wie sie in den Acta Mediolanensis formell begründet wurde, hätte anpassen müssen, was schliesslich zu einer gänzlichen Trennung von der Hauptkirche in Rom geführt hätte. ${ }^{68}$

Cesare Baronios Traktat De origine Oratori spielt demgemäss auf einen bislang von der historischen Forschung gänzlich unbeachteten Charakterzug des Oratoriums an. Baronio fasst den Ausbau der Kongregation in ihrer institutionellen Ord-

66 Collectanea, S. 57-58: „[...] praeterea per dimidium horae spatium ante auroram et post meridiem Missas celebrare, ac etiam qui ex eis, praevio examine, ad confessiones audiendas in ipsa Urbe a dicto Vicario approbati fuerint, extra eandem Urbem, absque alio examine de licentia tamen ordinariorum locorum indulto, et facultatibus huiusmodi uti ac potiri, libere et licite valeant, Apostolica autoritate tenore praesentium concedimus et indulgemus. [...]. Volemus autem, quod Philippus et presbyteri prefati huiusmodi indulto celebrandi ante diem parce utantur, quia cum Altaris ministerio immoletur Dominus noster Iesus Christus Dei Filius, qui candor est lucis aeternae, congruit hoc non noctis tenebris fieri, sed in luce“. Das Original befindet sich in ACR, A.V.1, f. 158r.

67 Briefschreiben Bordinis an Borromeo vom 31. Juli 1581 in ACR, RA, n.n und Pateri, Memorie, S. 83-84. Hierzu ausführlich auch Cistellini 1989, Bd. 1, S. 278-280. Vgl. auch den Brief Neris an Borromeo vom 15. Juli 1581 in Lettere e rime, S. 20-22. Zum Gebrauch der Charakterisierung der Oratorianer als presbyterorum et clericorum saecularium vgl. die Anerkennungsbulle Papst Gregors XIII. aus dem Jahr 1575 in Collectanea, S. 11.

68 Corrispondenza Tarrugi - S. Carlo, S. 245: „Perché essi intendono che quella Congregatione di preti che si metterà qui sia come membro di quella di Roma et habbia dipendentia di là; et io intendo ch'habbia da dipendere assolutamente di qua“. Zu Borromeos Verständnis des ambrosianischen Ritus hinsichtlich der Aufgaben von Priestern in der Mailändischen Diözese vgl. insbes. Prosperi 1988, S. 114-118. Dass Baronio selbst Kenntnis von dieser Form der ambrosianischen Liturgie hatte, lässt sich in seiner auf Bitten Papst Sixtus V. verfassten Biographie des Kirchenvaters lesen, worauf zu einem späteren Zeitpunkt noch einzugehen sein wird. 
nung entsprechend als ein wirkungsvolles Organ der römischen Kurie auf. Dieses besondere Narrativ der liturgisch-zeremoniellen Funktionalität der Kongregation des Oratoriums steht aber im Widerspruch zu den Bestrebungen und Wünschen Filippo Neris sowie seiner engsten Mitbrüder - vor allem seines treusten Biographen Antonio Gallonio -, die nach dem Tod Neris 1595 auf eine rasche Heiligsprechung ihres Gründervaters drängten. Dieser Prozess der Heiligsprechung, der erst am 12. März 1622 zum Abschluss gelangte, offenbart, wie stark Baronio sich vor allem während seiner ersten Arbeiten an der Neujustierung des römischen Ritus gemäss Tridentiner Vorstellungen von den Arbeiten seiner Mitbrüder im Oratorium entfernte.

\subsection{Die Heiligsprechung Neris als hagiographisches Programm}

Baronio war der Ansicht, dass die institutionelle Form des Oratoriums eine neubegründete Praxis der Predigt spiegeln sollte. Die Predigt sollte in der eucharistischen Verehrung eine Gelehrsamkeit spiegeln wiedergeben, sodass sie als rhetorisches Sprachmittel der Sakramentsverwaltung schlechthin angesehen wurde. Dennoch wies die Trennung zwischen liturgischer Verehrung und theologischer Gelehrsamkeit in der Entwicklung des Oratoriums zahlreiche Unklarheiten auf. Dieser Umstand ist nicht zuletzt Baronios eigenem Umgang mit der Figur Neris in seinen Annales Ecclesiastici geschuldet. Wie ist Baronios Distanzierung vom Oratorium, wie sie sich in seinem De origine Oratori zeigte, auch in Bezug auf seine Annales Ecclesiastici zu erklären, wenn er im achten Band Neri gleich als primum auctorem et architectum bezeichnet? ${ }^{69}$

Einen besonderen Aspekt zur Erschliessung dieser Problematik von Baronios Umgang mit dem Oratorium in seinen Annales bieten die Akten zu Neris Kanonisierungsprozess, der unmittelbar nach seinem Tod im Jahr 1595 begann. Die Heiligsprechung des Kongregationsgründers wurde sogar noch zu Neris Lebzeiten von seinen Mitbrüdern sowie von externen kurialen Prälaten, welche die Kongregation frequentierten, als zwiespältig betrachtet. Diese Zwiespältigkeit manifestierte sich mit dem Tod Neris, als eine Vielzahl an Bildern entstand, auf denen neben den vielen Episoden aus dem Leben des Gründers des Oratoriums auch ein besonderes Anliegen zutage trat. Die für diese Bildproduktion zuständigen Maler bemühten sich hauptsächlich um eine korrekte physiognomische Wiedergabe der Gesichtszüge Neris, für welche seine Totenmaske als Vorlage genutzt wurde (Abb. 1). Einige der ersten dieser post mortem entstandenen Bildnisse Neris, die anlässlich des Kanonisierungsprozesses in Auftrag gegeben wurden, bildete die verlorengegangene Serie von Malereien Cristoforo Roncallis, die zwischen Juli 1596 und März 1599 realisiert wurde und Episoden aus dem Leben Neris zeigte. Diese Serie, welche von Marcello

69 Ann. Ecc., VIII, n. p. (act. grat.), S. 2. 
Vitelleschi, Fabrizio Massimo, Antonio Gallonio sowie den beiden Crescenzi-Brüdern, Pier Paolo und Giovanni Battista, in Auftrag gegeben und finanziert wurde, war für die Ausschmückung von Neris privatem Zimmer in der Vallicelliana gedacht, worin dieser verstorben war. Die Bildnisse bilden nicht nur in Gallonios Vita einen besonderen Schwerpunkt, sondern tauchen ebenfalls während des Kanonisierungsprozesses in einer der vielen Zeugenaussagen Jacopo Crescenzis wieder auf:

De più [...] doppo la morte suo, ogn'anno, il giorno che passò al cielo, si è celebrato, alla Vallicella, la festa sua, con cantare la Messa et vespero solenne, con bellissima musica et gran concorso di gente et intervento di molti prelati et cardinali. Et, in particolare, questo anno si è fatto con più solennità, poichè ha cantata la Messa et il vespero pontificalmente, mons. Paulo de Curte, vescovo di Ravello, viceregente dell'ill.mo s.r cardinale vicario, con l'intervento del s.r card. de Terra Nova (=Simo Tagliavia) et molti altri prelati. Et, anchorchè fosse il papa con tutta la corte assente, et che fosse giorno di lavoro, et che festa non se fosse publicata, tuttavia si è visto tanto concorso di popolo, come se fosse stato il giorno di Pasqua. Et questo non fu solo in chiesa, ma alla sepoltura, la quale era benissimo adornata con fiori di seta et parati d'imbroccato; et alla stanza dove il santo padre morì, la quale se è accommodata in modo d'oratorio, con un altare in mezzo, con la sua effigie, et con la vita e miracoli suoi intorno intorno. Et per tutto si vedeva tanta compuntione et devotione di quelli che venivano [...]. ${ }^{70}$

Die Feierlichkeiten vom 26. Mai 1595, an denen auch die Kurie teilnahm, erlauben es zu vermuten, dass Baronios eigene Predigt, die er mit Hilfe von Psalm 79 zusammenstellte, sich auf dasselbe Ereignis bezieht, wie dies auch Giovenale Ancina in seiner Zeugenaussage festhielt. Es lässt sich demnach zeigen, dass die in Baronios achtem Band verfasste actio gratiarum von einer Wechselwirkung zwischen der Auseinandersetzung mit der Person Neris und seinem nun in den ersten Bildzeugnissen vermittelten Ausdruck zeugte. Darüber hinaus belegt diese Wechselwirkung ein durch den Kanonisierungsprozess ausgelöstes öffentliches Interesse an Filippo Neri, das sich nach der Überführung des Leichnams auch in der Ausgestaltung der Grabstätte in Santa Maria in Vallicella ausdrückte. ${ }^{71}$

Damit ist bereits ein grundsätzlicher Widerspruch zur bisherigen Annahme, dass im nachkonziliaren Gebrauch des tridentiner Bildkults für die Heiligenverehrung dieser in einem neuen liturgisch-zeremoniellen Rahmen der Heiligsprechungen funktionalisiert worden sei. Deshalb wurden Baronios Annales auch stark im

70 Primo Processo, II, S. 204-205. Vgl. auch Chiappini di Sorio 1985, S. 119-121; Barbieri/Barchiesi/ Ferrara 1995, S. 113-116.

71 Die Zeugenaussage Giovenale Ancinas befindet sich in BVR, Q 56, f. 60r. Diesbezüglich unterrichtet ebenfalls die bereits zitierte Zeugenaussage Crescenzis, dass Ancina selbst eine Predigt hielt, welche Neris Leben und Wunder beinhaltete. Hierzu Primo Processo, II, S. 205-206. Zur Bedeutung der Heiligenverehrung im Kontext des Tridentinums für die Heiligsprechungsprozesse nach 1588 vgl. v. a. Wohlmuth 2002, S. 776; Kemp 1948, S. 141-150; sowie zur Problematik der Bilderverehrung zuletzt Gerken 2004, S. 236-239; eadem 2015, S. 17-18. 
Kontext des Kanonisierungsprozesses Filippo Neris betrachtet. Man wollte nämlich in der Gründerfigur des Oratoriums den eigentlichen Entwerfer dieses magnum opus Baronios sehen. Das Verfahren zur Heiligsprechung Neris muss daher insbesondere im Zusammenhang mit einer bestimmten Bildprägung des Heiligen betrachtet werden. An der Entstehung eines spezifischen Heiligenbildes Neris lassen sich nämlich Baronios Einstellungen gegenüber der Heiligenverehrung von der Strategie einer möglichst raschen Heiligsprechung Filippos, die andere Mitglieder der Oratoriums verfolgten, deutlich trennen. Bislang hatte die Forschung bildliche Darstellungen von Heiligen als eine Strategie der kultischen Verehrung verstanden. Dies trifft aber nur auf solche Bilder zu, die erst nach der Heiligsprechung entstanden sind. An dieser Stelle soll deshalb ein Interpretationsmodell vorgestellt werden, mit welchem sich zeigen lässt, wie die Heiligenbilder, die anlässlich des Kanonisierungsprozesses hergestellt wurden, einen Produktionskontext vor und einen nach dem Tod des Heiligen aufweisen. Diesen Zusammenhang zwischen der Entstehung des Heiligenbilds und der Heiligsprechung liess Baronio in seine Annales Ecclesiastici einfliessen. Baronio nimmt in seiner Danksagung an Neri, welche er dem achten Band seines Werks voranstellt, einen deutlichen Bezug auf die für das Begräbnis des Ordensgründers hergestellten Votivbilder, welche die wundersamen Taten Neris festhalten. ${ }^{72}$ Die Gemäldeserie steht im Zusammenhang mit einer neu zu errichtenden Kapelle, die erst anlässlich der Überführung des Leichnams am 24. Mai 1602 eingeweiht wurde. Darüber hinaus weist sie deutliche Gemeinsamkeiten mit einer weiteren Bildserie auf, die Cristoforo Roncalli für das ehemalige Schlafzimmer Filippo Neris ausführte. Baronio erhielt zusammen mit Federico Borromeo und Francesco Maffa vom Aldobrandini-Papst Clemens VIII. die Erlaubnis, in diesem Zimmer, das ursprünglich zu einer Grabkapelle umgestaltet werden sollte, die Messe feiern zu dürfen. ${ }^{73}$ Gallonio erwähnt in seiner Biographie Neris zusätzlich ein Bild, welches sich am Altar befand und das Neri zeigt, wie er seine Kongregation dem Schutz der Madonna anvertraut. ${ }^{74}$ Hierbei muss es sich um eine zweite Version des Altarbildes für

72 Ann. Ecc., VIII, grat. act., S. 2: „[...] post migrationem ex hac vita, aucto multiplici soenore, ipse rependit. Siquidem ubi laguncula ferrea fracta est, quae latebat intus, sua charitate refulgens, lampas apparuit; \& quae absconda erat sub modio lucerna ardens \& lucens, super aeternitatis altum candelabrum exaltata, perspicua facta est, miraculorum fulgore coruscans. Tunc enim \& quae vivens edideras, sed occultaveras, mirifica signa, sunt cognita, \& alia quam plurima recens edita patuerunt. Splendet vile, licet adhuc utpote temporarium, sepulchrum tuum votivis tabellis, \& ex pretioso metallo signis affixis, tuorum miraculorum indicibus [...]“.

73 Primo Processo, II, S. 206, 251-252. Gegen Ende des 16. Jahrhunderts kam dann das Bedürfnis nach einer grösseren Grabkapelle in Santa Maria in Vallicella auf, die vor allem mit Hilfe des Florentiner Patriziers Nero del Nero finanziert wurde. Vgl. Melasecchi 1998, S. 8-9.

74 Gallonio, Vita Filippo Neri, S. 271: „Consulta dunque la cosa con Alessandro de’ Medici [...] fu detto luogo adornato a foggia di cappella e posevi quell'histesso altare, nel quale egli vivendo era stato solito celebrare, e avanti a quello la sua effigie fatta dal naturale in atto di raccomandare la Congregazione alla Gloriosa Vergine da Cristoforo Roncalli dalla Pomarance pittore principalissimo 
die Grabkapelle Neris gehandelt haben, wie dies aus einem Bericht Francesco Zazzaras hervorgeht. Zazzara berichtet über eine noch am Todestag Neris entstandene Komposition Roncallis, die am Altar installiert wurde und welche Neris Marienvision präsentierte. Derselbe Zazzara bezeugt in seiner Aussage vom 18. August 1596 ferner, dass es sich dabei um eine weitere Marienvision Neris handelte, die der Kongregationsgründer kurz vor seinem Tod erlebt haben soll. Am darauffolgenden Morgen hatte sich Neris Gesundheitszustand verbessert. Die Bildschöpfung Roncallis muss daher früheren Datums als die Zeugenaussage Zazzaras sein, da diese Episode aus dem Leben Neris mittels jener Aussage ihre offizielle Legitimation fand. ${ }^{75}$

Innerhalb der Forschung blieb die Frage, weshalb Roncalli mit der Anfertigung einer zweiten Altartafel beauftragt wurde, bisher unbeantwortet. Gerken vermutet, dass die Motivation hierfür in einer Verlagerung des Bildthemas zu suchen sei, bei welcher die Marienvision Neris zugunsten einer viel repräsentativeren Darstellung aufgegeben worden sei, welche die Marienverehrung der gesamten Kongregation zum Ausdruck bringen sollte. Die Herstellung eines neuen Altarbildes geht allerdings mit der von Papst Clemens VIII. am 29. März 1598 ausgesprochenen Erlaubnis einher, gemäss der die Kardinäle Baronio, Borromeo und der Abt Marc'Antonio Maffa die Messe im ehemaligen Wohnbereich Neris, abhalten durften. ${ }^{76}$ Es muss daher nach einer Erklärung gesucht werden, welche die kuriale Einbindung im Kanonisierungsprozess und deren Wechselwirkung mit der Wahl des Kapellenschmucks mitberücksichtigt. Ein solcher Einfluss der Kurie lässt sich im Unterschied der beiden Kompositionen Roncallis feststellen. Die Marienvision Neris war eine Erzählung aus seinem Leben, die der von ihm gegründeten Kongregation bekannt war. In den Augen der römischen Kurie konnte diese Anekdote hingegen nur wenig zur Heiligsprechung beitragen, weshalb Roncalli das Oratorium im zweiten Altarbild wie ein Organ des kurialen Administrationsapparates darstellt. Damit verfolgte der Maler offensichtlich das Ziel, Neris Heilscharakter im Kollektiv der Kongregation $\mathrm{zu}$ betonen. Ein bislang von der Forschung unerkannt gebliebenes Element der beiden Altarbilder Roncallis sind die Kleider, die Neri in den beiden Szenen trägt und die sich voneinander unterscheiden. Ein Wandbild in San Girolamo della Carità, das vermutlich 1605 ebenfalls von Roncalli ausgeführt wurde, hebt die zusammen mit den Reliquien und der Totenmaske des Verstorbenen auf dem Altar der neuen Kapelle positionierte liturgische Kleidung hervor. Anhand der Fresken, die Bernardino Barbatelli, genannt il Poccetti, für die Cappella Neri in der ehemaligen Zisterzienserkirche des Monastero di Cestello (heute Santa Maria Maddalena dei Pazzi) anfertigte, lässt sich rekonstruieren, dass die von Roncalli

e d'intorno vi furono di mano dell'istesso dipinti a olio in tele alcuni dei principali miracoli di esso Beato Padre“.

75 Primo Processo, I, S. 63-64. Vgl. dann Gallonio, Vita Filippo Neri, S. 226-228; Zazzara, Diario, S. 5. 76 Gerken 2015, S. 93. 
erstellte Marienvision die Figur des Ordensgründers im Habit der Oratorianer mit schwarzer Soutane und weissem Kragen dargestellt haben musste. Barbatelli hatte sich auf Roncallis Gestaltung im ehemaligen Zimmer Neris in der Vallicelliana gestützt, da zu diesem Zeitpunkt keine anderen bildlichen Darstellungen vorlagen, die als Vorbilder hätten dienen können. ${ }^{77}$ Roncallis zweite Version des Altarbildes führt somit eine Neuerung in die bis dahin die Darstellung Filippo Neris bestimmende Ikonographie ein, welche in dem von Guido Reni 1614 ausgeführten Ölgemälde von Filippo Neri im Gebet und eine Marienerscheinung ihre wohl berühmteste Wiederverwendung finden sollte (Abb. 2).

Roncallis malerische Neuformulierung von Neris Gewand im zweiten Altarbild für die Grabkapelle in Santa Maria in Vallicella entsprach demnach nicht nur den in diesem Raum gehaltenen Messefeierlichkeiten, sondern betonte zugleich das Selbstverständnis des Ordensgründers als Priester. Die spezifische Bildlösung deutet darauf hin, dass Roncallis Altarbild stark von der bereits unmittelbar nach Neris Tod publizierten Serie von Stichen beeinflusst gewesen sein musste, deren Genehmigung dem Maestro del Sacro Palazzo oblag. Ein von Pieter Coel nach einer Vorlage von Antonio Tempesta ausgeführter Stich zeigt in der Bildmitte Filippo Neri wie er vor einem Altar kniend zu einer sich über seinem Kopf öffnenden Wolke blickt (Abb. 3). Im oberen Teil der Bildmitte erscheint die Muttergottes in einem Medaillon, welches das Christuskind präsentiert. Um das zentrale Hauptbild sind Bildregister angeordnet, in denen weitere Szenen aus Neris Leben und seine thaumaturgischen Wunder gezeigt werden. Entlang des unteren Rands des Papiers ist ein Schriftzug sichtbar, welcher die Approbation seitens des damaligem socius des Maestro del Sacro Palazzo, des Neapolitaners Paulus de Francis, festhält: Publicetur fr. Paulus de Francis. Neap. socius [...] patris magistri sac. Palatii. ${ }^{78}$ Paulus de Francis war socius Giovanni Maria Guazzanis, der im Jahr 1607 den clementinischen Index herausgab. Dieser approbierte die beiden weiteren, 1606 entstandenen und auf Coels Stich aufbauenden Zeichnungen Mattheus Greuters, wie es die Annotationen auf den beiden Blättern bezeugen (Abb. 4a \& 4b). Noyes konnte jüngst belegen, dass diese Zeichnungen als Vorlagen für Drucke gedient hatten, die dem Maestro del Sacro Palazzo zur Approbation vorgelegt wurden. Zusammen mit seinem socius inspizierte der Maestro die vorgelegten Zeichnungen und genehmigte diese durch eine Auf-

77 Zur Ausstattungsgeschichte der Florentiner Cappella Neri im ehemaligen Convento di Cistello vgl. insbes. Müller-Bechtel 2001, S. 137-176; De Luca/Vasetti 1996, S. 159-172. Neri hatte noch bis 1588 in San Girolamo della Carità gewohnt. Vgl. hierzu Cistellini 1989, Bd. 1, S. 30-35. Das Fresko befindet sich am Ende des Eingangsflures im Konventsgebäude. Heute wird es durch die Suore di San Filippo verwaltet. Zum Fresko Roncallis vgl. Bacci, Vita, IV, cap. IX, n. 14; Zazzara, Diario, S. 19; Melasecchi 1998, S. 13-14.

78 Quetif 1959-61, I/1, S. 391. Zu den weiteren Aufgaben des Maestro del Sacro Palazzo vgl. Creytens 1942, S. 5-83. Bislang bleibt eine systematische Aufarbeitung dieses Amtes für das römische Cinquecento aus. 
schrift, welche sowohl die Druckerlaubnis als auch Angaben zur Publikation und deren Verbreitung - und sogar zum Verkauf - der Zeichnungen beinhaltete. ${ }^{79}$ Im Falle der noch unvollendeten Zeichnung Mattheus Greuters kann zudem vermutet werden, dass für die Gewährung einer Druckerlaubnis die Bildfelder, welche Episoden aus Neris Leben zeigten, von Vertretern der römischen Kurie oder sogar vom Maestro del Sacro Palazzo selbst vorgeschlagen werden mussten.

Im selben Jahr, in welchem Cesare Baronio auf Empfehlung Neris zum praepositus der Kongregation des Oratoriums ernannt wurde, erliess Papst Clemens VIII. ein Editto per gli altari et pitture. Das Edikt bildet die Grundlage eines Index für Bilder, der nach einem Prinzip konzipiert war, das dem Verzeichnis verbotener Bücher entsprach und der Zensur im Bereich der Altarmalerei dienen sollte. ${ }^{80}$ Dieses Dokument behandelte allerdings nicht nur die Herstellung von Bildern zu Gunsten der beati moderni, sondern thematisierte auch im Allgemeinen die Herstellung von Altarbildern, die während der Messzelebration aufgestellt wurden. Das Edikt des Aldobrandini-Papstes behandelte die Bildproduktion an sich, unabhängig vom Bildträger. Es schloss somit „Bilder jeglicher Art“ (pittura di sorte alcuna) ein. ${ }^{81}$ Die Forschung sah bislang in dieser Formulierung eine unscharfe Trennung zwischen der Produktion von Bildern, die für eine Aufstellung auf dem Altar vorgesehen waren, und solchen imagines, die in einen allgemeineren Bereich der Heiligenverehrung eingeordnet wurden, also Heiligenbilder. Aus dieser Perspektive erhält die Frage, inwieweit die Ritenund Zeremonienkongregation, welche auch Heiligsprechungsprozesse beurteilte, auf die Regulierung der Bildproduktion von noch nicht Heiliggesprochenen einen Einfluss ausgeübt hat, ein grösseres Gewicht. Damit ist sowohl Baronios eigene Einflussnahme auf die Kanonisierungsprozesse als auch seine Stellung zu Heiligenbildern, die bislang noch gänzlich ungeklärt ist, angesprochen. In einem Brief an den Papstneffen und Kardinal Pietro Aldobrandini hielt Dominico di Ginnasio fest, dass Baronio selbst

79 Noyes 2011, S. 811. Für einen Überblick zum Verhältnis zwischen dem römisch Kurienapparat und der Bildproduktion von Stichen im letzten Jahrzehnt des Cinquecento vgl. Leuschner 2005, S. 204-218; idem 2003, S. 65-67; idem 1998, S. 360; Wittkombe 1991, S. 133-145; idem 2004.

80 ASV, Misc. Arm., IV-V, 30, Bandi e editti, f. 171r-175v. Vgl. hierzu Fragnito 1997, S. 166-168, 173-174; Lincoln 2000, S. 189. Die Idee eines „Bilderindex“ stammte ursprünglich vom Kardinal und Erzbischof von Bologna, Gabriele Paleotti: Prodi 1959, Bd. 2, S. 555-561; idem 1984, S. 71-87. Die Entstehung dieses päpstlichen Erlasses für Bilder im Kirchenraum kann aus der Bedeutung der pastoralen Visitationen Clemens' VIII. in Rom abgeleitet werden. So hatte der Aldobrandini-Papst während einer Visitation des Gesù 1594 beschlossen, ein Bild, welches beati moderni des Jesuitenordens in der Gestalt der sieben Erzengel zeigte, zu verbieten. Das päpstliche Verbot stimmte mit der Anordnung, die vom Maestro del Sacro Palazzo noch nicht gebilligten Bildnisse im Kirchenraum für die Verehrung von noch nicht Heiliggesprochenen aufstellen zu dürfen, überein. Vgl. hierzu das Dokument in ASV, Misc. Arm. VII, 3, fol. 69v sowie die Ordini della Visita fatta da Sua Santità, in ARSI, Fondo Gesuitico 545, f. 8v. Des Weiteren auch Baglione, Vite, S. 32-33; Mancini, Considerazioni, I, S. 204; Zuccari 1990, S. 613-618; Luchinat 1999, Bd. 2, S. 181-190; Bailey 2003, S. $212-213$. 81 Beggiao 1978, S. 106; Noyes 2011, S. 811-814. 


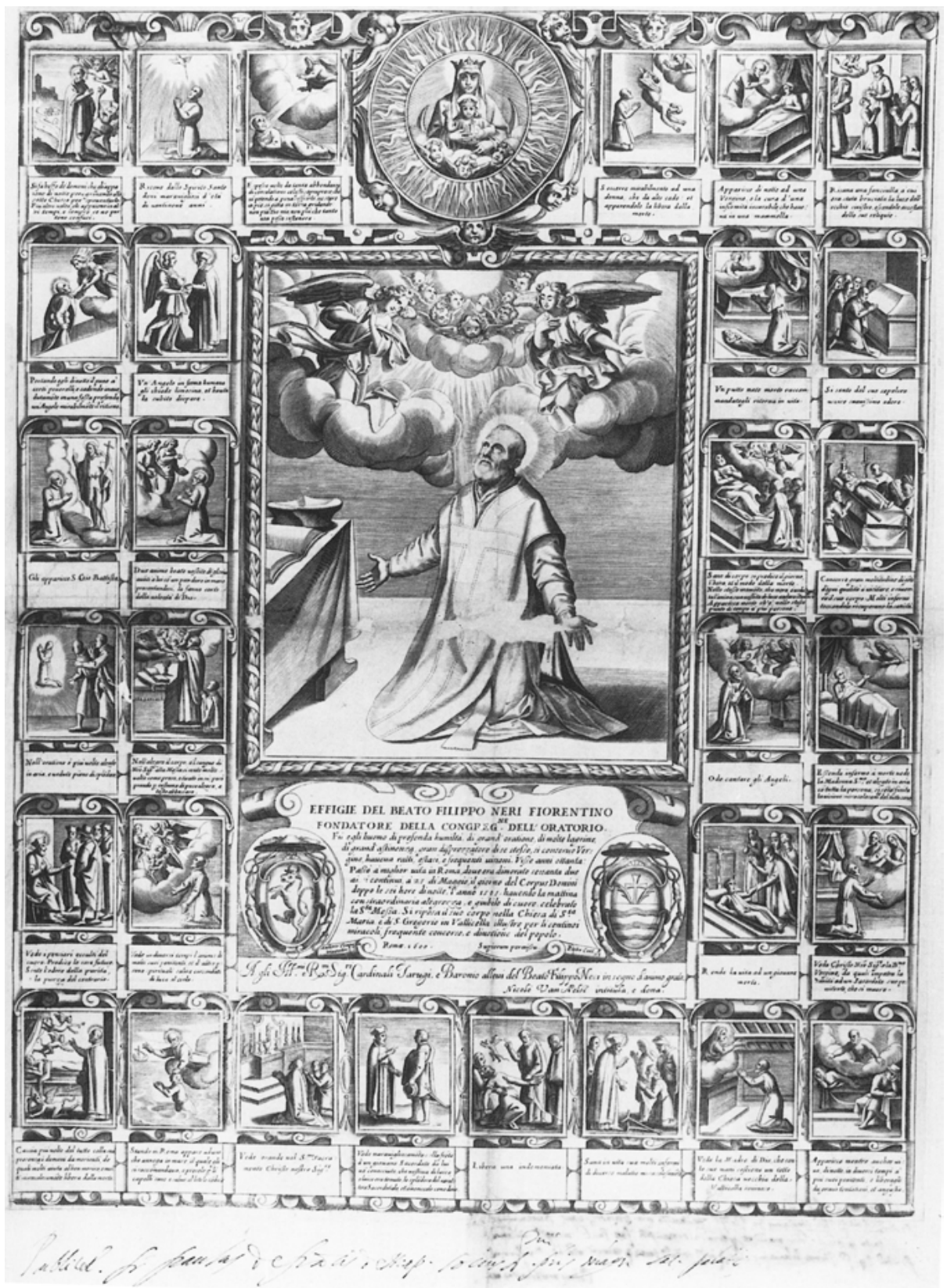

Abb. 3: Pieter Coel, n. Antonio Tempesta, Filippo Neri in Ekstase und Szenen aus seiner Vita, Kupferstich, 494 x 374 mm, 1600, Rom (ACR, A.III.51, f. 8r). 
einen Missbrauch von Heiligenbildern beging, als er während der Feierlichkeiten für Ignatius von Loyolas Todestag im Gesù ein Porträt des Jesuiten auf dessen Grab stellte. Dies hatte zur Folge, dass die Grablege zum Altar umgewandelt wurde und somit unmittelbar danach eine Verehrung des Ordensgründers einsetzte. ${ }^{82}$ Baronios Akt der Aufstellung eines Bildes über der Grablege des Jesuitengründers lässt sich in eine Tradition von noch nicht kanonisierten Schriften einordnen. Dieser hängt nämlich direkt mit einem von Antonio Gallio und dem Jesuiten Roberto Bellarmino am 5. Dezember 1602 verfassten memorandum zusammen, in welchem die Ausschmückung von Grabkapellen mit Bildnissen kürzlich con fama di santità Verstorbener thematisiert wird. Bellarmino selbst spricht in diesem Fall in seiner An liceat circa imagines eorum qui habentur pro sanctis antequam sint canonizati defingere miracula aut visiones, quae loquuntur in eorum vita über die beati moderni von „Heilige[n], die nicht, oder (noch) nicht kanonisiert wurden“". ${ }^{83}$ In der Quarta controversia generalis seiner Disputationes unterstreicht der im Jahr 1599 zum Kardinal ernannte Jesuit, dass es dem Papst erlaubt sei, eine öffentliche Verehrungspraxis auf der Grundlage von Heiligenporträts zu verbieten. ${ }^{84}$

Bellarmino beabsichtigte damit allgemeine Grundsätze festzulegen, welche die Verehrung von noch nicht heiliggesprochenen beati moderni regulieren sollten, um diese später rechtmässig als Heilige anerkennen zu können. So ist einem Brief Baronios an Antonio Talpa vom 14. Dezember $1602 \mathrm{zu}$ entnehmen, dass nicht nur die öffentliche Verehrung Neris und Loyolas nach einem Eingriff seitens des Papstes verlange, sondern dass deren öffentliche Verehrung derjenigen innerhalb der Kongregation und des Jesuitenordens widerspreche, die als Folge der Entstehung neuer Grabkapellen zu sehen sei:

Qui si è ecitata burrasca grande contro le cose del B. Padre, partorita dall'invidia della sontuosa Cappella volgarmente chiamata del B. Filippo. Il Papa è in dispiacere grande, parendoli,

82 ASV, Segr. Stato Spagna, 55, f. 422r-424v: „Si scusano, che da Roma vengano le stampe, et che il S.r. Card.le Baronio facci fare la festa in Roma, et metter li voti, et lampade avera à q.to loro P're Ignatio“. Vgl. auch denselben Bericht in Bellarmino, Autobiografia, S. 79. Levy 2004, S. 127 datiert das Ereignis in das Jahr 1599. Dieser Fall erregte deshalb grosses Aufsehen, weil Ignatius von Loyolas Kanonisierungsprozess im Unterschied zu demjenigen Filippo Neris noch nicht begonnen hatte. Vgl. neben dem avviso vom 2. Juni 1601 in BAV, Urb. lat. 1069, f. 347v; Papi 1988, S. 74.

83 Allgemein zur Historiographie von Heiligsprechungsprozessen vgl. Papa 1992, S. 147-209. Gallonios Schrift, Ad sepulcra et corpora recens defunctorum nondum canonizatorum, qui pro sanctis habentur, cultum dumtaxat publicus prohibetur, sed privatus conceditur, befindet sich in BVR, H 14, f. 378r-385r Vgl. diesbezüglich Ditchfield 2007, S. 211. Bellarminos An liceat ist ebenfalls in BVR, H 14, f. $362 r-v$, enthalten.

84 Bellarmino, Disputationes, II, S. 606: „Siquidem summus pontifex eo loco prohibet publicum cultum, ergo a contrario privatum censetur permittere [...]. Vocamus autem publicum cultum, non eum qui coram aliis exhibetur, sed qui nomine totius Ecclesiae, et tamquam ab Ecclesia institutus, exhibetur“. Bellarmino rät betreffend der Bildproduktion an, diese nicht quo aliorum sanctorum herzustellen. Vgl. auch Benedikt XIV, De serv. Dei, II, S. 50. 


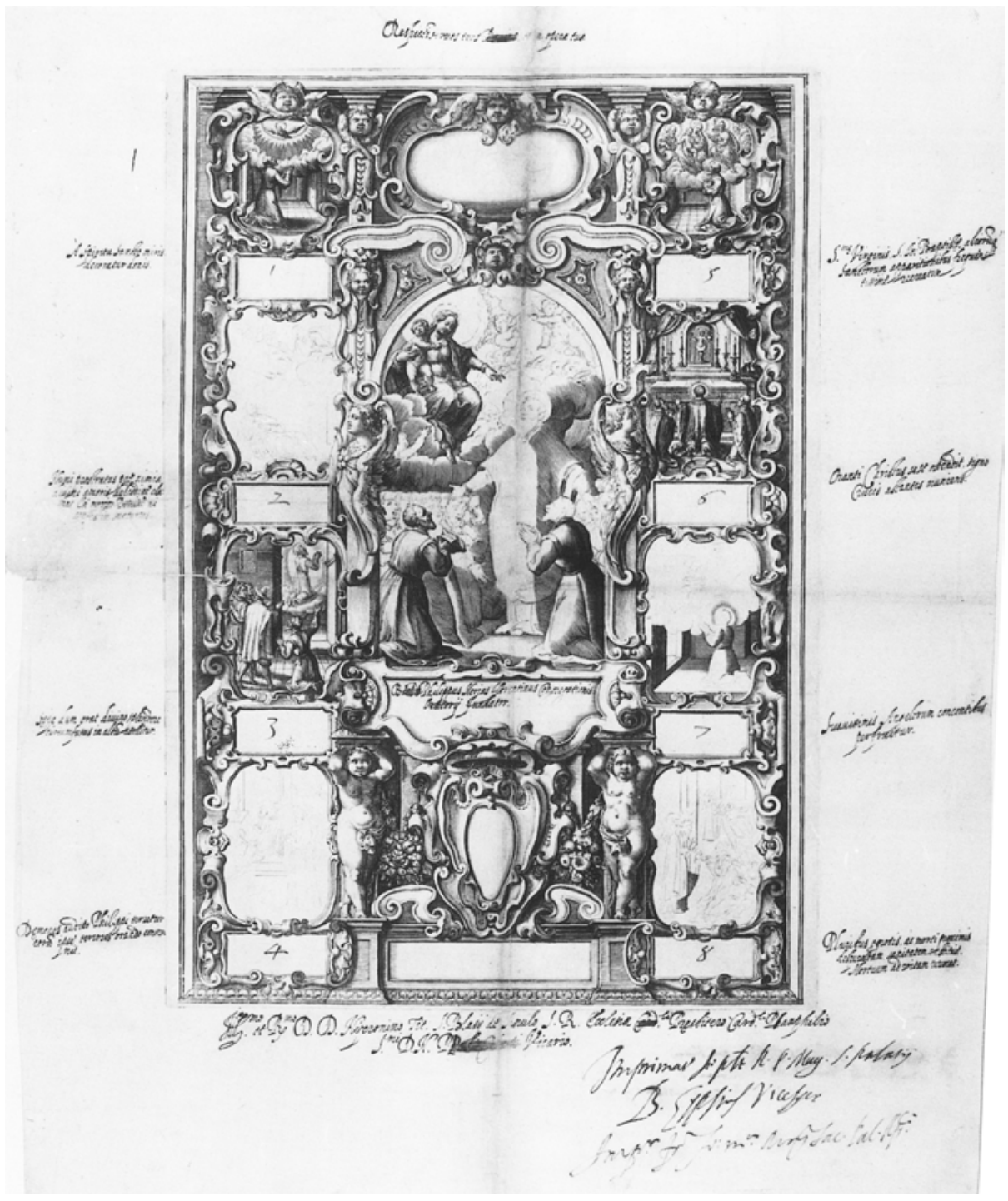

Abb. 4a: Matthäus Greuter, Filippo Neri empfiehlt seine Kongregation dem Schutz der Madonna, mit Szenen aus seiner Vita, Kupferstich, 1. Zustand, 400 x 277 mm, 1606, Rom (ACR, A.III.51, f. 13r). 


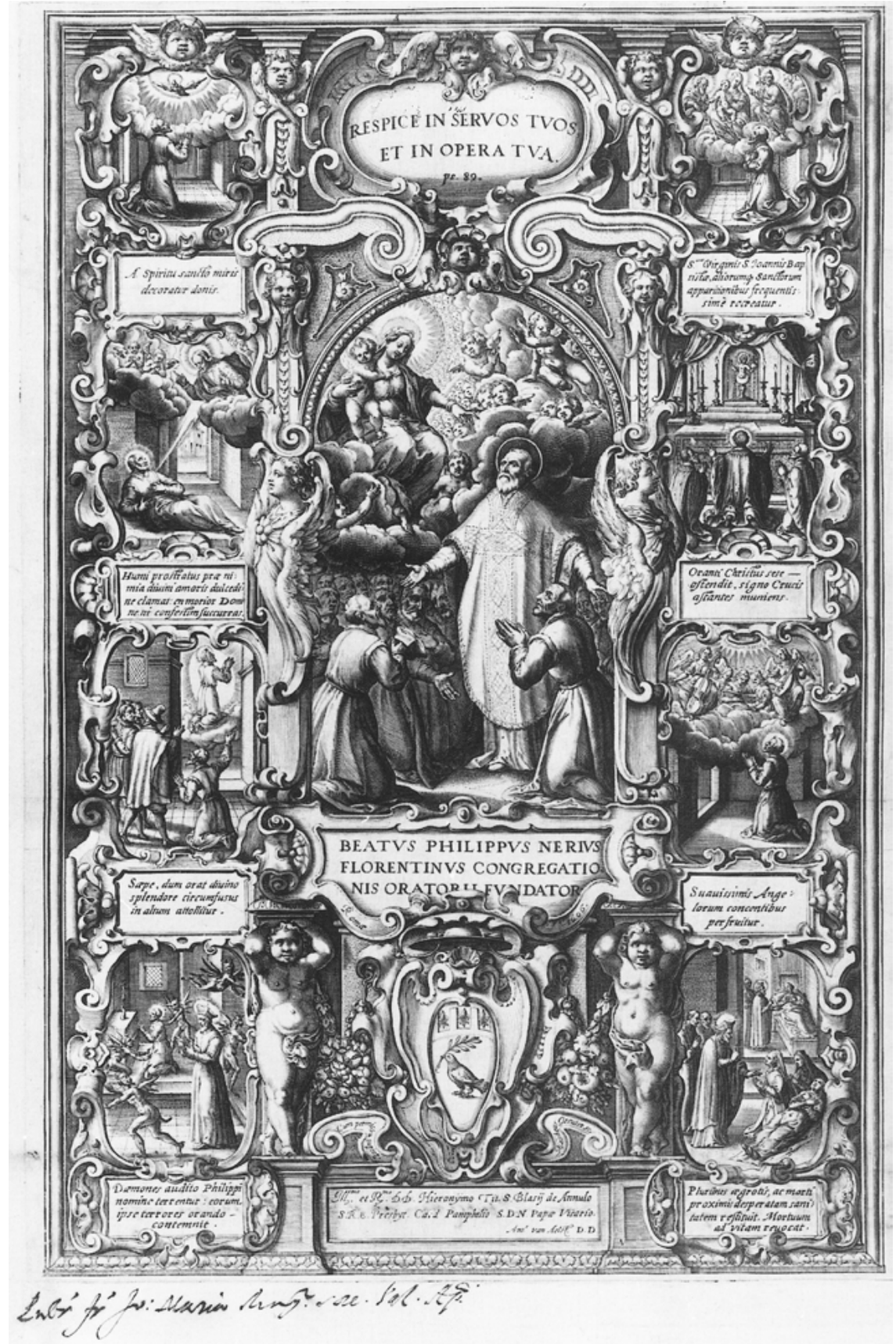

Abb. 4b: Matthäus Greuter, Filippo Neri empfiehlt seine Kongregation dem Schutz der Madonna, mit Szenen aus seiner Vita, Kupferstich, 2. Zustand, 400 x 277 mm, 1606, Rom (ACR, A.III.51, f. 14r). 
che prevenghi la Canonizzazione, quale tocca alla Sede Apostolica. A me toccano masticare pillole amare. Preghino per me, et per il negotio di tanta importantia, con il quale va congiunto quello del B. Ignatio, et del B. Ill.mo Borromeo. Si scoprono molti Cardinali poco favorevoli, et per la maggior parte tacciano d'imprudentia li nostri Padri della Vallicella, per non dire di temerità. Il Papa sopra di ciò ha fatta una Congregatione di 16 Cardinali, et altrettanti Consultori. La prima Congregatione sarà lunedi prossimo. ${ }^{85}$

Offensichtlich waren Baronio die Massnahmen Clemens’ VIII., die einen allmählich grösser werdenden Verehrungskult um Filippo Neri innerhalb des Oratoriums eindämmen sollten, bekannt. Der Papst erliess Mitte Dezember 1602 hierfür die Dubia de beatis non canonizatis, die anschliessend innerhalb einer neu entstandenen Kongregation für Heilige zirkulierte. ${ }^{86}$ Demzufolge muss der aus Valladolid berichtete Fall über Baronios Beteiligung an den Feierlichkeiten zum Todestag des Jesuitengründers Ignatius aus einem neuen Blickwinkel betrachtet werden. Es ist dabei entscheidend, zu fragen, welches Bild Baronio selbst überhaupt von den beati moderni und von Neri im Speziellen sowohl in seiner Dankesrede im achten Band der Annales als auch in seinen Zeugenaussagen während des Kanonisierungsprozesses entworfen hat. Andererseits muss in diesem Zusammenhang auch die politische Bedeutung der Verehrungspraxis neuer beati moderni wie Carlo Borromeo, Neri und Loyola stärker berücksichtigt werden, als es bislang in der Forschung getan wurde. Sie hängt in besonderer Weise auch mit Baronios Konflikt mit den spanischen Vertretern des Kardinalskollegiums zusammen. Ein Tag nach den Feierlichkeiten im Gesù verfasste nämlich der Jesuitenpater Alfonso Agazzari ebenfalls einen Brief, in welchem er die Ereignisse an der Grabstätte des Ignatius schildert und dabei Baronio erwähnt, der das Grab als kahl und ohne jegliches Zeichen von Heiligkeit bezeichnet habe. ${ }^{87}$ Auch wenn die Anbringung von Votivbildern und Bildnissen durch Baronio und Bellarmino am Grab des Jesuitengründers den Vorgaben des damaligen Ordensgenerals Claudio Acquaviva, der jegliche Anzeichen eines Kultes ausdrücklich verboten hatte, widersprach, weihten Jesuiten in Saragossa einen Altar zu Ehren ihres Gründers und liessen für diesen ebenfalls ein entsprechendes Altarbild anfertigen. Sie vertraten die Meinung, dass ihr Gründervater bereits seliggesprochen worden sei. Von einem solchen „falschen“ Altar wurde auch in Valladolid berichtet. Das Bild im Gesù wurde schliesslich nach einigen Monaten wieder vom

85 Primo Processo, II, S. 300; Calenzio, Vita, S. 590. Vgl. auch das weitere Briefschreiben Baronios an Talpa vom 21. Dezember 1602 in Alberici, Epistolae et opuscula, III, S. 131.

86 BAR, ms. 909, f. 102r-v; Benedikt XIV, De serv. Dei, II, S. 58-59. Vgl. auch König-Nordhoff 1982, S. 32-33. Die Schrift wurde auch in das Zeremonialtagebuch Giovanni Mucanzios eingefügt: BAV, Barb. lat. 2810, f. 315r-319v.

87 MHSI, Monumenta Ignatiana, Ser. IV, Scripta de sancto Ignatio de Loyola Societatis Iesu fundatore, II: 454-456. Vgl. auch König-Nordhoff 1982, S. 41; Levy 1993, S. 36. \& Gerken 2015, S. 103. 
Grab entfernt, wohingegen das Altarbild in Saragossa, welches Ignatius mit einem Heiligenschein zeigte, nur übermalt wurde. ${ }^{88}$

Der Wunsch der beiden Kardinäle, die Grablege des Jesuitengründers zu schmücken, kann durchaus, wie Levy bereits vermutete, im Zusammenhang mit der Verehrung des Grabes von Filippo Neri betrachtet werden. Die fehlende Inszenierung des Ignatius-Grabes ist allerdings abgesehen vom Verbot des Jesuitengenerals Acquaviva auch auf die Spannungen zwischen dem Jesuitenorden und dem Aldobrandini-Papst zurückzuführen, die im Jahr 1598 im Zusammenhang mit dem theologischen Streit um die Gnadentheologie enstanden war. ${ }^{89}$ In den bis zur Seligsprechung des Ignatius im Jahre 1609 gedruckten Viten wurden keine von ihm bewirkten Wunder erwähnt. Die spirituellen Wunder des Ignatius seien als bedeutender einzuschätzen als die körperlich fassbaren Heilungsmirakel, wie es Pedro de Ribadeneira in seiner 1586 herausgegebene Vita festhält:

Maggior miracolo è risuscitar l'anima, la quale ha da viver per sempre, che ritornar in vita il corpo, che di nuovo ha da essere alla morte soggetto. [...] Perche qual maggior miracolo del Signore pensi tù che fusse, ò il risuscitar Lazaro morto di quattro giorni, e restituir la vita al corpo setente di lui nella sepoltura; ò risuscitar l'anima di Saulo, che lo perseguitava, e convertirlo in Paolo; e farlo vaso d'elettione? Senza dubbio che maggior miracolo fu, e di profitto, \& utilità maggiore alla Chiesa di Dio la conversion di Paolo, che il risorger di Lazaro [...]. ${ }^{90}$

In seiner im achten Band der Annales Ecclesiatici enthaltenen actio gratiorum geht es Baronio ebenfalls um einen geeigneten Umgang mit der Figur Neris, der vor allem zum Ziel hat, ihn als Menschen zu präsentieren, der zusammen mit Gott wirkt (Dei cooperatorem hominem). Die Heiligkeit Neris und Ignatius' soll demnach anhand ihrer Mitwirkung am göttlichen Heilsgeschehen beurteilt werden, wofür auch die Betonung eines ordentlichen Gottesdienstes ins Zentrum gerückt wird. Tatsächlich ent-

88 Zur Episode in Valladolid vgl. v. a. Levy 2004, S. 128. Gotor 2002, S. 63; Burzer 2011, S. 11 weisen darauf hin, dass die Entfernung des Altarbildes aus der Hauptkirche der Jesuiten in Rom als Folge des Unmuts des Papstes selbst zu betrachten sei. Vgl. diesbezüglich die Rede des AldobrandiniPapstes vor einer am 25. November 1602 gehaltenen Sitzung der kürzlich gegründeten Congregazione delle Cause dei Santi, die sich in Papa 2001, S. 57 abgedruckt findet: „Un p.m. Filippo intendiamo nella Chiesa Nuova, che sia tenuto con tanta venerazione, che vi habbino eretto altare, ornatogli il suo sepolcro, posto fuori la sua immagine con lampade, lumi e voti: che se fosse canonizato non potrebbe quasi haver più. Così il p. Ignatio è tenuto in tanta veneratione, che niente più: et se bene l'habbiamo detto al p. generale del Giesù, che non lo permetta, pur tuttavia si vuol fare il tutto senza di noi“.

89 Die Debatte entstand aus Luis de Molinas Schrift über das Verhältnis zwischen libero arbitrio und Gnade. Vgl. hierzu v. a. Stella 1982, S. 169-189; Parera 1987; Quillet 2007 sowie zuletzt Broggio 2014, S. 88.

90 Ribadeneira, Vita, S. 586-587. Erst 1601 werden in der damals erschienenen Ignatius-Vita die bewirkten Wunder des Jesuitengründers eingefügt, worauf König-Nordhoff 1982, S. 38-39 bereits hinwies. Der typologische Vergleich zwischen Ignatius und Saulus/Paulus erklärt sich aufgrund des früheren Soldatenlebens des Jesuitengründers. 
spricht Neri in Baronios Dankesrede weitaus mehr einem der kirchlichen Liturgie konformen Zelebranten in einer durchdachten Nachahmung vom Propheten Elias. ${ }^{91}$ Es ist demnach festzustellen, dass Baronio zwischen einem bildproduktiven und einem liturgisch-feierlichen Umgang mit den beati moderni unterscheidet, wobei letzterer vor allem für Papst Clemens VIII. und die Kongregation für Riten und Zeremonien von grosser Bedeutung gewesen sein muss, wie ein avviso vom 2. Juni 1601 belegt, in welchem der Papst den Druck eines Ignatius-Stiches untersagte. ${ }^{92}$

Cesare Baronios Haltung gegenüber Neris Heiligsprechung erscheint in einem eindeutigen Kontrast zu Antonio Gallonios Bestrebungen, die Oratorianer gegen die von der päpstlichen Kommission vorgebrachten Vorwürfe zum Neubau einer Grabkapelle in der Chiesa Nuova zu verteidigen. In einem bereits 1596 verfassten Traktat ging Gallonio selbst auf die Probleme der Bilderverehrung, der Reliquienverehrung, der Anbringung von Lampen und ex-votos am Grab und eines öffentlich gefeierten Festtages ein. Neris Kanonisierungsprozess wurde nämlich am 1. Juli 1601 aufgrund des Neubaus der Grabkapelle in der Kirche der Oratorianer unterbrochen. Erst ab dem 8. Februar 1605 und bis zum 3. März desselben Jahres wurde er fortgeführt. In Gallonios Beitrag zur Heiligsprechung Neris anlässlich der Eröffnung der Grabkapelle am 2. August 1595 zeigte sich die Kongregation nicht als eine geschlossene Einheit. Ihr wichtigster Förderer hatte nämlich als einziger die Initiative ergriffen. ${ }^{93}$ Gallonio machte am 13. Januar 1597 in der Gegenwart des Kanonikers von San Giovanni in Laterano, Giacomo Buzzi, eine weitere Zeugenaussage, die in besonderem Zusammenhang mit seinem Verständnis der Bilderverehrung des noch nicht heiliggesprochenen Neris steht:

91 Ann. Ecc., VIII, act. grat., S. 3: „In quo quidem visus es imitatus Eliam, dum congressus cum sacerdotibus Baal, eos expugnaturus per ignem coelitus implorandum, qui propositam victimam inflammaret atque consumeret; in contrarium nisus, eamdem quatuor aquae hydriis tertio voluit affluenter aspergi, quo magis summa Dei potentia innotesceret. At vero alia ex parte cum promto animo idem tu ipse ad praestandum auxilium precibus tuis manum fortissime admovisti [...]“. Damit bezieht sich Baronio eindeutig auf 3 Kön. 18:25f.

92 BAV, Urb. lat. 1069, f. 347v: „Havendo Nostro Signore presentito, che li padri del Jesù facevano stampar imagini et figure del padre Ignatio lor fondatore con miracoli intorno, diede ordine l'altro hieri a monsignor viceregente, che facesse levar, come fece, tutte le sudette figure, imagini et stampe, perché in somma quelli miracoli non si hanno per autentiche, nè sono approbati; havevano proceduto in questi con l'essempio de padri della Chiesa Nuova, che così fanno stampar il padre Filippo, ma non è il medesimo caso, perché fanno del padre Filippo processo et il Papa istesso in un particolare si è esaminato“. Vgl. hierzu Regola e Fama, Kat.-Nr. 17; Orbaan 1920, S. 171; Levy 2004, S. 128-130. Nach mehreren Bittgesuchen bei der Ritenkongregation wurde schliesslich das Verfahren für den Kanonisationsprozess des Ignatius 1602 eröffnet, vgl. hierzu die neusten Untersuchungsergebnisse bei Gotor 2002, S. 57 f., $62 \mathrm{f}$.

93 Gallonio, De his, quae praestari possono non canonizatis, in BVR, H 14, f. 272r-307r. Vgl. hierzu Ditchfield 1995, S. 49-50. 
Argumento della santità sua mi pare, perchè cresce incredibilmente la devotione de popoli verso lui, non solo qui in Roma, in Firenze, ma in diverse città et luoghi; et, tanto più, perchè è cosa certa, come osservano li dottori et canonisti, che non permetterebbe Iddio ultra sex menses, et altri dicono minor tempo assai, che alcuno fosse adorato come santo, se realmente non fosse tale; et, più oltre, si sentono tuttavia et scoprono miracoli novi, non solo operati qui in Roma, per meriti del detto santo, ma fuori ancora. ${ }^{94}$

Dass Gallonio sein Augenmerk auf die Wunder des Gründers des Oratoriums gelegt hat, lässt darauf schliessen, dass die Kongregation - im Gegensatz zu Baronio den Memorialakt für Neri mit der liturgisch praktizierten Verehrung als Heiligem verbinden wollte, zu welcher ein reger Austausch von Kupferstichen mit dem Bildnis Neris als Heiligem beitragen sollte. Francesco Zazzara berichtet ferner in einem Tagebucheintrag vom November 1598, dass 3250 Blätter mit Neris Bildnis verkauft wurden. Die Kupferstiche wurden entweder auf losen Blättern verkauft oder fanden als Frontispiz in Büchern Verbreitung, wie beispielsweise Giacomo Lauros Darstellung Neris, die eine besondere Nähe zu Christus suggeriert, zumal sie auch neben einem Bildnis Christi als Salvator Mundi ausgeführt und elf Jahre später als Frontispiz in den Satzungen des Oratoriums - nun ohne das Christus-Pendant - wiederverwendet wurde.

Hatte die Forschung bislang den Zweck solcher Kupferstiche primär dahingehend gedeutet, dass sie den Gläubigen die Wundertätigkeit des Heiligen vorführen sollten, versäumte sie es umso mehr, eine Differenz zwischen liturgischer Verehrung und einer sich allmählich von dieser zeremoniellen Praxis abwendenden Bildproduktion zu erkennen. Im Zusammenhang mit Antonio Gallonios Vita des Filippo Neri wurden die Bilder gänzlich im Hinblick auf eine solche intercessio Neris gedeutet. Die theologischen Dimensionen wurden dabei kaum beachtet. So fand die Tat-

94 Primo Processo, II, S. 139. Insgesamt vier Mal wird Gallonio während des Heiligsprechungsprozesses Neris als Zeuge aussagen. Gallonio wird auch an den Kardinal Agostino Cusano in einem Brief im Jahr 1598 seine Freude über die zunehmenden Feiern in seinem eigenen Zimmer in S. Maria in Vallicella berichten, wo er einen kleinen Altar zu Ehren Neris aufstellte und dort jeden Freitag eine Zusammenkunft mit Gebeten, Predigten und Litaneien abhielt, bei der auch Cusano zusammen mit Marcantonio Maffa, Girolamo Pamphilii und Lorenzo Banchetti anwesend war: ACR, C.I.36, fols. 27r-28v; Zazzara, Diario, S. 4-8; Cistellini 1989, Bd. 2, S. 983-986, 1057-1058. Hierzu steht Baronios zweite Zeugenaussage vom 14. Dezember 1595 als diametrales Gegenbeispiel: „Il padre si sforzava non mostrare di esser spirituale, et, con quelli che lo visitavano, mostrava di esser homo come li altri, et occultava di esser tenuto spirituale. Era prudentissimo, de una vita austera, affabile, pieno di charità, disprezzatore del mondo, di gran libertà in riprendere li vitii, massime de prelati, a luogo et tempo. Haveva gratia di medicar le persone tentate inviolabilmente et consolare le persone afflitte. Et, in somma, regnavano et rilucevano in lui ogni virtù“. Zit. n. Primo Processo, I, S. 406.

95 Pastor 1893-1911, Bd. 12, S. 186; Wisch 1991 und Gerken 2004, S. 226-227. Zur Verbreitung dieser Kupferstiche vgl. insbes. Zazzara, Diario, S. 11; Cistellini 1989, Bd. 2, S. 1058 und De Belloc 1895, S. 309. Die bildprogrammatischen Stiche betonen zusätzlich die an der Grabstätte stattfindende memoria. Vgl. hierzu grundsätzlich Assmann 2003, S. 303-305 sowie Dupront 1993, S. 394-400. 
sache, dass während der Heiligsprechungsprozesse nach 1588 erstmals zwischen thaumaturgisch bewirkten Wundern und eigentlichen Kriterien von Heiligkeit unterschieden wurde, wenig Beachtung. ${ }^{96}$ In einem Brief an den Kardinal Federico Borromeo vom 21. Juni 1601 drückt sich Baronio betreffend der liturgischen Feierlichkeiten anlässlich Carlo Borromeos Todestag folgendermassen aus: „[...] circa del non prohibir né lumi, né tabelle, o altro venerando ossequio, qual si facci alla sepoltura della santa memoria del card. Borromeo, essendo già stato questo decretato altrimenti dalla Congregazione dei Riti, possonsi fare legittimemente [...]“. ${ }^{97}$ Baronios Darstellung Filippo Neris in seiner Dankesrede im achten Band der Annales Ecclesiastici weist demnach mehr Ähnlichkeiten mit dem Kupferstich Francesco Villamenas auf, den Gabriele Paleotti als Einleitungsbild für seinen 1595 verfassten Traktat De bono senectutis ausgewählt hatte. Paleottis Traktat stellt den Beichtvater Filippo Neri ähnlich dar wie Baronio in seiner zweiten Zeugenaussage. Paleotti bezeichnet Neri im Prolog aufgrund seiner Autorität, seines demütigen Geistes und seiner Frömmigkeit als vorbildhaften alten Mann (vivum exemplar senectutis). ${ }^{98}$

Die in diesem Abschnitt untersuchte Rolle Baronios beim Kanonisierungsprozess Filippo Neris zeigt im Kontext der liturgischen Verehrungspraxis eine eindeutige Übereinstimmung mit der kurialen Perzeption Neris nach seinem Tod. Sie stand geradezu im Gegensatz zu den Bestrebungen für die neu erbaute Grabkapelle in der Chiese Nuova. Baronio vertrat damit eine gegensätzliche Meinung zur Kommemorationspraxis des Kongregationsgründers, wie sie die Oratorianer ausübten. Selbstverständlich galt für Baronio, der ein Jahr nach der Papstwahl des Kardinals Ippolito Aldobrandini zum Vorsteher des Oratoriums berufen wurde, die Figur Filippo Neris insofern als vorbildlich, als Neri sich in eine übergeordnete Konstellation der karitativen Praxis neugegründeter Orden, die bereits mit der Gründung des Jesuitenordens 1545 einsetzte, einordnen liess. Neri und die mit ihm entstandene Priesterversammlung hatten eine neue Form der Predigt entstehen lassen, die wiederum die Strukturen

96 Lauros bereits besprochener Kupferstich Neris fand ebenfalls Eingang in Gallonios Vita des Heiligen als Frontispiz. Vgl. hierzu den Text zum Kupferstich in ACR, A.III.51, f. 3v: „,...] in cuius imaginis circuite decem alias imagines eiusdem epistunt, representantis particularia miracula eiusdem, cum descrip(tio)ne in fine cuius liber imaginis miraculi ad eius intercessionem facti [...]“. Gerken 2015, S. 78; Leuscher 2005, S. 299-304, möchten darin eine Verwandtschaft dieses Bildertypus mit dem von Klaus Krüger geprägten Begriff der „Vita-Ikone“ sehen. Leuschner sieht vor allem in diesem „Bildrahmenschema“ einen formalen Rückgriff auf byzantinische Ikonen. Vgl. auch Krüger 1992, S. 11; Leuschner 2005, S. 280-281.

97 Zit. n. Marcora 1964, S. 27. Vgl. dann die weiteren Briefschreiben Baronios an Borromeo vom 21. Juli und vom 27. September desselben Jahres in Turchini 1984, S. 15, 54-55.

98 Paleotti, De bono senectutis. Vgl. Cistellini 1989, Bd. 2, S. 976. Das Bildnis Neris wurde erst nach seinem Tod beim Druck des Traktates eingefügt, was zur Folge hatte, dass das ursprünglich für diesen Zweck vorgesehene Blatt des Filippo Flammingo verdrängt wurde. Dieses zeigte Gottvater in feierlicher Versammlung mit Greisen. Vgl. hierzu Prodi 1959/76, Bd. 2, S. 568 und Baronios Zeugenaussage in Primo Processo, I, S. 406. 
der römischen Kurie massgeblich und nachhaltig verändern sollte. Dies löst einen besonderen Widerspruch zwischen Baronios erster Zeugenaussage und einem an seinen Vater gerichteten Brief, den Baronio unmittelbar nach seiner Ankunft in Rom nach Sora sandte, auf. In einem Briefschreiben an seinen Vater vom 18. März 1558 wies Baronio die Anklage, er habe sich dem „Leben der Theatiner“ verschrieben, entschieden zurück. ${ }^{99}$ Wie kann es also sein, dass der in Rom angekommene neunzehnjährige Cesare Baronio sofort mit Neri und seiner ersten Versammlungen in Verbindung trat? Baronios erste Erfahrungen in Rom um die Mitte des Cinquecento sollen im Folgenden aus diesem Blickwinkel römischer Bruderschaften betrachtet werden. Die neuen Bruderschaften begannen sowohl die städtische Topographie Roms als auch die visuelle Wahrnehmung der römischen Kurie nachdrücklich zu prägen.

\subsection{Das frühe Oratorium im Kontext urbaner Bruderschaften}

Paenitenimi et credite evangelio.

$(\mathrm{Mk} 1,15)$

In seinem Tagebuch, das der englische Pilger Gregory Martin anlässlich seines Rombesuchs zwischen 1576 und 1578 verfasste, führt er unter dem Abschnitt über die „Wohltätigkeiten Roms“ die Erzbruderschaft der SS. Trinità dei Pellegrini inmitten eines weitgespannten Netzes verschiedener Bruderschaften des Cinquecento auf. Diese Bruderschaft hatte sich, so Martin, wegen ihrer karitativen Tätigkeit die Bezeichnung la gloriosa verdient:

The Companie of the Trinitie is that which for renowned charitie thereof in the last yere of Jubilee [...] is called La gloriosa, the glorious Companie. They take the charge [...] of al poore pilgrimes and of al that begin to recover, out of all other Hospitals. In their Oratories is the weekely preaching to the Jewes, where they attend to make al commodious provisio [...] that they may have no cause to complaine [...]. They maintaine ten Chaplens, to say dayly Masse,

99 BVR, Q 46, f. 5v-6r; Calenzio, Vita, S. 21-22: „E questo perché vego ch’ ogni cosa pigliate al contrario. Che s'io vi scrissi, che vi avessivo da confessare a questa medesima pasqua, ció vi scrissi, perché mi ricordo che è stato alcuna volta vostro solito lassar la pasqua, e le feste, e differirla in altro tempo [...] Se vi è riferito ch' io stia macilento [...] che per il medesimo Dominico vi scrissi, ch' io non mi sentiva al tutto sano, e che mi senteva alquanto alterato. E questo [...] per il troppo mangiar di pesci, de quali ne havemo tanta abundantia, che vengono da Gaeta, che cognosco mangiarne troppo [...] Mi scrivete ch' io mi sia dato alla vita theatina, e che non studio. Vi dico, e vi confermo quel che vi desse, quando che partiste da Roma, ch' il mio stile saria stato di communicarmi la pasqua, il dì del Corpo di Christo, il dì di Santa Maria de mezzo Agosto, et il Natale, e di questo di novo v'affermo di non volere mancare [...]“.Vgl. auch den Eintrag in Zazzara, Memorie, S. 87-88: „Di più mi disse che pochi mesi doppo che lui fù gionto in Roma, sapendo suo padre carnale che lui andava spesso à S. Giorlamo, et attendeva alla vita spirituale, non gli piaceva niente, dubitando che non si facessi Prete come era l'animo suo, et gli prese tant' odio, et cominciò à fargli de' dispiaceri, essendo che lui era figliuolo Primogenito [...] et dove prima gli mandava denari per il suo vitto et vestito [...]“. 
and on Sundaies and Holy daies, Mundaies and Saturdaies, to sing [...]. They goe to Confession and receave the B. Sacrament every Moneth; and afterward goe in solemne procession with the said Sacrament, and make continual prayer [...] for the space of 40 houres before the $\mathrm{B}$. Sacrament set forth with al glorious furniture upon the altar, which is so solemne a custome among the Confraternities, that it is knowen and renowmed by this terme Quarantae horae. ${ }^{100}$

Dieser Verdienst, als „glorreiche“ Bruderschaft bezeichnet zu werden, ging auf die regelmässige Praxis der quarant'ore, der sich die SS. Trinità dei Pellegrini e Convallescenti gewidmet hatte, zurück. Diese besondere Form der Andacht für das während vierzig Stunden öffentlich in einem Kapellenraum zugängliche Heilige Sakrament der Eucharistie lag im Zentrum des liturgischen Lebens dieser Bruderschaft. Die Bruderschaft konnte aber auch stolz darauf sein, dass ihre Gründung mit einem Jubeljahr zusammenfiel. Die Bruderschaft hatte vor allen Dingen im Rahmen der Vorbereitungen zum Heiligen Jahr 1550 für die Unterbringung der zuströmenden Pilger zu sorgen. Verschiedene während Filippo Neris Heiligsprechungsprozess gemachte Zeugenaussagen gehen auf seine fundamentale Rolle als Gründer jener Bruderschaft und den von ihm eingeführten quarant'ore ein. Pompeo Pateris Zeugenaussage vom 5. Mai 1610 zufolge habe er vom Kardinal Francesco Maria Tarugi erfahren, dass es der Verdienst der SS. Trinità gewesen sei, die quarant'ore in Rom eingeführt zu haben. Für Pateri hatten Neris früheren Predigten eine entscheidende Rolle bei der Einführung dieser Liturgie gespielt, an die er sich wie folgt erinnert:

Quanto all'oratione et contemplatione, si può veramente dire, che tutta la vita del beato Filippo fosse una continua oratione. Infinite volte, ho sentito dire, dal p. Francesco Maria Tarugi, et da altri padri di casa, et gentil'huomini, in diversi tempi et occasioni, che cominciò da giovanetto, poichè lassò li studii, per attendere all'oratione. [...]. Et tanta era la dolcezza, che sentiva in tale essercitio, più presto d'angeli che d'huomini, che procurava, per quanto poteva, che tutti si dessero a questa oratione. Et, per questo, procurò (per quanto ho inteso più volte dal card. Tarugi et da altri) insieme con m.s Persiano Rosa, che s'instituisse la compagnia della Santissima Trinità, et che, ogni prima domenica del mese, si facesse l'oratione delle Quaranta hore, che non si solevano fare. [...] Et a questo, di continuo, invitava et esortava li suoi figlioli spirituali [...]. ${ }^{101}$

Innerhalb des engeren Kreises von Neris Mitbrüdern im Oratorium, zu denen auch der Priester aus der SS. Trinità dei Pellegrini, Domenico Migliacci, zählen musste, sollte Neri als Gründer dieser Erzbruderschaft hervorgehoben werden. In seiner

100 Martin, Roma Sancta, S. 205. Vgl. auch betreffend des im Jahr 1600 während des Pontifikates Clemens VIII. durchgeführten Jubeljahres dann Fanucci, Trattato, S. 54-56.

101 Primo Processo, III, S. 156. Neben Neri wirkte auch Persiano Rosa als Gründer der Bruderschaft, wobei Rosas Anteil mit der Entwicklung des Oratoriums zunehmend aus der Gründungsgeschichte verdrängt wurde. Vgl. Tacchi-Venturi 1950, Bd. 1, S. 235-238 sowie die Zeugenaussage des Notars innerhalb des Oratoriums, Giovanni Francesco Bucca, in Primo Processo, I, S. 103. Im Allgemeinen zu den quarant'ore innerhalb der historischen Forschung vgl. zuletzt Weil 1974; Petersen 2012; Black 1989, S. 99-100. 
Frühzeit musste sich das Oratorium in San Girolamo della Carità, um sich als legitime Versammlung behaupten zu können, gegen jene Stimmen verteidigen, die seine Mitgleider als chietini bezeichneten. Dieser Begriff galt im Rom des del MontePontifikates noch als Schimpfwort für Gruppierungen der ersten Regularkleriker. Kardinal Girolamo Pamphili erinnerte sich in seiner Zeugenaussage vom 6. August 1596 daran, wie er zusammen mit Neri durch die Strassen Roms gelaufen und dieser im Gegensatz zu anderen Mitgliedern des Oratoriums nicht mit dieser Bezeichnung „stigmatisiert“ worden sei. ${ }^{102}$

Cesare Baronios ersten Jahre in Rom wurden bislang stets vor dem Hintergrunds seiner Zeugenaussagen zum Kanonisierungsprozess Neris beurteilt, die seine Nähe zum Oratorium und Neri hervorheben. Jene Aussagen Baronios, die seine grosse Begeisterung für die städtischen Bruderschaften und deren Verehrung des Heiligen Sakramentes der Eucharistie beschreiben, weisen allerdings Widersprüche auf. Baronio sagt nämlich aus, dass ihn Neri unmittelbar nach seiner Ankunft in Rom in San Girolamo della Carità predigen liess, obwohl Baronio erst vier Jahre später zum Diakon geweiht wurde. ${ }^{103}$ Baronios ersten Jahre in Rom waren wesentlich von einem Spannungsverhältnis zwischen Neris frühem Oratorium und den stadtrömischen Bruderschaften geprägt. Baronios frühen Jahre nach seiner Ankunft in Rom müssen deshalb im Zusammenhang mit einer Erneuerung des Predigtwesens, wie sie das Tridentiner Konzil bereits während der erster Sitzungsperiode von 1546 klar vorgeschrieben hatte, neu beurteilt werden. Baronio war den karitativen Andachtspraktiken, wie sie innerhalb römischer Bruderschaften gepflegt wurden, besonders verbunden. Zusammen mit einem erneuerten Predigtwesen wirkten jene Praktiken als sichtbare Manifestationen der kurialen Verwaltung einzelner rioni. In der Widmung an Sixtus V. im ersten Band seiner Annales Ecclesiastici hielt Baronio fest, dass er „schon seit ungefähr dreissig Jahren“ das für dieses Werk notwendige Material gesammelt habe. Diese vage Angabe zum Entstehungszeitraum seines opus magnum hat die bisherige Forschung davon abgehalten, Baronios frühen Jahre kritisch zu hinterfragen, was zu einer hagiographischen Stilisierung des Oratorianers geführt hat. Auch die neueren Biografien

102 Primo Processo, II, S. 109. Die negative Bezeichnung von Regularklerikern als chietini oder teatini (Theatiner) geht womöglich auf einen von Francesco Berni 1529 verfassten Brief zurück: Paschini 1926, S. 150-151. Zur Problematik der alleinigen Gründerrolle Neris bei der Gründung der SS. Trinità dei Pellegrini vgl. insbes. Primo Processo, III, S. 380 sowie ibid., I, S. 71. Zudem dann die Stelle in Gallonio, Vita, S. 21: „[...] una cum Persiano Rosa [...] sodalitium SS. Trinitatis nomine instituire aggressus est“. In der italienischen Ausgabe der Lebensbeschreibung Neris schreibt Gallonio jedoch, dass Neri derjenige gewesen sei, der Persiano Rosa dazu überredet habe, die Bruderschaft zu gründen.

103 Primo Processo, I, S. 136. Zu Baronios Diakonatsweihe vgl. neben dem Briefschreiben an den Vater vom 16. Dezember 1560 in BVR, Q. 46, f. 6v-8r auch Calenzio, Vita, S. 42-44 sowie Cistellini 1989, Bd. 1, S. 70. 
Baronios, die nach Calenzios Vita erschienen sind, halten weiterhin an dieser hagiographischen Darstellung der ersten Jahre in Rom fest. ${ }^{104}$

Eine Untersuchung über Baronios Anfänge in Rom kann nicht ohne eine genauere Betrachtung der Bedeutung des bereits in De origine Oratori vorkommenden Begriffs des „Weltklerus“ erfolgen. Zu Recht hat bereits Gilles-Gerard Meersseman in seinen Arbeiten auf die Bedeutung dieser „dritte[n] Kraft der Kirche“ (terza forza della Chiesa) hingewiesen. ${ }^{105}$ Bedauerlicherweise richtete sich der Blick bisheriger Studien zu dieser besonderen Gruppe von Klerikern im Zusammenhang mit vormodernen Bruderschaften vor allem auf die Zeit vor dem Tridentinum. Daher soll im Folgenden zuerst gezeigt werden, inwieweit das Tridentiner Konzil in seinen beiden ersten Sitzungsperioden ein besonderes Augenmerk auf diese sogenannten presbyter saeculorum und eine Stärkung der bischöflichen Strafgewalt gelegt hat. Bereits während der ersten Tagungsperiode ist ein Bewusstsein für diese besondere Bezeichnung von Klerikern zu erkennen. In ihrem zweiten Dekret vom 17. Juni 1546 beschlossen die Konzilsväter, dass sich „die Bischöfe hüten sollten, einem von denen, die zwar dem Namen nach Regularen sind, jedoch ausserhalb des Klosters und der Obödienz ihrer Orden leben, oder einem der Weltpriester [...] in ihrer Stadt oder Diözese die Predigterlaubnis zu geben“. Solange also die Bischöfe den Apostolischen Stuhl nicht darüber konsultierten, war es ihnen erlaubt, diesen Weltpriestern die Predigterlaubnis zu verwehren. ${ }^{106}$ In diesem Vorschlag zur Predigterlaubnis der Regularen sowie der Weltpriester durch die Diözesanbischöfe manifestiert sich ein Spannungsverhältnis zwischen Seelsorge- und Ordensklerus, das den mittelalterlichen Mendikantenstreit in Bezug auf eine Unterscheidung zwischen Predigt- und Priesteramt aufnimmt. Während es im Spätmittelalter hauptsächlich die Bettelorden waren, die das Predigtwesen am deutlichsten prägten, war es für die Tridentiner Konzilsväter das Bischofsamt, das im Zentrum einer Reform des Predigtwesens stand. Der episcopus war gleichermassen Seelenführer und Prediger. Der Generalkongregation vom 5. April 1546 diente eine von den Konzilsvätern verfasste Zusammenstellung

104 So v. a. Pullapilly 1975, S. 18-19. Zu Baronios Arbeit an seinen Annales vgl. Ann. Ecc., I (n.p.): „Necque enim deliberate ac consulto tantum opus ante annos circiter triginta aggressus sum“.

105 Meersseman 1960, S. 27.

106 COD, S. 670: „Caveant praeterea episcopi, be aliquem vel eorum, qui cum sint nomine regulares, extra claustra tamen et obedientiam religionum suarum vivunt, vel presbyterorum saecularium [...] etiam quorumlibet privilegiorum praetextu in sua civitate vel diocesi praedicare permittant, donec ab ipsis episcopis super ea re sancta sedes apostolica consulatur [...]“. Hierzu auch CT, V, S. 105-108. Tatsächlich hätte dieses Dekret zusammen mit dem über die Erbsünde bereits in der 4 . Sitzung verabschiedet werden sollen. Da aber die Legaten dieses dem Konzil erst am 13. April vorlegten, verpasste es die Frist der Promulgation derjenigen Dekrete aus der 4. Sitzung vom 8. April 1546. Zur Entstehung des Dekrets vgl. Jedin 1949-1975, Bd. 2, S. 83-103. Allerdings lag am 5. April bereits eine Vorlage für den Dekretentwurf vor: $C T$, V, S. 72-75, woraus eine erste Dekretform dann am 12. April verfasst wurde. Diese zweite Form findet sich in CT, V, S. 105-108 abgedruckt. Vgl. auch O'Malley 2013, S. 99-102. 
zu den „Missbräuchen“ (abusi) und deren „Heilmittel“ (remedia) hinsichtlich des Studiums der Heiligen Schrift sowie des Predigtwesens. Deshalb beschlossen die Konzilsväter einen methodus herauszugeben, der den Studierenden das Studium der Bibel wesentlich erleichtern sollte. Der zweite Teil dieser Vorlage richtete sich gegen die Unterlassung der Predigt durch zahlreiche Bischöfe sowie gegen die Verkündigung durch ungebildete und nicht offiziell beauftragte Personen aus dem Welt- und Ordensklerus. Schliesslich forderten die Konzilsväter, dass die Bischöfe in der Kirche wieder als Hirten und Lehrer erachtet werden sollten. Die Vorlage lässt sich somit auf die Bulle Superni dispositione consilii von Pauls III. aus dem Jahr 1542 zurückführen, in welcher der Grundsatz festgehalten wurde, dass „niemand auf Grund apostolischer Privilegien predigen darf, wenn er nicht durch seinen Oberen oder dem Ordinarius vorgestellt und von diesem approbiert worden ist“ “. ${ }^{107}$

Eine der wirkmächtigsten Kräfte hinter dem Tridentiner Dekret war der Augustinergeneral und Erzbischof von Salerno Girolamo Seripando. Seripando wirkte vor allem in seiner Rolle als Vermittler im Streit um die Predigterlaubnis der Ordensleute innerhalb ihrer Kirchen, der während der Generalkongregation vom 10. Mai zwischen Braccio Martello und dem Legaten Del Monte ausbrach. Anlässlich dieses Streits verfasste Seripando einen Zyklus von Predigten für das Pater noster. Hatte der Dominikaner Girolamo Savonarola noch 1494 in seiner Espositione sul Paternoster zwischen einem nach innen gewandten und damit mentalen Gebet und einer nach aussen gewandten, zeremoniellen Form des Betens unterschieden, nutzte Martin Luther in seinem Kommentar zum Pater noster dessen Popularität aus, um den Andachtsbräuchen eine spirituell begründete Gebetspraxis entgegenzusetzen. Wie die Forschung deutlich zeigen konnte, lässt sich mit den verschiedenen Auslegungen des Pater noster im Italien der 1540er Jahre in der Folge von Savonarolas Unterscheidung zwischen mentalem und äusserem Gebet eine Zunahme an Darstellungen ähnlichen Charakters feststellen. Diese bewegten das römische Santo Uffizio dazu, eine Espositione dell'oratione del Signore in volgare, composta per un padre

107 Zit. n. Jedin 1957, Bd. 2, S. 85. Vgl. dann CT, V, S. 72-73; Ganzer 1975, S. 407. Zum Mendikantenstreit insbes. Zerfass 1974, S. 85-86. Die Forderung, dass die Bischöfe die Hochmacht über die Predigterlaubnis des Welt- und Ordensklerus' innehaben sollten, geht auf das Reformdekret des V. Laterankonzils vom 19. Dezember 1516 zurück, in welchem die Predigt als munus bezeichnet und entsprechend in ecclesia Dei praecipuum ac pernecessarium verortet wird. Hierzu COD, S. 634. Während des Lateranense kam es somit bereits zu Auseinandersetzungen, bei denen die Bischöfe auf die „Übermacht der Bettelorden“ in der städtischen Seelsorge hinwiesen. Dasselbe Dekret reagierte sodann mit dem Reformvorsatz, dass nun „der Ordensprediger die Predigtlizenz seines Oberen dem zuständigen Ordinarius auf Verlangen vorzuweisen hat.“ Vgl. Jedin 1957, Bd. 2, S. 84. In Bezug auf die Verpflichtung der Bischöfe zur Predigt seitens des Tridentinums vgl. COD, S. 669: „Quia vero christiane rei publicae non minus necessaria est praedicatio evangelii quam lectio, et hoc est praecipuum episcoporum munus: statuit et decrevit eadem sancta synodus, omnes episcopos, archiepiscopos, primates et omnes alios ecclesiarum praelatos teneri per se ipsos, si legitime impediti non fuerint, ad praedicandum sanctum Iesu Christi evangelium“. 
non nominato in ihrem Index liprorum prohibitorum aufzuführen. ${ }^{108}$ Die Massnahmen der Inquisitoren in Friuli zeigen beispielsweise deutlich, dass das nach innen gerichtete Gebet im Gegensatz zur Verehrung des Heiligen Sakramentes der Eucharistie stand:

Non facea stima d'altro che del Pater noster. Quando io andava alla chiesa alla chiesa mi inginochiava inanti al sacramento et ivi col nudo Pater noster preava il signor Giesù Christo che pregasse il Padre celeste per me, né per cosa alcuna volevo sentir la intercession de' santi. Solo a lui rimetteva di core li miei peccati, solo in lui speravo la remission di quelli, et quando alle volte mi appresentavo al sacerdote, dicea: 'Padre, io ho peccato grandemente et offeso la maestà divina nelli 10 comandamenti della lege, nei sette peccati mortali, nei cinque sentimenti del corpo, nelle tre virtù theologali; non mi sono dato troppo all'opere della misericordia corporali né spirituali. Ho creduto però et credo a un solo Iddio et nel suo Figliuolo singor nostro Giesù Christo, ch'el sia concetto di Spirito Santo, et anchora nato di Maria vergine, et a tutto 'l resto de questi 12 articoli della santa fede et in ogni altro modo et via che io havesse offesa la sua divina maestà, l'anima mia et il prossimo mio, con tutto 'l core dico la colpa mia. Ideo pecor'. Tal era la confessione ch'io facevo all'hora et anchorché egli mi assolvesse, lenivo d'esser stato asslto dalla potente man d'Iddio, percioché sempre precedeva la confession mentale. $^{109}$

Das Predigtdekret des Tridentiner Konzils bildete somit einen entscheidenden Grundstein, um die Ausbreitung häretischen Gedankenguts im Italien um die Mitte des Cinquecento einzudämmen. Der Bischof von Verona, Luigi Lippomano, hatte neben seiner Espositione volgare des Pater noster aus dem Jahr 1548 den sieben Jahre später zum Papst gewählten Kardinal Marcello Cervini in einem Brief daran erinnert, dass die „Häresie der Lutheraner mit dem Pater noster anfing und mit Pike wie Hakenbüchse enden wird“. ${ }^{110}$ Lippomanos Espositione volgare zeigt deutlich, dass sich die römische Kurie noch vor der Herausgabe des Index Pauls IV. der Folgen, die eine Übertragung des Pater noster in die Vulgärsprache haben könnte, bewusst war. Lippomano zufolge

108 Es würde deutlich über die Grenzen dieser Untersuchung hinausgehen, würde man noch die präzisere Entfaltung des Pater noster im Licht der Ausbreitung von Häresien auf der italienischen Peninsula verfolgen wollen. Für ein generelles Bild dieser Entwicklung vgl. Seidel Menchi 1977, S. 40-45; Simoncelli 1979, S. 101; Prosperi 1995, S. 210-229; idem 1996, S. 207-208; Caravale 2003, S. 3-26.

109 Udine, Archivio Arcivescovile, Confessione di fra Vincenzo da Udene della vita tenuta in Spilimbergo 1548 sino al 1555 [...], f. 3v-4r, zit. n. Miccoli 1994, S. 1042. Das Pater noster wurde von Philoprotestanten in Venedig, Lucca, Siena und sogar auch in Bologna als das schlechthin einzig wahre christliche Gebet erachtet: Ambrosini 1999, S. 195-196; Adorni Braccesi 1994, S. 125; Marchetti 1975, S. 75; Dall'Olio 1999, S. 343; Seidel Menechi 1987, S. 73-74 und Caravale 2003, S. 23-24. 1521 hatte der Bischof von Brugnato, Filippo Sauli, bereits empfohlen, die Kenntnis des Pater noster bei Hilfspredigern in sein Opus Noviter editum pro sacerdotibus curam animarum (1521) aufzunehmen: Prosperi 1989, S. 97-98.

110 Zit. n. Prosperi 1996, S. 216: „Questa heresia comincia dal Pater noster e finisce nella picca et nel archibuso“. Vgl. auch Buschbell 1910, S. 289-290; Firpo/Marcato 1984, II/1, S. 247-248. 
hatte dieses Gebet „nutzbringenden Vorteil“, und zwar „nicht nur für alle Armen, sondern auch für alle andächtige Menschen“. ${ }^{111}$ Das Tridentiner Dekret, in welchem die Auslegung der Heiligen Schrift sowie das Predigtwesen festgehalten wurden, war demgemäss in die sozialen Konstellationen im Italien des Cinquecento eingebunden. Folglich muss dasselbe Dekret auch starke Auswirkungen auf das Predigtwesen innerhalb städtischer Gesellschaften ausgeübt haben. Die Verwaltung ärmerer rioni wurde deshalb zunehmend einzelnen Bruderschaften anvertraut. Bereits Taylor konnte feststellen, dass der Zusammenhang von Armut und Predigt für das gesamte Europa der Vormoderne charakteristisch war. Wegen den allmählich kritischen Ausmassen, welche die Armut in der Frühen Neuzeit anzunehmen begann, hatten sich auch Prediger am Elend der Gesellschaft angenommen. ${ }^{112}$ Mit dem Jubeljahr 1550 und einem unerwartet grossen Zustrom an Pilgern muss dieses Phänomen besonders das Rom der 1550er Jahre intensiv geprägt haben. Noch siebenunddreissig Jahre später hielt Sixtus V. in der Papstbulle Quamvis infirma fest, dass die Dekrete Pauls III. vom 9. Juni 1542 und Pius` V. vom 27. März 1566 Bettlern den Zugang zu den Kirchen der Stadt verboten hätten. Allerdings wurden diese bis zum PerettiPontifikat nicht befolgt. Die Papstbulle vom 11. März 1587 nimmt des Weiteren eine spezifische Beschreibung der Bettler vor. Damit sprach sie nicht nur die Vernachlässigung der „guten Sitten“ (bonorum monorum) an, sondern beabsichtigte gleichzeitig, die päpstlichen Eingriffe in die römischen Strassennetze zu Gunsten einer sozialen Neuordnung der Stadt auszulegen. ${ }^{113}$ Zusätzlich betonte die Papst-

111 Lippomano, Espositioni volgari, c. A2r: „[...] a profittevole utilità di tutte le divote e povere persone, et massimamente di quelle, che non vogliono, o non possono studiare la sacra scrittura, overo così bene non la intendono [...] in lingua volgare il Simbolo Apostolico, il Pater nostro, et i dia precetti della Charità, nelle quali tre cose consiste ciò che si dee da noi credere, desiderare, er operare in questo modo, et osservandole l'huomo intieramente, senza dubbio si può chiamare perfetto Christiano, et acquistare la gloria immortale di vita eterna.“ Die Bedeutung, welche diese Schrift einnahm, wird umso deutlicher, wenn man zusätzlich die ausgewogene Betrachtung Lippomanos zwischen den nach innen gerichteten Eigenschaften des Gebetes und den äusseren Aspekten der Andacht betrachtet: „Et quando noi oriamo, non doevmo venire a Dio solamente con preghiere nude, \& instrettuose, peroche è inutile dimanda quella laquale fa a Dio la sterile oratione. Et dicendosi che quell'albero che è infruttuoso, sarà tagliato, \& gettato nel fuoco, cosi il parlare che non ha frutto, non puo acquistare Dio. Però ci ammaestra la Scrittura divina dicendo, buona è la oratione con il digiuno, \& la elemosina“. Zit. n. ibid., 89v-90r.

112 Taylor 1992, S. 150.

113 Mag. Bull. Rom., II, S. 625-626: „[...] plateas tota Urbe dispersi ac vagantes, victum quaeritando defatigentur, ne, non modo poblica loca, aut privatarum aedium vestibula, sed ipsa quoque templa gemitibus, \& eiulationibus compleant, ne suis clamoribus obstrepant fidelibus dum divinis officiis, aut Missae sacrificio intenti sunt, ne in Ecclesiis, in quibus debet esse quieta conservatio, quaerimoniis, lamentis, ac vociferationibus tumultus excitent, ne ipsa divina officia, \& circumadstantium devotionem importunis ac molestis vocibus perturbent, ne, quod, praecipue nobis cordi est, dum incertis sedibus Urben peragrant, proprium Parochum non agnoscentes, absque alicuius divini praecepti, aut bonorum morum notitia, tanquam bruta animalia rationis expertia [...]“. Für die Dekrete Pauls III. und Pius` V. vgl. Tacchi Venturi 1930-1931, I/2, S. 263-264. Camillo Fanucci hielt in 
bulle Sixtus“ V. die notwendige Unterscheidung zwischen Bettlern, die „Krankheiten vortäuschten“ (simulata infirmitate), und „wahrhaft Kranken“ (vere infirmis). Im Gegensatz zur ersten Gruppe repräsentierten Letztere die tatsächliche paupertas Roms, denen rechtmässig Almosen zustünden. Deshalb forderte der Peretti-Papst in seiner Bulle die Errichtung weiterer Hospitäler. Diese sollten dazu beitragen, die römische Infrastruktur mit Einrichtungen, die seit dem 15. Jahrhundert zur Kranken- und Seelsorge dienten, nachhaltig zu erweitern. Der Bau von weiteren Hospitälern ist aber nicht allein als päpstliche Massnahme zu betrachten. Diese Bautätigkeiten sind nämlich in der Nachfolge der Erneuerungsarbeiten am alten Ospedale von San Gicaomo degli Incurabili, die hauptsächlich durch Kardinal Anton Maria Salviati finanziert wurden, zu sehen. Salviati wird in der Papstbulle auch als einer der Kardinäle aufgeführt, die die Massnahmen Sixtus 'V. ratifizierten. ${ }^{114}$ Nichtsdestotrotz nimmt dieselbe Bulle Bezug auf die Entwicklung der Armenfürsorge im Rom während der tridentiner Jahre. Diese Entwicklung hat ein spezifisch römisches Verständnis der caritas innerhalb des stark verflochtenen Bruderschaftssystems geprägt, das mit der Vorstellung über die bischöfliche Diözesanverwaltung einherging. Die Armenfürsorge hatte massgeblich die Verwaltung der Bischofsdiözese Seripandos in Salerno beeinflusst.

Als Vorsteher des Augustinerordens legte Seripando in seiner Diözese besonders großen Wert auf die Gestaltung des Predigtwesens, das er mit einer besonderen Theologie der caritas verbunden sah. Seripando verstand die Predigt in ihrer Förderung der karitativen Fürsorge hauptsächlich auf den Grundlagen augustinischer Theologie. In seiner dritten Predigt zum Pater noster präsentierte er nämlich eine Idee der caritas als Erneuerung des christlichen Lebens: Der Gläubige ersucht Gott nicht nur um Glauben und Hoffnung, sondern auch um Barmherzigkeit. Die erste Regel der misericordia schreibt vor, dass „Gott nicht nur wie ein eigener Vater geliebt werden sollte, sondern auch aus ganzem Herzen, aus ganzer Seele und aus ganzem Verstand“ (amar Dio come padre, il che non vuol dire altro ch'amarlo con tutto il cuore, con tutta l'anima, con tutta la mente). Während Seripando somit dem pater die Gottesliebe einschreibt, verweist das noster, wie er weiter ausführt, auf die Nächstenliebe. Eine weitere Predigt Seripandos führt schliesslich eine besondere

seinem 1601 erschienenen Traktat ebenfalls fest, dass man „in Rom nichts anderem, als nur Bettlern begegnet, die so zahlreich sind, dass es unmöglich ist, sich auf der Strasse zu bewegen, ohne sie um sich zu haben." Vgl. Fanucci, Trattato, S. 70-71; Delumeau 1957, Bd. 1, S. 404-407. Für ein generelles Bild sozialer Schichten im Italien des Cinquecento vgl. Black 2001, S. 86-106; Pullan 1994, Nr. IV; Woolf 1986; Zardin 1995; D’Amico 1995, S. 273-290. Für einen europäischen Kontext während der Vormoderne vgl. dann auch entsprechend Cowan 1998, S. 150-169.

$114 \mathrm{Zu}$ San Giacomo degli Incurabili und den finanziellen Eingriffen Salviatis im Zusammenhang mit der urbanistischen Systematisierung des sixtinischen Pontifikats vgl. Benvenuto 1986, S. 145153; Heinz 1981, S. 31-49; Innocenti Presciuttini 1992, S. 182-183; Lio 2000; Wiedmann 2004, S. 228-233. 
Stelle im Römerbrief an, wo die Barmherzigkeit als Vollendung des Gesetzes beschrieben wird. Damit wird das Gebet zur gesprochenen Fürbitte panem nostrum quotidianum da nobis hodie („Unser täglich Brot gib uns heute“) umgewandelt. Seripando fordert bewusst die zur Predigt versammelten Gläubigen dazu auf, die sieben körperlichen Werke der Barmherzigkeit nicht zu vernachlässigen. In diesem Sinne paraphrasiert er auch die Handreichung Jesu aus dem Matthäusevangelium:

Ma non ci dimentichiamo le sette sporte che avanzarono che sono le sette opere di misericordia con le quali sin'al fine del mondo dovemo nella chesa pascer l'un l'altro, anzi pascer Christo com'egli stesso dice che quando si pasce un famelico, è pasciuto lui, quando si dà da bere a un sitibondo, si dà da bere a lui, quando si riceve un pellegrino, è ricevuto lui, quando si veste un ignudo, è vestito lui, quando si visita un infermo, è visitato lui, quando si consola un carcerato, è consolato lui [...]. Christo piglia quell'opera cioe fatta nella persona sua. ${ }^{115}$

In seiner sechsten Predigt zum Pater noster präsentierte Seripando schliesslich das Bild der „gesegneten Stadt“ (beata città). Die Metapher sollte den Gläubigen dazu dienen, sich weiterhin auf den „Wegen der Gerechtigkeit“ begeben zu können. Ein jeder Gläubige erlangt sodann in einer solchen Stadt, wo „reine Wahrheit herrscht“ (regna la verità pura), im tridentinischen Verständnis neben der göttlichen Rechtfertigung (sanctificati et giustificati) auch den Eintritt in die Gemeinschaft der Engel, wodurch er „Gott verherrlichen, loben und preisen“ (magnificare, esaltare, glorificare) kann. ${ }^{116}$ Seripandos Bild der beata città weist eine auffällige Übereinstimmung mit dem Rom der 1550er Jahre auf, wo sich die Verehrung des Heiligen Sakramentes der Eucharistie zu einer entscheidenden Komponente der Bruderschaften entwickelt hatte. Die Auswirkungen dieser Entwicklung auf die soziale Konstellation karitativer Bruderschaften müssen Cesare Baronio in seinen ersten Romjahren begleitet haben, wie später noch deutlicher gezeigt werden soll.

Die Auffroderung Seripandos an die Gläubigen seiner eigenen Diözese, die Werke der Barmherzigkeit auszuüben, wurde bereits in der 1550 erlassenen Bulle Papst Julius‘ III., Illius qui misericors, artikuliert. Die Bulle hatte nämlich nicht nur einen grossen Wert auf die Verwaltung der Beichte selbst gelegt, sondern hatte diese gleichsam auf den römischen Stadtraum übertragen. Den Beichtvätern wurde die Abnahme der individuellen Beichte über eine spontanea comparizione sowohl vor einem „inneren“ (interno) als auch vor einem „äusseren“ (externo) Forum ge-

115 Zit. n. Abbondanza 1982, S. 240-241. Vgl. auch Röm. 13:8-10 sowie insbes. Mt. 25:31-46. Zum augustinischen Verständnis der caritas vgl. Zumkeller 1987, S. 71-72; Trapé 1959, S. 2-3 und die entsprechende Diskussion, mit Bezug zu Seripando, bei Cesareo 1997, S. 7.

116 Abbondanza 1982, S. 149: „Queste sono le vie che ce conducono a quella beata città [...] ove [...] non entra cosa alcuna inquinata, non cosa che possa far dominatione, non bugia, perché in quella città regna la verità pura [...] alla quale la gratia del S. Dio che ce ha lavati sanctificati et giustificati sia quella che ci guida accioche possiamo sempre in compagnia degl'Angioli magnificare, esaltare, glorificare [...] questo santo nome“. 
stattet. ${ }^{117}$ Über das foro interno wirkte die Beichte für die caritas im römischen Stadtraum verbreitend und erhaltend. Sie wurde nicht nur in Seripandos eigenen Predigtenzyklus über das Apostolische Glaubensbekenntnis aufgenommen. Unter anderem ist die Beichte auch ein besonderes Merkmal zahlreicher während des Heiligsprechungsprozesses Neris gemachter Zeugenaussagen, an die Cesare Baronios eigene Deposition vom 1. September 1595 anschliesst, die wiederum über seine frühen Jahre in Rom Aufschluss geben kann. Die Forschung hat dieser Zeugenaussage Baronios bislang wenig Beachtung geschenkt. Als zentraler Aspekt des Lebens Filippo Neris wird in den Zeugenaussagen stets sein Wirken und seine Anerkennung als wichtigster Beichtvater im Rom der 1550er Jahr genannt. Das Oratorium entstand demgemäss innerhalb eines komplexen und mannigfaltigen Netzwerks römischer Bruderschaften. Eine solche Betrachtung der Entstehungsgeschichte des Oratoriums kann einen entsprechenden terminus post quem in Bezug auf die Frage, wann Baronio diesem überhaupt beitreten konnte, bieten.

In seiner ersten Zeugenaussage zum Kanonisierungsprozess bemerkte Baronio, dass Neri ihm bei seiner Ankunft in Rom 1557 bereits in San Girolamo della Carità die Beichte abgenommen habe: „Io venni a Roma l'anno 1557, et, in quell'anno istesso, mi cominciai a confessare dal p. m.s Filippo Neri, in S. Hieronimo della charità“. ${ }^{118}$ Aus Francesco Zazzaras Memorie geht allerdings nicht hervor, ab welchem

117 Mag. Bull. Rom., I, S. 791-793, 792: „[...] non ad alicuius nobis super hoc oblatae petitionis instantiam, sed de mera deliberatione, \& certa scientia nostris, omnes, \& singulos utriusque sexuus, tam laicos, quam clericos, seculares, \& quorumvis Ordinum, \& Militiarum Regulares, tam milites quam presbyteros, non tamen sub generali Inquisitione Hispaniae, ac Portugalliae Regnorum comprehensos, de praemissis culpabiles, cuiscumque status, fradus, ordinis, vel conditionis, aut praeeminentiae existant, etiam si Pontificali, aut alia quacumque, etiam maiori Ecclesiastica, vel mundana dignitate praesulgeant [...] coram Inquisitoribus Civitatum, in quibus ipsi degunt, se personaliter exhibuerint, \& suas haereses coram eis privatim abiuraverint, \& se ad poenitentiam privatam eis per dictos Inquisitores iniungendam adimplendum paratos obtulerint, eamque postmodum cum effectu adimpleverint, ab omnibus, \& singulis eorum haeresibus, \& a fide Christi Apostasiis, ac quibusvis aliis in eadem fide erroribus, quantumcumque gravibus, \& enormibus, necnon excommunicationis, suspensionis, \& interdicti, aliisque sententiis, censuris, \& poenis tam Ecclesiasticis quam temporalibus, etiam bonorum privatis,\& corporis afflictivis [...]“. Vgl. insbes. Prosperi 1996, S. 222; Black 2009, S. 61-62 sowie hinsichtlich der Funktionalität dieser spontanea comparizione in Italien v. a. Brambilla 2007, S. 123; eadem 2000, S. 381-402. Zur Unterscheidung zwischen foro interno und esterno vgl. Masini, Sacro Arsenale, S. 385: „L'Heretico assoluto nel foro della coscienza, etiam dio dall' istesso Sommo Pontefice, se poi vien' accusato nel foro esterno, non perciò schifa le pene à gli heretici dovute; percioche per la pena imposta nel foro interno sodisfà à Dio, \& à lui si riconcilia: ma la pena del foro esterno spetta alla publica vendetta, \& alla sodisfattione della Republica“. Hierzu auch Prosperi 1997, S. 314-315; Lavenia 2004; Prodi 2003, S. 207-216.

118 Primo Processo, I, S. 136. Gallonios Deposition vom 7. September desselben Jahres während des Heiligsprechungsprozesses hält ebenfalls die Beschreibung Neris als Beichtvater in ibid., I, S. 186, fest: „Fattosi confessore, non uscì mai fuori di Roma, assisteva sempre al confessionario, per guadagnar le anime, et così continuò sino a questi ultimi anni, fino al pontificato di Gregorio XIIII (sic!). [...] Ho sentito dire più volte, dal mede[si]mo padre, che, quando era giovane, innanti giorno, 
Zeitpunkt Neri als Beichtvater Baronios aufgetreten ist. Baronio selbst verfasste in diesem Zusammenhang auch einen Traktat, nämlich eine De vita, virtutibus et gestis B. Philippo Nerii, an die sich Zazzaras Rekonstruktion der Beichten Baronios stark angelehnt haben muss:

Condotto Baronio a Filippo da un certo uomo per confessarsi, il beato Padre l'accolse con gran carità, ed a poco a poco gl'insegnò che la divina legge fosse migliore e più ricca delle leggi umane scritte su tavole. Imperochè la legge di Dio è immacolata, e converte le anime, e dà la sapienza ai piccini, ed illumina gli occhi, ed è dolce più del mele e del favo, e nell'osservarla havvi molta retribuzione. Con queste pienissime esortazioni l'indusse a servire Dio. Ed egli intento all'orazione, ed andato spesso a confessarsi da lui, aprì le orecchie, e mutato consiglio si propose di abbracciare prima la legge divina, tenerla in cuore quasi tesoro, ed ordinò la legge civile alla divina, come l'ancella è sottomessa alla padrona. Il perchè ogni dì andava da Filippo per confessarsi, frequentava l'Oratorio per pregarvi, e con duri flagelli aspramente domava il corpo. ${ }^{119}$

Die Nähe dieser Schilderung zu Baronios eigener Beschreibung während des Heiligsprechungsprozesses lässt vermuten, dass Baronios Traktat nicht vor der ersten Deposition verfasst wurde. Damit steht Baronios De vita, virtutibus et gestis B. Philippi Nerii wiederum in engem Zusammenhang mit dem bereits erläuterten Spannungsverhältnis zwischen der in den Annales beschriebenen actio gratiorum und dem Heiligsprechungsprozess. Mit der Aussage, er habe sich sofort nach seiner Ankunft in Rom bei Neri die Beichte abnehmen lassen, beabsichtigte Baronio offenbar, die Heiligsprechung voranzubringen. Die Aussage muss daher in Bezug auf die Stellung Filippo Neris in Rom während des Carafa-Pontifikates neu bewertet werden. In der ersten Zeugenaussage Antonio Gallonios wird ein zwischen Neri und der Bruderschaft von San Girolamo della Carità entstandener Konflikt erwähnt. Gallonio berichtet nämlich, dass Neri oftmals Schmähungen von Seiten der Prediger jener Bruderschaft ausgesetzt gewesen sei, und zwar insbesondere während seiner Messzelebrationen:

Il detto p. m.s Filippo ha patito diverse persecutioni, in S. Hieronimo, et una volta mi disse che quelli preti, che officiavano la chiesa di S. Hieronimo, quali erano calabresi sfratati, li facevano de molte ingiurie et, massime, mentre voleva celebrare la Messa, ascondendoli hora il missale, hora il calice, hora una cosa, hora un'altra, et facendoli altre cose simili. Et una volta, tra l'altre, mentre si li facevano questi dispetti, dicendo Messa, disse a Iddio: Signore, che cosa è questa? io dico ogni giorno Messa, per acquistar la patientia, et mi vengono sempre innanti occasioni de turbarmi; il che havendo finito di dire, sentì dirse interiormente: Filippo, che me domandi la patientia? oh guadagnatela per questa via, che per questo ti vengono questi incontri.

\footnotetext{
haveva confessare più di cinquanta persone et mandatole a l'hospedale. (ibid., S. 191)“. Die Rolle Neris als Beichtvater in den Zeugenaussagen für seinen Prozess der Heiligsprechung bleibt seitens der Forschung immer noch offen. Diese müsste über das Verständnis der Beichte während des Aldobrandini-Pontifikats Clemens' VIII. näher beleuchtet werden.

119 BVR, Q 70, f. 81v-82r. Baronios De vita, virtutibus et gestis B. Philippi Nerii et instituto Congregationis Oratorii befindet sich in BVR, O 7, hier f. $51 r-v$.
} 
Et, in somma, continuando con grandissima patientia, et considerando ciò uno di quelli sfratati, misse le mani al collarino de un de quei preti, che dicevano mal del padre, volendolo affocare; et ripensando meglio alla patientia incredibile del padre, si compose talmente, che retornò nella sua religione. Ho inteso dire da sua reverentia, che pativa assai per amor de Christo, essendo chiamato a tutti i tribunali, opponendoli che era ritrovatore et inventore de conventicole, et che era un superbono, uno ambitioso [...]. ${ }^{120}$

Gallonio weist damit auf das Verhältniszwischen dem Gründer des Oratoriums und den zu jener Zeit wichtigsten Bruderschaften Roms hin. Dieser Aussage Gallonios wurde bislang wenig Beachtung geschenkt. Sie ist deshalb von Bedeutung, da sie die Gründung des frühen Oratoriums in eine entscheidende Phase einordnet, während der das Santo Uffizio massiv in das Geflecht römischer Bruderschaften und ihrer karitativen Aufgaben bezüglich der Spende der Sakramente eingriff. Tatsächlich erliess Papst Paul IV. am 20. Juli 1558 eine Bulle, die sich gegen „umherschweifende Mönche“ richtete. Gallonio zufolge hatten sich solche sfratati vornehmlich in der Confraternità di San Girolamo della Carità eingefunden. ${ }^{121}$ Bereits im Del Monte-Pontifikat Julius' III. wurden einzelne Verfügungen gegen solche Ordensleute erlassen. Jedoch blieben sie bezüglich einer Verbesserung der Apostasie ohne Wirkung. Daher knüpfte die Bulle Pauls IV. Postquam divina bonitas vom 3. August 1558 bewusst an ein auf den 16. Dezember 1555 datiertes Dekret, in welchem solche als Kommende verliehene Klöster nicht an Mönche ohne Ordenszugehörigkeit verliehen werden durften, an. Damit ermöglichte die Papstbulle eine entsprechend rechtskräftige Verurteilung solcher aus einem Orden ausgetretenen Mönche. Zusammen mit diesem Dekret ist die Papstbulle daher als entscheidende Weiterführung der Tridentiner Beschlüsse zur Predigt anzusehen. Die Konzilsväter gaben den Klöstern nämlich nicht nur die Auslegung der Heiligen Schrift vor, sondern legten gleichzeitig fest, dass, falls „die Äbte in dieser Sache nachlässig“ seien, „sie von den Ortsbischöfen mit geeigneten Mitteln dazu gezwungen werden sollten“. ${ }^{122}$ Die Papstbulle Pauls IV. ordnete dementsprechend die Entziehung von Pfründen solcher Priester, die ausserhalb der Klöster ihres Ordens lebten, an. Apostaten durften somit Zeit ihres Lebens keine Pfründe mehr erwerben. Ebenfalls sollte ihnen die Ausübung kirchlicher Ämter sowie der Empfang kirchlicher Einkünfte und Pensionen verwehrt bleiben. Ferner sollten sie keine Seelsorge oder kirchlichen Dienst mehr ausüben dürfen, kein Sakrament spenden und

120 Primo Processo, I, S. 177.

121 Vgl. hierzu insbes. auch das avviso vom 25. Juni 1558 in BAV, Urb. lat. 1038, f. 283r-361v: „Е commessa una bolla gagliardissima contra gli sfratati“. Die Bulle wurde bereits im Konsistorium vom 21. Oktober mit weiteren Reformmassregeln betreffend des Santo Uffizio und gegen die Priestersöhne verlesen. Vgl. diesbezüglich das avviso vom 19. November 1558 in BAV, Urb. lat. 1038, f. $351 v-352 v$.

122 COD, S. 668: „In monasteriis quoque monachorum, ubi commode fieri queat, etiam lectio sacrae scripturae habeatur. Qua in re si abbates negligentes fuerint, episcopi locorum [...] eos ad id opportunis remediis compellant“. 
keine Messe feiern. ${ }^{123}$ Ein avviso vom 27. August 1558 berichtet in diesem Zusammenhang, dass am Abend des 22. August 1558 sämtliche Tore Roms geschlossen wurden und die Polizei gegen die „umherschweifenden Mönche“ vorgegangen sei. ${ }^{124}$ San Girolamo della Carità scheint gemäss Gallonios Zeugenaussage ein besonderer Anziehungspunkt für die Streifzüge der sbirri gewesen zu sein. Dort wurde auch ein Kirchendiener mit dem Namen Filippo festgenommen, worauf „viele gemeint haben, es hätte sich hierbei um Vater Neri gehandelt“. ${ }^{125}$

Diese Jahre des päpstlichen Vorgehens gegen Apostaten waren für die Confraternità di San Girolamo della Carità in Bezug auf deren Aufnahme neuer Mitbrüder besonders folgenreich, da ab dem Carafa-Pontifikat auch „Fremde, die zu Bürgern Roms erklärt wurden“ (forestieri fatti cittadini di Roma), in die Bruderschaft eintreten durften. Wie bereits in den Statuten von 1536 festgehalten worden war, lag die Entscheidung über eine Zulassung zur Bruderschaft bei deren deputati. ${ }^{126}$ Der Zeu-

123 Bull. dipl. rom., VI, S. 540: „[...] patroni quoque eorumdem beneficiorum personas idoneas, infra tempus a iure statutum, ad ipsa beneficia praesentare possint, et nisi praesentaverint, eorum libera collatio ad ordinarium spectet et pertineat, vacare, ac reservationes fructuum, redditum et proventuum huiusmodi expirare decernimus, ita ut de cetero ipsi apostatae, quamdiu vixerint, aliqua benificia ecclesiastica obtinere vel aliquod officium ecclesiasticum exercere, aut fructus, redditus et proventus ecclesiasticos [...] percipere vel exigere, seu curam animarum vel aliquod ministerium ecclesiasticum exercere, aut sacramenta ecclesiastica ministrare, seu missam celebrare [...]“. Vgl. auch Pastor 18911933, Bd. 6, S. 476-477.

124 BAV, Urb. lat. 1038, f. 335v. Für weitere Berichte vgl. Ancel 1907, S. 26. Selbst der Kustode der vatikanischen Bibliothek, Basilio Zanchi, wurde eingekerkert. Hierzu Caracciolo, Vita Pauli IV, S. 84 sowie das avviso vom 8. Oktober 1558 in BAV, Urb. lat. 1038, f. 342v, das über den Tod Zanchis berichtet. Über das Vorgehen Pauls IV. berichtet der Kardinal Alfonso Carafa in Biblioteca Nazionale di Napoli, Apolog. Cod. X, F. 55: „Fece darsene notamento da tutte le religioni per sapere quali non obedivano, et se di questi tali alcune se le fosse presentato avanti che fosse stato suo caro amico mentre era in religione, lo ributtava ne volea più vederlo dicendo che non lo conosceva“.

125 Primo Processo, I, S. 182: „Un giorno, corse rumore per Roma, che un Filippo era stato fatto priggione [...]. Questo Filippo era servitore sotto sacristano in S. Hieronimo, et, per essere nominato che era di S. Hieronimo, molti pensavano fosse il p. Filippo: quali venivano a S. Hieronimo, et, trovandolo che confessava, restavano confusi nella sua cerdulità. [...] li essecutori et birri andavano cercando queste persone, et dicevano, che quelli preti, che erano infetti, si mutavano in viso. Et venendo il barigello di Roma dal padre, che era all'hora in S. Hieronimo, lo guardò un pezzo fisso. Et il padre, stando al confessionario, si levò et li disse:,che volete? che cercate?` Il barigello disse:, niente, signore', et se ne andò via“.

126 BCR, Misc. IV, Statuti della Compagnia della Carità, I, cap. 3: „[...] della detta congregatione, s'eleggano, ovvero cavino per bussola sei officiali chiamati gli deputati da durare per un Anno, che diligentemente debbiano curare gli negoci, e l'opere di detta Compagnia, fina à tanto, che gli altri novi s'elegano, overo si cavino per bussola, come disopra“. Die Bruderschaft wurde mit Papst Leos X. Bulle Illius qui caritas vom 28. Januar 1520 gegründet Am 22. September 1524 wurde sie von Clemens VII. zur Erzbruderschaft erhoben. Für die Bulle Illius qui caritas vgl. Bull. dipl. rom., V, S. 739740. Die Bulle Clemens' VII. befindet sich in ASR, S. Girolamo della Carità, tom. 192, f. 29r-v. Ursprünglich schrieb die Gründungsbulle vor, dass die Bruderschaft keine neuen Gläubigen aufnehmen dürfe, sondern nur dumtaxat presbyteros saeculares. Vgl. hierzu auch Marangoni, Vita, S. 61. 
genaussage Germanico Fedelis vom 8. Juni 1610 kann entnommen werden, dass sich Filippo Neri von den beiden wichtigsten Mitgliedern der Bruderschaft von San Girolamo - Persiano Rosa und Buonsignore Cacciaguerra - dazu überreden liess, doch die Priesterweihe anzunehmen. Rosa stellte Neri im März 1551 dem Generalvikar der Bruderschaft in San Girolamo, Filippo Archinto, vor, woraufhin Neri Ende des Monats in San Giovanni in Laterano die Diakonats- und schliesslich am 29. Mai in San Tommaso in Parione die Priesterweihe erhielt. ${ }^{127}$ Die Erzbruderschaft hielt allerdings erst in einem ihrer Dekrete vom Oktober 1558 fest, dass es Neri und zwei weiteren Priestern erlaubt sei, ein pane papalino zu erhalten, und zwar ,in der Art und Weise wie dieses den Palastprälaten" verliehen wird (in modo et forma prout datur praelatis Palatii). Erst ab diesem Zeitpunkt kann Neri als Mitbruder von San Girolamo della Carità gezählt werden, da dies auch zeitlich mit der Verfolgung der Apostaten in Rom übereinstimmt. ${ }^{128}$

Bislang wurde dem Einfluss, den das Santo Uffizio auf ein von dieser Bruderschaft ausgehendes Netzwerk weiterer Priesterzusammenschlüsse im Rom des Carafa-Pontifikates ausübte, wenig Beachtung geschenkt. Die Arciconfraternita di San Girolamo della Carità war eine der römischen Kurie besonders nahestehende Bruderschaft, die über ihren Kardinalprotektor (Cardinale Protettore) Giovanni Morone, der dieses Amt zwischen 1553 und 1563 innehatte, Anbindungen zum Santo Uffizio gehabt haben muss. Die deputati der Bruderschaft debattierten in einer am 19. Juli 1557 einberufenen Versammlung über die Zulassung von Neubewerbern. Sie beschlossen, dass nur Personen omnes exteri sowie Curiali famigliari dei Cardinali der Bruderschaft beitreten konnten. Mittels dieser Vorkehrung festigte die Bruderschaft während des Carafa-Pontifikates Pauls IV. ihre Bindungen zur römischen Kurie. ${ }^{129}$ Noch vor der Veröffentlichung von Carlo Borromeos Avvertenze für die Beichtväter in Mailand hatte sich in Rom bereits ab dem Tridentinum eine spezifisch auf die Arbeiten der Tribunale des Heiligen Offiziums ausgerichtete Theologie der Beichte $\mathrm{zu}$ etablieren begonnen. Eine wichtige Position nahm dabei das Sakrament der

127 Primo Processo, III, S. 266: „Per humiltà non ardiva farsi sacerdote e repugnò tanto, sino a che fu astretto a farsi per comandamento del suo padre spirituale; [...] et questo l'ho sentito dire da esso beato Filippo, et per questo s'ordinò sacerdote di molta età“. Vgl. auch die Deposition Marcello Ferros vom 23. April 1610 in ibid., III, S. 42. Betreffend der Priesterweihe und der dafür entscheidenden Rolle Persiano Rosas vgl. ferner Gallonio, Vita beati p. Philippo Nerii Fiorentini, S. 28; idem, Vita di San Filippo Neri, S. 28. Zu San Tommaso in Parione vgl. insbes. Armellini 1942, S. 470-472.

128 ASR, S. Girolamo della Carità, Decr. 11.10.1558, Lib. II, f. 78r. Vgl. auch die Zeugenaussage Pateris vom 7. Mai 1610 in Primo Processo, III, S. 143: „Di questi padri (di S. Girolamo) alcuni erano stipendiati dalla sopradetta Compagnia della Carità come cappellani, et altri vivevano del proprio, vivendo ognuno separatamente, come fece detto beato Padre“. Vgl. auch Cistellini 1989, Bd. 1, S. 35-36.

129 BCR, Constitutiones Venerabilis Archiconfraternitatis Sancti Hieronymi Charitatis de Urbe 1694, cap. XI. Für Morones Protektorat auch im Zusammenhang mit seinem Prozess vor dem Santo Uffizio dann das Dokument in ASR, S. Girolamo della carità, tom. 220, f. 103r-v. 
Busse ein. Die Stellung Filippo Neris als offizieller Gründer des Oratoriums deckt sich mit seiner durch Cesare Baronio bezeugten Rolle als Beichtvater in San Girolamo della Carità, die aber erst nach 1558 anzusetzen ist. ${ }^{130}$ Von der Theologenkongregation des Tridentinums wurden zwischen dem 20. und 30. Oktober 1551 zwölf Artikel über das Busssakrament und vier über die Krankenölung erlassen, die sich mit der in der ersten Auflage von Calvins Institutio Christianae religionis enthaltene Erklärung auseinandersetzten. Calvin hatte Beichte und Busse in einem theologischen Spannungsverhältnis gesehen. Obwohl das Rechtfertigungsdekret vom 13. Januar 1547 die Busse als Sakrament bezeichnet hatte, legte Calvin eine Auslegung derselben vor, gemäss der sie in ihrer Substanz zwar aus göttlichem Recht (ius divinum) entstehe, in ihrer Form aber dem positiven, also zivilen Recht zuzuordnen sei. ${ }^{131}$ Die Theologenkongregation in Trient musste sich mit den Fragen auseinandersetzen, ob die in der Tradition der alten Kirche stehende „geübte Busse“ noch dem Begriff des Sakramentes entspreche und ob die Busse überhaupt noch als ein sichtbares Zeichen einer unsichtbaren Gnade gelten könne. Das am 25. November 1551 verabschiedete Dekret erklärte die Busse zum eigenständigen Sakrament, das eine vom Sakrament der Taufe unabhängige Gültigkeit beanspruchte. Zur Trennung zwischen Taufe und Busse, die im Dekret über die Rechtfertigungslehre noch als gemeinsames Sakrament betrachtet worden waren, trug insbesondere der Kanon über die Beichte (confessione) bei. Für die Mehrzahl der Theologen am Tridentinum stellte sie den eigentlichen Grund der Kontroverse dar. Die spanische Vertretung der Theologenkommission kam immer wieder darauf zurück, dass die Absolution, die einen richterlichen Charakter der Beichte darstelle, an sich nicht als richterlicher Akt zu behandeln sei, da die Beichte einem Tribunal des Gewissens gleiche. ${ }^{132}$ Diese Vorstellung der Beichte als richterlich eingesetztes Tribunal sollte auch im

$130 \mathrm{Zu}$ den mailändischen Bedingungen vgl. De Boer 2000, S. 45; Black 2009, S. 73; idem 2004, S. 103-106. Die Forschung verfolgte bislang die Argumentation, dass die Beichte einen Mechanismus sozialer Disziplinierung dargestellt habe. Zurzeit besteht ein starker Diskurs um eine Klärung darüber, inwieweit der Beichtstuhl als Instrument der Inquisition genutzt wurde, um ein Bild einer ängstlichen, ja gar - wie in manche Studien argumentiert wird - unterdrückten Gesellschaft zu zeichnen: Prosperi 1996, S. 278-289, 316-335. Dieses verzerrte Narrativ der Inquisition als zentrales Phänomen des Tridentinums geht zurück auf die Forschungsarbeiten Paolo Prodis betreffend der Wechselwirkung zwischen Sozialdisziplinierung und Konfessionalisierung. Vgl. diesbezüglich Prodi/Penuti 1994 und für eine Übersicht Prinz 1992, S. 1-25; Hudon 1996, S. 783-804; Murphy 2002, S. 446-469; Tutino 2014, S. 14-19.

131 CT, VII/1, S. 233-240; COD, S. 675-676 und Calvin, Christ. rel. inst., III, cap. 4. Vgl. auch die 21. Konstitution des IV. Laterankonzils, Omnes utriusque sexus, in welcher festgelegt wurde, mindestens einmal im Jahr zu beichten: COD, S. 245.

132 So bei Olave in CT, VII/1, S. 264 und die Beichte als actus iudicalis bei Francisco de Toro in ibid., 276. Vgl. insbes. Jedin 1970, Bd. 3, S. 318-319; O’Malley 2013, S. 152-154. Zum Forschungsstand über das Busssakrament vgl. ferner Emmet McLaughlin 2008; Semmelroth 1962; Peter 1968; Arendt 1981; Prosperi 2001, S. 175-197 sowie zuletzt Mezzardi/Tagliaferri 2011 und Prodi 2012, S. 40-47. 
5. Kapitel des Dekrets über das Sakrament der Busse aufgenommen werden. In diesem werden die Priester als „Vorsitzende und Richter“ eines Tribunals beschrieben, da sie Kraft ihrer ebenfalls Sünden vergeben können. ${ }^{133}$

Die Beichte verleiht dem Sakrament der Busse demnach eine Dimension der Versöhnung des Sünders mit der Kirche, wobei deren Beziehung derjenigen zwischen einem Arzt und einem Kranken gleicht. Diese Metapher spiegelte sich ab dem Del Monte-Pontifikat in den karitativen Praktiken römischer Bruderschaften. Damit wurde die Verwaltung der Sakramente mit einem theologischen Verständnis der caritas gleichgesetzt, die sich dann insbesondere in der karitativen Krankenpflege der ersten Oratorianerpriester von San Girolamo manifestierte und an der sich Cesare Baronio ebenfalls beteiligte. Als sich Baronio eines Nachmittags zur Beichte begab so Baronio in seiner ersten Zeugenaussage zu Neris Heiligsprechung -, schickte ihn sein Beichtvater Neri zum Hospital von Santo Spirito in Sassia, damit er sich um die Kranken kümmere. Baronio beschreibt in seiner Zeugenaussage weiter, wie er im Hospital neben der Krankenfürsorge auch die Spende der Letzten Ölung an die Sterbenden beobachtet hatte. ${ }^{134}$ Es bleibt aber zweifelhaft, ob Baronio tatsächlich auch selbst während seiner ersten Jahre in Rom die Spende der Sakra-

133 COD, S. 705-706: „[...] institutam etiam esse a Domino integram peccatorum confessionem, et omnibus post baptismum lapsis iure divino necessariam existere, quia dominus noster Iesus Christus, e terris ascensurus ad coelos, sacerdotes sui ipsius vicarios reliquit tanquam praesides et iudices, ad quos omnia mortalia crimina deferantur, in quae Christi fideles ceciderint, quo pro potestate clavium remissionis aut retentionis peccatorum sententiam pronuncient [...]. Qui vero secus faciunt et scienter aliqua retinent, nihil divinae bonitati per sacerdotem remittendum proponunt. Si enim erubescat aegrotus vulnus medico detegere, quod ignorat, medicina non curat. [...] Sed et impium est, confessionem, quae hac ratione fieri praecipitur, impossibilem dicere, aut carnificinam illam conscientiarum appellare; constat enim, nihil aliud in ecclesia a poenitentibus exigi [...]“. Die Notwendigkeit der Beichte nicht nur in Bezug auf die Schlüsselgewalt (Mt. 18:18), sondern auch hinsichtlich der Binde- und Lösegewalt gem. Jh. 20:23 begründete Johannes Arze in CT, VII/1, S. 252.

134 Primo Processo, I, S. 138: „Una domenica al tardo, andando in S. Hieronimo a confessarme, il padre, senza volerme ascoltare, disse:,vatene a S. Spirito a quelli infermi'; et replicando io, che già l'hora era passata del mangiare, et ci era che fare, lui mi replicò, che andasse a far l'obedientia. Andando in S. Spirito, non trovando che fare di essercitio manuale, andai dove era il Crocefisso con la lampada, che si sòl mettere a morienti che hanno havuto l'Olio Santo. Quale era venuto il giorno inanti ne l'hospedale, fuor d'hora, et, per questo, subito messo in letto, senza confessarsi come è il solito; et, in effetto, fu scordato a farlo confessare e communicare, ma vedendolo moribondo, il dettero l'Oglio Santo. Onde, accostandome io a quel povero, domandandoli il suo stato, et trovando che non era confessato nè communicato, subito lo feci confessare et communicare, il che fatto, rese lo spirito a Iddio“. Baronios Aussage über die sonntäglichen Besuche des Hospitals von Santo Spirito in Sassia wiederholt sich in ibid., II, S. 292. Vgl. auch die weiteren Zeugenaussagen in ibid., I, S. 135 (Francesco Cardoni), 391 (Pietro Focile), 22 (Simone Grazzini), 29 (Monte Zazzara) und in ibid., III, S. 389 (Donato Conversi), 262-263 (Germanico Fedeli). Dieses Element der Krankenfürsorge zieht sich durch das gesamte Heiligsprechungsverfahren durch und kann somit als ein weiteres hagiographisches Merkmal betrachtet werden, das in Bezug auf eine genauere Untersuchung 
mente administrieren durfte, zumal er erst 1564 zum Priester geweiht wurde. Vielmehr als den Umgang mit den Sakramenten selbst möchte Baronio in dieser Zeugenaussage seine eigene Begegnung mit der von diversen Bruderschaften praktizierten caritas der Kranken- und Armenpflege beschreiben. Seine Begegnung mit der Mannigfaltigkeit bruderschaftlicher caritas im römischen Stadtraum, der durch die Bussprozessionen einzelner Bruderschaften zusätzlich eine visuelle Dimension verliehen wurde, ging mit der sich etablierenden Eigenständigkeit der Sakramente und ihrer jeweiligen Verwaltung während der zweiten Sitzungsperiode des Tridentinums einher.

Diese anhand des theologischen Verständnisses der Busse aufgezeigte Trennung der Sakramente spiegelt sich insbesondere in der Entwicklung der Confraternita del Divino Amore, die ihre Ursprünge in Genua hatte. Aus dieser sodalitas sollte Filippo Neri zusammen mit seinem Beichtvater Persiano Rosa die Bruderschaft der SS. Trinità dei Pellegrini gründen. In der bereits erwähnten Praxis der quarant'ore sollte zudem die sakramentale Verwaltungspraxis mit der Verehrung der Heiligen Eucharistie übereinstimmen. Die Gründung der Confraternitàa del Divino Amore in Rom geht auf das mediceische Pontifikat Leos X. zurück, der dieser Bruderschaft für ihre Versammlungen die Pfarrkirche von Santi Silvestro e Doroteo in Trastevere zur Verfügung stellte. ${ }^{135}$ Diese römische sodalitas unterschied sich von ihrem Vorbild in Genua insofern, als dass sie auch Priester aufnahm, von denen zumindest fünf nach 1520 das Bischofsamt bekleideten. Ein weiterer Unterschied zum Divino Amore in Genua war die Einberufung eines sindaco sowie eines camerlengo. Während Letzterem die Aufgabe erteilt wurde, die jeweiligen Sitzungen im Libro di Compagnia aufzuzeichnen, oblag die Moderation der Zusammenkünfte dem sindaco, die ebenfalls Eingang in die von Bartolomeo Stella 1520 festgehaltenen Statuten fanden. In denselben Statuten wird auch dem Begriff eines oratorio eine besondere Bedeutung zugesprochen. Die Aufgabe des sindaco bestand nämlich darin, die Mitbrüder im versammelten Oratorium der Bruderschaft durch das liturgische officium zu leiten:

[...] procurare che factosi la congregacione in oratorio se servi silencio infra li fratelli: quali atendino a meditare ovvero fare qualche tacita oracione insino che siano gionti li fratelli a dire l'officio. Et procurare che essendo preposta alguna cosa in consultatione, non sia de fratelli chi presumi parlare in dire el voto suo finché dal priore non gli serà comandato, ovvero secondo l'ordine a lui tochi dovere parlare [...] né se usino parole contradictorie quando li voti andranno intorno, né altercacione [...] Admonisca li contrafacienti fraternamente [...] et perse-

von Baronios frühen Jahre in Rom noch erforscht werden muss. Bella 2006, S. 182-183 erwähnt die durch Neri veranstalteten Besuche der römischen Hospitäler, geht darauf aber nicht weiter ein.

135 Die Bestätigungsbulle Papst Leos X., die Pastor auf das vierte Pontifikatsjahr datierte, gilt heute als verschollen: Pastor 1891-1933, Bd. IV/2, S. 549. Hierzu dann die neuesten Untersuchungen bei Camillocci 2002, S. 75-76. 
verando lo inobediente: lo conferisca cum lo priore et consilierj in potestà de li quali et arbitrio sia la penitentia conveniente al delinquente. ${ }^{136}$

An dieser Beschreibung des Versammlungscharakters der Compagnia fällt auf, dass der Begriff des Oratoriums eng mit demjenigen der Busse verschränkt ist, die wiederum durch die Rezitation der sieben Busspsalmen unterstrichen werden soll. Sie lösten für die römische Bruderschaft den komplexen liturgischen Wochendienst ab, den die Genueser Compagnia praktiziert hatte und der in der Geisselung der Mitbrüder bei gelöschtem Kerzenlicht kulminierte. Die römische Bruderschaft verfolgte hingegen eine sich auf die Liturgie der Heiligen Eucharistie konzentrierende Andacht, wodurch sie sich bezüglich der Durchführung von Bussprozessionen während der Osterwoche noch deutlicher von der Bruderschaft aus Genua unterscheiden wollte. Der Ausschluss dieser disciplina aus den Statuten der römischen Compagnia del Divino Amore kann auch dadurch erklärt werden, dass eine solche Praxis einerseits bereits fest in den Bestimmungen der Gonfalone-Bruderschaft verankert war. Andererseits waren die Aufführungen solcher Bussprozessionen während der Karwoche im Kolosseum seit der Gründung der Bruderschaft im ausgehenden Quattrocento zu einer der meistbesuchten Attraktionen der römischen Gesellschaft avanciert. Deshalb erhielt die Bruderschaft 1550 erstmals eine päpstlich erlassene Plenarindulgenz. ${ }^{137}$ An die Stelle der Geisselung trat eine Messfeier, bei der für die Mitbrüder der Compagnia mindestens einmal im Monat das Ablegen der Beichte und das Empfangen der Heiligen Kommunion vorgesehen war. Bartolomeo Stella fügte in den Kapiteln

136 Zit. n. Cistellini 1948, S. 275. In der Reihe der 56 im elenco des Bartolomeo Stella - datiert auf den 1. August 1524 - aufgeführten Mitbrüder der Compagnia finden sich 26 Kleriker, 17 Laien (zwei davon fanden 1524 Eintritt bei den Regularklerikern) sowie 13 Mitbrüder, von denen mindestens zwei über eine Beschäftigung innerhalb der römischen Kurie verfügten. Vgl. hierzu Camillocci 2002, S. 95 und Cistellini 1948, S. 22-283. Für die Genueser Statuten seit dem Jahr 1497 vgl. Tacchi Venturi 1922-92, I/2, S. 25-41. In dieser edierten Sammlung wird das ms B III 39 aus der Biblioteca Universitaria di Genova abgedruckt. Für die reformierten Statuten aus den Jahren 1570 und 1585 vgl. dann Biblioteca Universitaria di Genova, ms. C.V.18, f. 1r-15r: Capitoli della Fraternita del Divino Amore sotto protettione di S. Geronimo riformati l'anno 1570. La quale compagnia hebbe principio l'anno 1497 a 26 di decembre giorno di S. Stefano.

137 Zur 1550 verliehenen indulgenza plenaria an die Bruderschaft des Gonfalone vgl. insbes. Ruggieri 1866, S. 228-229, bei dem das Dokument wiedergegeben wird, in welchem die Prozession der Geisselung in der Nacht des Karfreitags erwähnt wird, welche bei der Chiesa del Confalone (Santa Lucia Nuova) begann und die bei San Pietro in Vaticano endete. Wie vor allem die Untersuchungen Barbara Wischs zeigen konnten, fanden diese Prozessionen der Gonfalone-Bruderschaft auch Eingang in das zwischen 1569 und 1576 von verschiedenen Malern ausgeführte Bildprogramm im Oratorium der Bruderschaft, auf welches zu einem späteren Zeitpunkt dieser Untersuchung noch detaillierter einzugehen sein wird. Vgl. Wisch 1991, S. 243-254 sowie eadem 2013, S. 415-430. Für den zeitlich grösseren Zusammenhang vgl. auch Newbigin 2000, S. 173-202; Wisch 2000, S. 203234. Neuere Untersuchungen zur Gonfalone-Bruderschaft, die auch eine Praxis des Sklavenloskaufs praktizierte, vgl. zuletzt Piersching 2012, S. 259-301; eadem 2015, S. 191-212. 
über die zu beachtenden liturgischen Dienste der Bruderschaft an, dass „diejenigen, die nicht Priester seien“, der Anordnung der regelmässigen Beichte und Kommunion sogar noch öfter als die übrigen Mitbrüder nachkommen sollten. ${ }^{138}$

Die Bruderschaft zeichnete sich somit durch die regelmässige Andacht der Sakramente aus, aus welcher sich schliesslich ein bruderschaftliches officium entwickelte, das einen spirituell-gemeinschaftliche Zusammenschluss der Mitglieder innerhalb der Bruderschaft betonte. Das liturgische Moment, das im bruderschaftlichen Zusammenleben dieser Compagnia eine besonders hohe Anerkennung genoss, wurde durch den regelmässigen Besuch des Ospedale di San Giacomo degli Incurabili ergänzt. In der Papstbulle vom 19. Juli 1515 hatte Leo X. dieses Hospital als „Haupt aller Spitäler für Arme, Kranke und Unheilbare“ (caput omnium hospitalium pauperum infirmorum incurabilium) bezeichnet. San Giacomo degli Incurabili wurde zusätzlich, zusammen mit den beiden Hospitälern von Santo Spirito in Sassia und demjenigen des San Salvatore ad Sancta Sanctorum bei San Giovanni Laterano, über die Einnahmen päpstlicher und kurialer Almosen finanziert. Diese galten als die Haupteinkommensquelle des Hospitals. ${ }^{139}$ Dadurch schloss sich die Compagnia del Divino Amore der Confraternità di Santa Maria del Popolo an, die ebenfalls für den Unterhalt dieses Hospitals zu sorgen hatte. Das erwähnte motu proprio Papst Leos X. billigte die Verbindung dieser Bruderschaft und derjenigen von San Giacomo in Augusta in Hinsicht auf die Administration ihres Patroziniums, dessen Ursprünge in das Trecento reichen und das von den Colonna verwaltet wurde. Dadurch wurden die jährlichen Verwaltungsaufgaben des Hospitals nicht nur durch die römischen Stadtbürger erfüllt, sondern der Zustrom von fremden Besuchern nach Rom (forenses) erlaubte es zusätzlich, das Hospital finanziell zu erhalten. Die stranieri trugen sodann zur karitativen Ausrichtung des Hospitals von San Giacomo bei. Dies erlaubte es den Mitgliedern des Hospitals, sich stärker der bereits erwähnten Pflege von infirmorum incurabilium zu

138 Zit. n. Camillocci 2000, S. 97: „[...] quelli solum non sono Sacerdoti, existimando loro debbano exercitarlo molto più spesso“. Vgl. auch Tacchi Venturi 1922-92, I/2, S. 31-32, wo die beiden Kap. IX und X der Genueser Statuen aufgeführt werden, in denen die wöchentlichen Zusammenkünfte der Bruderschaft sowie die Meditationen über die Passionsgeschichte Jesu enthalten sind. Für einen Überblick zu ähnlichen Bräuchen in weiteren spätmittelalterlichen Bruderschaften Italiens vgl. Meerssemann 1977, S. 508-509.

139 Bull. dipl. rom., V, S. 639-648. Die Bulle erwähnt allerdings die Compagnia del Divino Amore nicht direkt, sondern nennt die antiqui et moderni confratres der Bruderschaften von Santa Maria del Popolo und San Giacomo. Wie die jüngsten Untersuchungen Camilloccis zeigen konnten, wechselten einige der Mitbrüder aus dem Divino Amore in secretum in die Bruderschaft von Santa Maria del Popolo. Dadurch entstanden weitere, zentrale Bindungen zum römischen Kurienapparat, die den Unterhalt des Hospitals aufrechterhalten sollten: Camillocci 2000, S. 124-130. Zur Finanzierung von San Giacomo vgl. insbes. ASR, Ospedale di San Giacomo degli Incurabili, reg. 1145 (15151516), reg. 1146 (1518-1519), reg. 1149-1150 (1520-1521). 
widmen. ${ }^{140}$ Der im Hospital von San Giacomo in Augusta auf die Pflege von unheilbar Kranken gelegte Schwerpunkt lässt sich auch anhand von dessen Erweiterung als arciospedale zeigen, das mit den bereits erwähnten Hospitälern von Santo Spirito in Sassia und dem zum Lateran gehörigen Salvatore ad Sancta Sanctorum verbunden wurde. Die nächste Papstbulle verlieh allen Gläubigen, welche die Kirche von San Giacomo in Augusta besuchten und ihr Almosen darbrachten, für die gesamte Karwoche, den Festtag des San Giacomo und den Festtag Mariä Empfängnis eine Plenarindulgenz. Einen Monat später erliess Papst Leo X. eine weitere Bulle, in der San Giacomo in Augusta mit den beiden anderen Hospitälern Roms für Unheilbare wieder in die Obhut der apostolischen Autorität der römischen Kurie übergeben wurde. Einerseits gelang die Übernahme der Verwaltung von San Giacomo durch die Kurie, weil die Administration von der städtischen Obrigkeit kontrolliert wurde. Andererseits kam diese Überführung zu Stande, da die Bruderschaft von Santa Maria del Popolo eine starke Anbindung an die römische Kurie und eine hohe Anzahl von Mitbrüdern, die entweder ein Benefizium besassen oder einen Dienst innerhalb der Kurie ausübten, vorweisen konnte. ${ }^{141}$

Es lässt sich anhand der Privilegien, die der Confraternità di Santa Maria del Popolo für ihr Wirken in San Giacomo degli Incurabili zugesprochen wurden, zeigen, dass die Zusammensetzung dieser Bruderschaft sich eindeutig von derjenigen

140 Bei der Durchsicht der im ASR überlieferten Dokumente zum Hospital konnte keine edierte Ausgabe der alten Statuten der Bruderschaften von Santa Maria del Popolo und von San Giacomo gefunden werden. Einzig bleibt ein Dokument aus ASR, Ospedale di San Giacomo delgi Incurabili, B 292 vorhanden, welches eine Übersetzung der Statuten der beiden Bruderschaften aus dem Lateinischen in die italienische Sprache ist. Vgl. Camillocci 2000, S. 120-121 und Bull. dipl. rom., V, S. 640: „[...] dictum hospitale infirmorum incurabilium denominaretur et in eo omnes et singuli utriusque sexus infirmi, quovis etiam gallico nuncupato (praeteream epidemiae et leprae) morbo infecti, ad illud pro tempore confugientes vel alias ducti reciperentur, alerentur et curarentur. [...] dicti pauperes, morbo incurabili laborantes, per Urbem victum quaerentes tota die, etiam parvis curribus et vehiculis discurrere, seque et alios eis obiectos taedio et impedimento afficere; pluresque ex eis, nullo adiuti in eorum vita regimine, in graviores morbos excidere et omnium christifidelium auxilio destituti, prematuram mortem subire cogerentur“. Tatsächlich erwähnt das motu proprio auch Mitglieder als moderni confratres im Unterschiedzu solchen antiqui als Fremde, die neu der Bruderschaft von Santa Maria del Popolo beitraten, unter denen sich vornehmlich solche französischer Nationalzugehörigkeit (gallicos) befanden. Zur Gründung des Hospitals von San Giacomo in Augusta durch die Colonna 1339 vgl. ASR, Ospedale di San Giacomo degli Incurabili, b 359 r 18. Hierzu dann Canezza 1933, S. cxxviii-cxxxv sowie Carpaneto 1938, S. 106-108. Für die guardiani des Hospitals ASR, Ospedale di San Giacomo degli Incurabili, reg. 1145, f. $2 r, 4 r, 6 r-v, 9 v$.

141 Bull. dipl. rom., V, S. 644-648. Für die Bulle Illius qui in altis habitat vgl. Carpaneto 1938, S. 242-246. Die Anzahl kurialer Mitglieder der Confraternita di Santa Maria del Popolo steigt zwischen 1515 und 1522 von ursprünglich zwei Mitbrüdern auf neunzehn, wovon sieben ein Benefizium verwalten. Unter Papst Clemens VII. bis zum Sacco di Roma finden sich immer noch unter 64 Mitbrüdern 13 kuriale Mitglieder. Vgl. hierzu insbes. die Zusammenfassung der Mitgliedereinträge aus den im ASR überlieferten Auflistungen des Ospedale di San Giacomo degli Incurabili bei Camillocci 2000, S. 298-384. 
der Compagnia del Divino Amore unterschied. Die Statuten des Divino Amore geben Aufschluss über die Zusammensetzung der Bruderschaft. Neben der karitativen Sorge um die incurabili ist auch eine in Geheimhaltung operierende Compagnia zu erkennen:

Che ognuno de' fratelli sia obbligato tenere occulto et secreto le opere et modi de ditta fraternita. Et chi intendesse alguno de fratelli havere revelato alguna cosa sia obligato riferirlo al priore [...], et ritrovando così essere il vero, la punitione et la penitentia sia in lor mani, et usque ad privationem de nostra fraternitate. ${ }^{142}$

Die Aufnahme von Kurienprälaten - wie zum Beispiel Kardinal Gian Pietro Carafa in die Compagnia, musste für deren Vorsitzenden (priore) ein besonderer Dorn im Auge gewesen sein. Im achten Kapitel der römischen Statuten trat sodann ein besonderes Verständnis der Busse (penitenza) als ein Moment der Geheimhaltung auf, das sich auch in der Herausbildung eines bruderschaftlichen officiums widergespiegelt hatte. Daraus lässt sich das entscheidende Verhältnis zwischen Predigt (oratione) und Oratorium ableiten. Innerhalb der Compagnia wurde eine congregatione dell'oratorio eingesetzt, die neben der regelmässigen Zusammenkunft ihrer Mitbrüder auch für die regelmässige Predigt zu sorgen hatte, bei der das Pater noster im Zentrum stand. Diese congregatione stellte somit einen zeremoniellen Rahmen dar, innerhalb welchem ein liturgischer Vollzug der Beichte sowie der Kommunion stattfinden konnte. Dieser zeremonielle Rahmen wurde aber in secretum hergestellt. ${ }^{143}$

142 Zit. n. Cistellini 1948, S. 277.

143 Cistellini 1979, S. 280-315. Vgl. für die Genueser Statuten v. a. Tacchi Venturi 1922-1992, I/2, S. 30-31: „Et però che l'oratione et devotione è quella che n'unisce con Dio et ne fa impetrare tutte le gratie, adonque se conforta tutti li fratelli, che vogliano essere soliciti, come sono levati la matina, a voltare il suo core a Dio et offerirsegli mentalmente con grande affetto de core, et pregarlo che gli faccia tutto il dì caminare segondo il suo beneplacito. Et poi ogni dì, in memoria delle sette hore canoniche, in le quali Cristo Iesu Signor nostro pattì l'accerba morte per noi, dicanse col core, esplicando con la bocca, sette volte la dominica oratione, et altre tante l'angelica salutatione, et sempre che si va a mensa ogn'uno dica il paternostro et l'avemaria. Et al levare della mensa dica: Tu autem, Domine, miserere nostri, et oltra questo ogni lunedì dica ogn'uno cinque paternostri et cinque avemarie per l'anime de fratelli defonti. Et questa sia l'ordinaria oratione che ogn'uno, almanco ogni giorno dica. Poi il sabato o il dì venere, o altro giorno in arbitrio del priore et consiglieri, et oltra la vigilia della Purificatione, la vigilia di Penthecoste, la vigilia dell'Assuntione de Maria, la vigilia del glorioso prottetor nostro san Gieronimo, et la vigilia di tutti li Santi, congregatevi in l'oratorio, et in esso tenendo li modi ordinati nel capitolo de boni costumi, dicendo l'offitio consueto. Il giovedì santo, da poi il disnare, si congregino li fratelli; et, mentre se congregano, legansi qualche cosse devote, et poi si faccia la lavatione de pedi con le serimonie chi se conteneno ne 'l libro de l'offitio, o altre, segondo parerà a priore; et poi si dica matutino grande, et poi si faccia disciplina al modo usato. Et quando alchuno de nostri fratelli passerà di questa vita, si dica, un giorno ch'ordinerà il padre in l'oratorio, l'offitio da morti, o al meno il primo notturno per anima sua, et li sacerdoti li dicano una Messa per uno per anima sua, et l'altri fratelli gli dicano .XII. giorni continui il Miserere, il Deprofundis, il Deus in nomine con tre paternostri e tre avemarie, o vero gli dicano .XV. paternostri et .XV, avemarie ogni giorno [...] Oltra di questo ogn'uno, più spesso che 'l po, faccia mentione delli vostri fratelli defonti, et ogn'anno alla sera del dì delli Santi, si congregen 
Mit dem am 2. Mai 1524 verfassten breve berief der damalige Papst Clemens VII. den Kardinal Gian Pietro Carafas ad sacrorum ordinum collationes et promotiones, nec non quorumcumque ordinandorum diligentes examinationes faciendas. Der wichtigste Mitbruder der Compagnia del Divino Amore sollte sich gegen die Aufforderung zur Geheimhaltung wenden und daraus einen neuen Orden gründen, und zwar denjenigen der Chierici Regolari Theatini. Die vom Papstbiographen Antonio Caracciolo nach dem Tod Pauls IV. verfasste Vita führt die Gründung des neuen Ordens auf eine am 14. September 1524 stattgefundene Prozession vor dem Hauptaltar in der Peterskirche zurück, während welcher der Kardinal Carafa seine drei Gelübde zu Armut, Gehorsam und Keuschheit ablegte. ${ }^{144}$ Die Gründung des Theatinerordens wird somit als Abspaltung von der römischen Bruderschaft des Divino Amore und ihres Hospitals von San Giacomo degli Incurabili dargestellt. In Caracciolos Erzählung wurde Carafa die ,alleinige Aufsicht über die Orden sowie die Berufung des Klerus“ anvertraut. ${ }^{145}$ Sechs Jahre spätere legte Carafa dem Medici-Papst seine $D e$ Lutheranorum haeresi reprimenda et ecclesia reformanda vor. Dabei stellte der später zu Papst Paul IV. gewählte Kardinal fest, dass Bischöfe, die sich „in den Winkeln Roms aufhielten“, „respektlos und unverschämt“ Priester ordinierten. ${ }^{146}$ Unmittel-

li fratelli nell'oratorio, et lì si dica l'offitio da morti [...] et li religiosi de nostri gli dicano una Messa per uno in fra giorni otto, et lo simile si faccia uno giorno di quadragesima, segondo ordinerà il priore“. Vgl. dann auch ibid., S. 33.

144 BCR, ms. 349 (Caracciolo, Vita et gesti, 1619), f. 82v: „A 14 di settembre di questo anno 1524, fecero professione de i tre voti solenni nella chiesa di San Pietro a Roma su l'altare dove sta il santissimo corpo dell'apostolo san Pietro e san Paolo primo fondatore dopo Christo del christiano clero“. Vgl. auch das Dokument in AGT, ms. 11 (Decreti dei capitoli generali), f. 5r. Sanuto notierte ebenfalls in seinem Tagebuch, gestützt auf einem Brief des Spaniers Girolamo La Lama, die feierliche Gründung des Theatinerordens in Marino, I Diarii, Bd. 37, col. 35: „El episcopo et missier Gaetano et altri doi feceno la professione solennissima hoc modo. Andarono a Sato Pietro a bona hora, quasi in aurora, per farla secreta senza gente, ma al Signore ha piaciuto si facesse pubblica. El episcopo casertano havea da dire la messa a bona hora ma fu occupato e venne tardo, in tempo che tutto il mondo era in la ecclesia, et lui celebrò in altare sancti Andreae et comunicò el episcopo theatino.“ Zum Brief La Lamas cfr. Biblioteca Nazionale di Napoli, San Martino, ms. 511 (Relazioni e memorie), f. 157r-158r. Zur jüngsten Forschung über den Theatinerorden vgl. insbes. Vanni 2010, S. 75-104; idem 2011, S. 101-119.

145 BCR, ms. 349 (Caracciolo, Vita et gesti, 1619), f. 72v: ,[...] solo il vescovo theatino havelle l'autorità sopra gl'ordini et promotione del cleri, et così avveniva che che moltissimi ignoranti, bastardi, inetti, stroppiati, che non si fidavano comparir dinanzi al vescovo thatino, che n'andavano furtivamente a qualche lor vescovo buon compagno, che gli ordinasse“.

146 CT, XII, S. 71-72: ,[...] nel primo anno del suo pontificato, avendo commesso Sua Santità l'offitio del ordinar ad un suo servo fedele et prohibito strettamente ogni altro che in ciò non s'impiacciasse, si trovarono nondimeno alcuni vescovi [...] che impudentissimamente, senza rispetto della presentia di Sua Santità, andavano per li angoli di Roma ordinando quanti castroni potevano congregare“. Der Kardinal wurde dadurch zum alleinigen Aufseher für Bischofs- und Priesterordinationen. Vgl. hierzu das in Pelliccia 1946, S. 462-463, abgedruckte breve Clemens VII. vom 2. Mai 1524: „[...] omnes et singulos in dicta romana curia nunc et pro tempore residentes et ad illam confluen- 
bar nach der solenne processione in der Peterskirche vom 14. September 1524 sollte sich die Anbindung des padre episcopo an die Compagnia del Divino Amore als überflüssig erweisen. Für den späteren Biographen Caracciolo kam diese Trennung tatsächlich einem Bruch mit dem sodalizio gleich: Die Entwicklung des Divino Amore stellte nämlich einen Verfall des Predigtoffiziums dar. Diesem Verfall sollte der neu gegründete Theatinerorden nun entsprechend entgegenwirken. ${ }^{147}$ Gian Pietro Carafa verfolgte mit dieser Abspaltung bewusst das Ziel, mit dem neuen Theatinerorden nicht nur die in Rom, sondern auch in ganz Italien vom Papst vorgesehene Reform von Klerus und Kurie zu übernehmen.

Auch wenn die Entstehung des Theatinerordens zeigt, dass Spaltungen innerhalb einzelner Bruderschaften im römischen Cinquecento häufig anzutreffen sind, verfolgten die neu entstehenden Priesterbündnisse nicht immer dasselbe Ziel. Die Gründung der SS. Trinità dei Pellegrini e Covalescenti aus ihrer Abspaltung von der bereits erwähnten Confraternita di San Girolamo della Carità stand - im Gegensatz

tes et venientes undecunque, et cuiusque nationis, sufficientes tamen et idoneos, ad primam clericalem tonsuram et minores ac sacros etiam presbyteratus ordines tam temporibus ad id a iure statutis quam etiam extra illa in quibusvis tribus diebus dominicis vel festivis alias tamen rite promovendi, illosque ad id examinandi et examinari faciendi, ac pro tanti negocii faciliori expeditione quoscqunque examinatores, etiam singularum nationum ad eosdem promovendos diligentissime examinandum, ac notarios vel scribas, qui de examine et promotione ac aliis necessariis actibus plenam fidem faciant, et alios quoscunque ministros ad id necessarios deputandi, ac quibusvis aliis episcopis et etiam Camerae apostolicae ac vicariis Urbis et aliis notariis et scribis, seu ab eis nunc et pro tempore deputatis“.

147 BCR, ms. 349 (Caracciolo, Vita et gesti, 1619), c. 42v: „[...] hebbero intentione [...] di dare esempio e forma di vivere al clero che andava declinando e di costumi e lettere [...] per ritornare a' preti l'offitio di predicare che l'havevano quasi tralasciato [...]“. Vgl. auch AGT, ms. 147 (Caracciolo, Vita et gesti, 1613), f. 42v. Dieser Bruch lässt sich auch anhand des bereits erläuterten Umstandes zeigen, dass in der Verwaltung des Hospitals von San Giacomo degli Incurabili der Divino Amore nicht erwähnt wird, sondern lediglich die beiden Bruderschaften von Santa Maria del Popolo und San Giacomo. Der Bruch hatte zur Folge, dass im Zuge des Jubeljahres 1525, während welchem die Compagnia die „kleine Kirche“ (chiesetta) von Santa Maria Porta Paradisi errichtet hatte und die sich direkt an das Hospital von San Giacomo anschloss, nun die Bruderschaft von San Giacomo das aus dem Quattrocento stammende Wunderbild der Madonna dei Miracoli verwalten durfte. In Wirklichkeit stand aber die Finanzierung zur Aufrechterhaltung des kleinen Kirchenraumes im Hospital, wo dieses Wunderbild beherbergt wurde, allein der Bruderschaft von Santa Maria del Popolo zu, und zwar aus den in das Hospital von San Giacomo eingeflossenen Almosen ihrer benefattori. Das Bestreben, das Hospital von San Giacomo degli Incurabili als sakralen Raum zu konstituieren, liegt somit in einer Strategie begründet, diesen Raum mit einem Bildnis auszustatten, welches demjenigen in der Kirche von Santa Maria del Popolo ähnlich war, um dadurch die dem Hospital zugesprochenen Indulgenzen aufrechtzuerhalten. Vgl. die hierzu stattgefundenen Zeremonien seitens der beiden Bruderschaften in ASR, Ospedale di San Giacomo degli Incurabili, B 292, f. 8v-10r; ivi, B 362, fasc. 1. Zur weiteren Systematisierung des Theatinerordens unter der Führung Gian Matteo Gibertis innerhalb von Santa Maria del Popolo vgl. weiter ASR, Notai, Collegio Notai Capitolini, Stephanus de Amannis, 72, f. 178v: „[...] cum domo et cisterna [...] intra moenia urbis in loco dicto lo monte de Pinci“. 
zum Reformgedanken des Theatinerordens - ganz im Zeichen des bevorstehenden Jubeljahres. In diesem Gründungsmoment lässt sich nicht nur der Charakter Filippo Neris selbst, sondern auch derjenige des frühen Oratoriums erkennen. Das Jubeljahr Papst Julius' III. stand ganz im Zeichen einer Intensivierung der karitativen Pflege im römischen Stadtraum, die es der Confraternita della SS. Trinità dei Pellegrini ermöglichte, sich in das weitgespannte Netz solcher karitativer Bruderschaften Roms einzugliedern. In den ersten Statuten der Confraternita spiegelt sich dieser Prozess der sozialen Eingliederung wider. ${ }^{148}$ Die Bruderschaft, deren Entstehung der Zusammenarbeit Neris mit seinem Beichtvater Persiano Rosa zu verdanken war, hatte mit dem Ritus der Fusswaschung bei Pilgern der caritas einen besonderen Ausdruck verliehen. Einerseits sollte sich in diesem Ritus die Offenheit der Bruderschaft gegenüber fremden Pilgern zeigen, andererseits sollte er ein spezifisch bruderschaftliches officium festigen. Die Pilger wurden von den Mitgliedern der Bruderschaft, die innerhalb eines eigens dafür eingerichteten Raumes auf „erhöhten Sitzen“ (alti seditori) sassen, begrüsst. Ein Bruder der Confraternità, der in liturgischem Habit gekleidet war, führte den Ritus mit dem incipit ein, indem er den Pilgern erklärte, dass durch die äussere Fusswaschung auch die innere Verunreinigung beseitig werde. ${ }^{149}$ Dieser besondere Ritus des Pilgerempfangs stellte zusammen mit deren Bewirtung innerhalb des Bruderschaftskonvents eine bestimmte Form der caritas dar, die folgendermassen in den Statuten von 1578 aufgeführt wurde:

La medesima hospitalità si vede in Abraham, \& in Lot, i quali nell'albergo loro ricettarono ancora gli Angeli: \& doppo questi, \& altri di quel tempo sopra tutti fù lodata sempre l'hospitalità di Maria, \& di Marta, che ricettarono il Signore in casa loro alcuni giorni avanti la Passione sua: \& quella delli sue Discepoli, che l'invitarono, \& sforzarono, essendo in forma di Pelegrino ad albergare con essi loro Emaus. Sopra il che S. Gregorio nella sua Homelia dice, che non solamente si devono invitare i Pelegrini all'albergo, ma è da indurueli, \& tirarneli, la qual'opera l'istesso S. Gregorio Papa essercitò con tanto ardore di carità, che hebbe gratia tra li poveri, ch'egli raccoglieva ogni dì alla sua tavola d'havervi un' Angelo, che ci bastino, per dimostrare a ciascuno de' nostri Fratelli, quanto quest'opera dell'hospitalità sia accetta al Signore. ${ }^{150}$

148 Obwohl das Gründungsjahr dieser Bruderschaft umstritten bleibt, kann durchaus davon die Rede sein, dass sie zumal auch aus einer in der Compagnia del Divino Amore weilenden Spiritualität, die sich dann auf Neri selbst durch seine Besuche der Compagnia und des Hospitals von San Giacomo degli Incurabili übertragen haben musste, entstand. In ASR, Ospedale di San Giacomo degli Incurabili, B 359, f. $7 r$ tritt der Name Philippo Neri da Santo Ludovico fiorentino auf. Der Eintrag kann auf das Jahr 1548 datiert werden. Zur Unsicherheit des genauen Gründungszeitpunktes der Confraternita della SS. Trinità vgl. Ponnelle/Bordet 1931, S. 57 sowie Borzacchini 1984, S. 238.

149 Eine detaillierte Beschreibung des Ritus findet sich in ASR, SS. Trinità dei Pellegrini, 2, Congregationi dal 1564 a tutto 1572, fols. 64r-77v. Vgl. auch den Nachruf in BAV, Vat. lat. 6822, f. 80r. Zur Fusswaschung im Neuen Testament vgl. die entsprechende Stelle in Jh. 13,5. Zuletzt hierzu Fiorani 1998, S. 322-323; idem. 2000, S. 452-453.

150 Statuti Archiconfraternita della Santissima Trinità de` Pelegrini, c. 83. 
Dieser bruderschaftliche Ritus, der im Übrigen auch von der Gonfalone-Bruderschaft vor ihren Bussprozessionen während der Karwoche ausgeführt wurde, erfuhr auch innerhalb eines kurialen Prälatenkreises seine Rezeption. Eine vom Bologneser Maler Girolamo Muziano ausgeführte Vorzeichnung, die sich heute in einer Privatsammlung befindet und erst kürzlich bei den Vorbereitungen zur Ottawa-Ausstellung zum Vorschein gekommen ist, hält ein von Kardinal Ippolito d'Este in Auftrag gegebenes Tafelbild für die Kirche von San Salvatore in Lauro noch fest (Abb. 5a). Seit einem Brand in dieser Kirche im Jahr 1591 gilt das von Muziano ausgeführte Gemälde als verschollen. Auch wenn der ursprüngliche Vertrag zwischen Muziano und d'Este nicht mehr vorliegt, lässt sich aus den entsprechenden Zahlungsbelegen im Archivio Estense di Modena ableiten, dass Muziano dem Kardinal eine Replik nach Frankreich gesandt haben muss, die dann in der Kathedrale von Reims installiert wurde und 1914 dem Brand der Kathedrale zum Opfer fiel. ${ }^{151}$ Sowohl im British Museum als auch in der Collezione Spada-Potenziani in Rom sind Kopien erhalten, die mit der Bildkomposition Muzianos übereinstimmen (Abb. 5b). ${ }^{152}$ Das erhaltene Blatt Muzianos diente als Vorlage für das Tafelgemälde, das insgesamt 18 auf 24 palmi gemessen haben musste, was ca. 400 auf $525 \mathrm{~cm}$ entspricht. Muzianos Fusswaschung trägt in ihrer Bildkomposition noch die Züge eines Einflusses venezianischer Bildlösungen desselben Sujets, die Muziano bei seinem Aufenthalt in Venedig, kurz vor seiner Weiterreise nach Rom gesehen haben musste. Muzianos Version erinnert nämlich an das von Giuseppe Porta für die Kirche von San Paolo entworfene Gemälde sowie Jacopo Tintorettos Tafel, die sich heute im Madrider Prado befindet. ${ }^{153}$ Ein Jahr bevor der Kardinal Ippolito d'Este als Legat nach Frankreich reiste, verfasste Papst Pius IV. eine Bulle, mit welcher er die Anerkennung der Bruderschaft der SS. Trinità wegen

151 Vgl. Pacifici 1923, S. 289. Das Gemälde Muzianos wurde nicht nur in Borghinis Riposo gepriesen, sondern fand auch in einer anonym verfassten Vita Lob: Procacci 1954, S. 251 sowie Borghini, Il Riposo, S. 575. Zur Künstlerbiografie dann auch Baglione, Vite, S. 46-50. Vgl. zudem Kat. Ottawa 2017, S. 264-266.

152 Weitere Kopien im Musée de Louvre, Paris, Inv.-Nr. 5141 sowie im J. F. Willumsen-Museum in Dänemark. Zu Letzterem vgl. Italian Drawings in the J. F. Willumsen Collection, Nr. 93. Borghini erwähnte sogar, dass der Florentiner Niccolò Gaddi ein „quadro di chiaro oscuro“ desselben Sujets besass, das aber bislang nicht aufgefunden werden konnte: Borghini, Il Riposo, S. 575. Weitere drei Versionen der Fusswaschung lassen sich aus dem posthum erstellen Inventar Muzianos erschliessen. Hierzu Da Como 1930, S. 193-196.

153 Vgl. Marciani 2000, S. 45-51. Seitens der Forschung wurde auch diskutiert, ob Muzianos Version sich an Taddeo Zuccaros Fresko in Santa Maria della Consolazione orientiert haben könne. Wie aber Marciani 2002, S. 116, deutlich zeigen konnte, liegt hier vielmehr der Fall einer generellen Ähnlichkeit als eines direkten Einflusses Zuccaris vor. Anlass zu dieser Frage gab eine in den Uffizi erhaltene Vorzeichnung, wiederum aus der Hand Muzianos, die sich aus zwei Karten zusammensetzt: während die obere Hälfte, Uffizi 18261F, deutlich Muziano zugeschrieben werden konnte, wurde die untere Hälfte, Uffizi 12900Fv, irrtümlicherweise als die Grablegung Christi identifiziert und Tizian zugeschrieben. Muzianos eigene Version der Grablegung Christi ist aber tatsächlich im Gabinetto Disegni e Stampe der Uffizien, als Fragment 18261F, erhalten. 
ihrer caritas erneuerte. Zwei Jahre später erhob er sie zur Erzbruderschaft. Dieselbe Bulle gestattete es der Bruderschaft auch, Indulgenzen an Pilger zu vergeben, welche die Kirche der Confraternita della SS. Trinità sowohl am Festtag der Heiligen Dreifaltigkeit als auch an demjenigen des heiligen Benedikts besuchten. ${ }^{154}$

Sowohl der Ritus der Fusswaschung als auch die Bewirtschaftung der Pilger waren als Vorbereitungen auf den Empfang des Heiligen Sakramentes der Eucharistie gedacht. Damit reihte sich die Confraternita della SS. Trinità dei Pellegrini in eine spezifische Tradition jener Bruderschaften ein, die eine besondere Andacht zum Heiligen Sakrament ausübten und sich an der Vorbildhaftigkeit der Confraternita del Santissimo Sacramento orientierten. ${ }^{155}$ Diese Bruderschaft hatte ihren Sitz in der Dominikanerkirche von Santa Maria sopra Minerva, deren Gründer der Dominikaner Tommaso Stella war. Bevor Stella dieser Bruderschaft beitrat, war er Mitglied der Confraternita di San Girolamo della Carità und wirkte in dieser seit dem 22. April 1554 als einer ihrer deputati. ${ }^{156}$ Ursprünglich sollte die Bruderschaft der SS. Trinità dei Pellegrini in Neris Vorstellung eine Zusammenkunft bilden, der jeder frei betreten konnte und welche frei von administrativen Formalitäten sein sollte. Jedoch wird in den Statuten der Bruderschaft Neri nur als ihr Gründer aufgeführt, der bald nach seiner Priesterweihe wieder nach San Girolamo della Carità der SS. Trinità zurückkehrte. Neri selbst konnte daher keinen Einfluss auf die Ausgestaltung des Ritus der Fusswaschung genommen haben. Dieser sollte bewusst als ein officium praktiziert werden, der eine besondere Form des Pilgerempfangs darstellte und sich daher nicht allein aus der bruderschaftlichen Pflege- und Sorgetätigkeit der nach Rom zuströmenden Pilger herausgebildet hatte. Die Fusswaschung war mit der Entwicklung der Bruderschaft eng verflochten, die ab dem Carafa-Pontifikat Pauls IV. allmählich fassbare Regulierungsmechanismen des Zusammenlebens ihrer Mitglieder verliehen bekam. Die von Neri ins Leben gerufene Confraternita della SS. Trinità hatte rasch nach 1548 ihre Frömmigkeits- und Andachtspraxis für Pilger gemäss eines rituellen und seitens der Kurie anerkannten Vorgehens zu gestalten begonnen. Im Folgenden wird daher näher auf die Andachtspraxis dieser Bruderschaft einzugehen sein und auf die Frage, inwieweit diese vom Santo Uffizio gesteuert wurde. Innerhalb der Forschung wurde erst vor Kurzem begonnen, den Zusammenhang zwischen den Arbeiten der Inquisitionsbehörde als römisches Gewissenstribunal und den Bruderschaften $\mathrm{zu}$ erschliessen. ${ }^{157}$ Bislang gelang es der historischen Forschung

154 Bull. dipl. rom, VII, S. 23-26. Der Kirchenraum, der von der Bruderschaft seit Paul IV. Carafa genutzt wurde, war dem heiligen Benedikt geweiht.

155 Dies geht aus dem VII. Kapitel derselben Statuten der SS. Trinità hervor, welche die Prozession an Gründonnerstag zu ihren „,nobelsten und berühmtesten Prozessionen“ zählt: Statuti Archiconfraternita della Santissima Trinità de‘ Pelegrini, II, cc. 54-55.

156 ASR, San Girolamo della Carità, 220, f. $104 r$.

157 Vgl. zuletzt Black 2011, S. 293-305, der aber eine sehr eingeschränkte Sichtweise auf das Santo Uffizio vorlegt, in der er nämlich dessen Arbeitsweise nur auf die Verfolgung sowie Verurteilung 
aber noch nicht nachzuweisen, ob die Tätigkeiten des Santo Uffizio dazu führten, dass sich, wie bereits im Fall der Compagnia del Divino Amore während der 1520er Jahre, neue Gruppierungen aus bereits bestehenden Bruderschaften herausbildeten, um die Abspaltungsprozesse womöglich keinem inquisitorischen Untersuchungsverfahren unterziehen zu müssen. Dieselbe Strategie, der rechtlichen Überprüfung durch das Santo Uffizio zu entkommen, verfolgte auch Filippo Neri selbst in der Prägung seiner Kongregation des Oratoriums. Jedoch wurde sie bislang nur als eine hagiographische Stilisierung Neris betrachtet, in welche die Gestalt Cesare Baronios ebenfalls eingebettet wurde.

Tatsächlich entwickelte die Confraternita della SS. Trinità dei Pellegrini über die weiteren Jubeljahre des 16 . sowie 17. Jahrhunderts eine bestimmte Feindlichkeit gegenüber „falschen Pilgern“ (falsi pellegrini), die in verschiedenen Erinnerungsurkunden erwähnt werden. ${ }^{158}$ Anhand der ersten Statuten der Bruderschaft lässt sich eine Festigung ihrer Frömmigkeitspraktiken, die unmittelbar mit dem Jubeljahr 1550 ansetzten, feststellen. Dieselben halten nämlich fest, dass die Spende des Heiligen Sakraments der Eucharistie nur in Bezug auf die Beichte und beim monatlichen Kommunionsempfang erlaubt sei. Die geregelte Verwaltung des Sakraments sollte insbesondere die bruderschaftliche Zusammenkunft repräsentieren. ${ }^{159}$ Die Besonderheit der Spende des Sakraments der Eucharistie, welche das Tridentiner Konzil bis zu den Dekreten der 13. Sitzung vom 11. Oktober 1551 beschäftigen sollte, lag darin, dass sich in dessen theologischer Auslegung die sinnlich fassbare Sichtbarkeit der Kirche als mysterium fidei zu manifestieren hatte. Diese Vorstellung hatten

von Häretikern in Italien beschränkt und diese zusätzlich als eine Konstante ohne wesentliche Veränderungen selbst ansehen möchte. Vgl. hierzu den Eintrag in DSI, Bd. 1, S. 377-381 mit weiterführender Literatur.

158 Vgl. beispielsweise Salamonio, Diario delle cose occorse l'anno 1650, in ASR, SS. Trinità dei Pellegrini, b. 372, sowie die Aufforderung des Zelebranten gegenüber neueintretenden Pilgern nach dem Ritus der Fusswaschung, dass sie sich die Beichte abnehmen lassen sollten, um daraufhin in Bezug auf ihre Kenntnis des katechetischen Unterrichts geprüft zu werden: ASR, SS. Trinità dei Pellegrini, I, Congregationi dell'anno 1563 a tutto 1567, I: Congregatione del 5 giugno 1565, f. $13 \mathrm{v}$. Vgl. diesbezüglich auch Fiorani 2000, S. 453.

159 Statuti Arciconfraternita della Santissima Trinità dei Pellegrini, II, cc. 48-50. Die Bruderschaft sollte während des Carafa-Pontifikates Pauls IV. sogar die zentrale Bedeutung dieses Sakramentes in eine ihrer wichtigsten Prozessionen während der Karwoche integrieren, während der die Pilger das Heilige Sakrament der Eucharistie in der päpstlichen Cappella Paolina besuchen durften. Vgl. die Stelle in ibid., 55: „Recreati dunque tutti i Fratelli di tanta gratia del Signore, doveranno la sera ad hora competente ritrovarsi all'Oratorio co'l sacco, \& con la torcia gialla, accioche unitamente, \& processionalmente con la debita divotione, \& ordine vadino prima à visitare, \& adorere il santissimo Sacramenti riposto nella Cappella Paolina per mano del sommo Pontefice nel Palazzo Apostolico, ove si conseguisce l'Indulgenza conceduta tal' effetto dalla Santità sua, \& poi di lungo calino à basso nella Chiesa di S. Pietro à veder' il santissimo Sudario, \& il ferro della Lancia che trasisse il costato del Signore Nostro Giesù Christo, che quivi con molta divotione si riferivano, \& mostravano in tal notte“. 
die Konzilsväter im 3. Kapitel des Dekrets dadurch erreicht, dass sie der Eucharistie die Hoheit über die anderen Sakramente zuschrieben. Die Eucharistie wurde als „sichtbare Gestalt der unsichtbaren Gnade“ verkündet. Ferner affirmierte das Dekret in einem weiteren Kapitel über den Kult und die Verehrung, die diesem Sakrament zu erweisen seien, dass „in der Kirche Gottes der Brauch eingeführt worden sei, jedes Jahr an einem eigenen Festtag dieses hohe und verehrungswürdige Sakrament mit einzigartiger Verehrung und Festlichkeit zu feiern und in Prozessionen ehrfürchtig und ehrenvoll durch die Strassen und öffentlichen Plätze zu tragen“. ${ }^{160}$

Die Konzilsväter fassten im Tridentiner Dekret die Eucharistie somit als ein Sakrament auf, das nur mittels einer sinnlich-sichtbaren Präsentation gegenüber den Gläubigen überhaupt erst für deren Gnadenerlass wirksam sein konnte. Im Votum des ehemaligen Maestro del Sacro Palazzo und Dominikanertheologen Egidio Foscararis vom 28. September 1551, dem Kardinal Morone sein Bistum in Modena ein Jahr vorher in einem Brief an den Herzog von Ferrara überliess, sind zwei Betrachtungen von Bedeutung, die unmittelbar diese Sichtbarkeit des Sakramentes der Heiligen Eucharistie betonen. Einerseits müsse das Konzil sorgfältig zwischen Häresie und Irrtum unterscheiden. Andererseits forderte Foscarari, dass vor der Kommunion die Beichte abzulegen sei, die aber weder göttlichen Rechts noch ein Kirchengebot sei. Zusätzlich legte er grossen Wert auf einen möglichst engen Anschluss der Tridentiner Artikel an frühere Konzilien. So sollte im ersten Artikel des Dekrets auf das Nicaeum, im fünften auf das Ephesium und schliesslich im achten Artikel auf die Konzilien in Konstanz und Basel verwiesen werden. ${ }^{161}$ Als Dominikaner und seit 1547 als Maestro del Sacro Palazzo tätig, über dessen Wahl sich der Kardinal Morone in einem Brief an Reginald Pole beklagte, war Foscarari für die Ausführung des im Jubeljahr 1550 veröffentlichten breve Julius‘ III., Cum meditatio coris nostri, innerhalb der Diözese von Modena zuständig. Dadurch bekam Foscarari die Erlaubnis, Priester und Ordensbrüder vor Gericht, und zwar in foro conscentiae, vorführen

160 COD, S. 694-695: ,[...] in Dei ecclesiam inductum fuisse hunc morem, ut singulis annis peculiari quodam et festo die praecelsum hoc et venerabile sacramentum singulari veneratione ac solemnitate celebraretur, utque in processionibus reverenter et honorifice illud per vias et loca publica circunferretur. [...] Commune hoc quidem est sanctissimae echaristiae cum caeteris sacramentis, symbolum esse rei sacrae et invisibilis gratiae formam visibilem; verum illud in ea excellens et singulare reperitur, quod reliqua sacramenta tunc primum sanctificandi vim habent, cum quis illis utitur, at in eucharistia ipse sanctitatis auctor ante usum est." $\mathrm{Zu}$ diesem Brauch vgl. die Bulle Papst Urbans IV. aus dem Jahr 1262, Transiturus de hoc mundo, in Corp. iur. can., II, S. 11741177. Der Konzilssekretär Angelo Massarelli verzeichnete in seinem Tagebucheintrag vom 4. April 1550 eine seitens der Bruderschaft des Gonfalone stattgefundene Prozession, welche die konziliaren Beschlüssen stark vorwegzunehmen schien: CT, II, S. 166.

$161 C T$, VII/1, S. 168-172. Vgl. auch das Votum Lippomanis in ibid., S. 173-175. Zeitgleich mit dieser Sitzungsperiode erschien der erste Band der Heiligenviten Lippomanis, welcher durch die Konzilsväter und Theologen starke Beachtung fand. Vgl. diesbezüglich das Briefschreiben Lippomanos an Marcello Cervini vom 5. Oktober 1551 in CT, XI, S. 654. 
zu dürfen. Dieses breve, zusammen mit einem weiteren, nämlich Illius qui misericors, welches am 29. April 1550 herausgegeben wurde, war als Katalog sogenannter „Gnadenedikte“ (editti di grazia generale) gedacht, die es der Penitenzieria Apostolica erlaubte, Beichtenden mittels einer geheim gehaltenen (segreta) Abschwörung und in enger Zusammenarbeit mit dem Santo Uffizio die Absolution erteilen zu dürfen. Foscarari konnte sich dadurch auf die Lesung von Büchern häretischen, und somit verdächtigen Inhaltes konzentrieren. Das zweite breve hingegen erlaubte den Gnadenerlass derjenigen, die sich beim Inquisitor freiwillig ihre Beichte abnehmen liessen. ${ }^{162}$ Die beiden Breven Papst Julius' III. waren somit deutlich gegen eine weitere Rezeption des Beneficio di Cristo, das insbesondere innerhalb der Ecclesia Viterbiensis zirkulierte, durch Prediger und Ordensmänner gerichtet. Die Verwaltung über den göttlichen Gnadenerlass wurde damit in die Hände einer Instanz der römischen Kurie gelegt, um die Sakramente der Busse und der Beichte sichtbar im römischen Stadtraum erfassen zu können. Diese sichtbare Mannigfaltigkeit der zwei für das Tridentinum somit wohl wichtigsten Sakramente sollte sich im Rom des del Monte-Papstes am prägendsten während einer päpstlichen Messefeier im Beisein des Sacro Collegio in Santa Maria sopra Minerva manifestieren, die im Tagebuch des Konzilssekretärs Angelo Massarelli erwähnt wird. ${ }^{163}$

Die Bedeutung dieser Feier scheint sich in der bisherigen Forschung zur Geschichte des Santo Uffizio nur marginal widergespiegelt zu haben. Das Zeremoniell der Abschwörung hat sich vor allem im Garten des Konvents der Dominikanerkirche von Santa Maria sopra Minerva ereignet, der als Tribunal zur Durchführung inquisitorischer Prozesse genutzt wurde, wie beispielsweise derjenige des Maestro del

162 Zum Brief Morones an Pole vgl. Mayer 2002/2008, Bd. 2 (2003), S. 22. Zu Foscararis Verwaltung von Modena ab 1550 vgl. die neusten Untersuchungen bei Felici 2010, S. 79-116; Fontaine 2006, S. 37-51 sowie Firpo 2014, S. 167-179. Vgl. dann entsprechend auch CT, IX, S. 533, wo Morone anscheinend auch einen regressus für Foscarari sicherte. Zu Egidio Foscarari selbst vgl. den Eintrag Simona Fecis sub voce in DBI, Bd. 49, 1997.

163 CT, II, S. 162: „[...] in festo annunciationis b. Mariae virginis, celebrata fuit missa solemnis pontificia in ecclesia b. Mariae supra Minervam iuxta consuetudinem hactenus in huiusmodi die observatam. Cui missae interfuit pontifex cum omnibus cardinalibus, eaque absoluta traditae fuerunt nuptui 150 virgines pauperes, quarum cuilibet dati sunt in dotem 150 floreni monetae antiquae, qui constituunt quadraginta aureos auri in auro, ipseque pontifex dedit manu propria cuilibet virgini marsupium unum ex serico albo cum dicta summa pecuniarum. Absolutionis ceremoniis suprascriptis pontifex recessit ex dicta ecclesiae Minervae profectusque est in arcem S. Angeli, comitatus ab omnibus cardinalibus ibisque pransus fuit. Deinde hora 23. reversus est palatium apostolicum“. Die Messzelebration fand am 25. März des Jubeljahres 1550 statt. Für die beiden brevi Julius“ III. vgl. Fontana, Documenti vaticani, S. 412-414 (Cum meditatio cordis nostri) sowie Mag. Bull. Rom., VI, S. 414-416 (Illius qui misericors). Hierzu dann Brambilla 2010, S. 381-387, und Prosperi 1997, S. 95-96, 222-223, der allerdings nur das zweite breve beachtet. Vgl. auch Simoncelli 1988, S. 9-11, sowie Tamburini 1990, S. 111-140, bezüglich der fundamentalen Rolle der Penitenzieria Apostolica unter der Leitung der Pucci-Kardinäle Lorenzo, Antonio und Roberto für die administrative Organisierung des Santo Uffizio. 
Sacro Palazzo Girolamo Muzzarelli gegen den Bologneser Juristen Annibale Monterenzi. ${ }^{164}$ Die Bedeutung dieser Messefeier lag vor allem darin, dass nun ein Kirchenraum für die Arbeiten der römischen Inquisition umfunktioniert wurde, in welchem das Santo Uffizio sein Tribunal einrichten und dieses erfolgreich mit dem römischen Messeritus verbinden konnte, indem es mit einer päpstlich zelebrierten missa solemnis gleichsam inauguriert wurde. Die Tätigkeit dieses Tribunals in Santa Maria sopra Minerva kann auch anhand der durch den späteren Kardinalsinquisitor Giulio Antonio Santori vorgelegten Schrift De persecutionis haereticae pravitatis historia aus dem Jahr 1556 rekonstruiert werden. Santori berichtet von zwei in seinem Beisitz abgehaltenen Prozessen aus dem Pontifikat Julius' III. Er assistierte den im Garten der Dominikanerkirche versammelten Kardinäle des Santo Uffizio erstmals am 16. März 1554 in der Abschwörung von „17 Häretikern, die gelbe Busskleidung und ein rotes Kreuz trugen und eine Brandfackel hielten“. Santori berichtet weiter, dass vor dem Ritus der Abschwörung eine Bussprozession durch die Strassen Roms vom Inquisitorenpalast im rione Ripeta nach Santa Maria sopra Minerva zog. Die Kirche sei dann vor allem einem starken Besucherdrang ausgesetzt gewesen, da ,jedem an dieser Busse und Abschwörung Anwesenden ein Plenarablass seiner Sünden vergeben wurde“. Das Zeremoniell der Abschwörung fing mit dem „Anzünden von Kerzen“ vor dem Notar an, woraufhin ein Kurienprälat mit der Lesung der siebzehn Verurteilungspunkte begann. Während der Lesung berührte und schwörte der im Bischofshabit gekleidete und die Mitra tragende Abt aus San Sebastiano, den ein Diakon sowie ein Subdiakon begleiteten, jeden einzelnen büßenden Häretiker ab, währenddessen die Mönche das Te Deum sangen. ${ }^{165}$ Die Mehrheit der singenden Mönche bestand aus den Mitgliedern der in der Kirche von Santa Maria sopra Minerva ansässigen Bruderschaft, die als erste römische Bruderschaft zur Verehrung des Heiligen Sakramentes der Eucharistie gegründet wurde. Wie bereits vorhin erwähnt, hatte sich Filippo Neris und Persiano Rosas Bruderschaft der SS. Trinità dei Pellegrini an diese überwiegend von Dominikanern zusammengesetzte Bruderschaft in Santa Maria sopra Minerva stark angelehnt. ${ }^{166}$

164 ACDF, S. O., Decreta, I, f. 33v, 101v-114r.

165 Santoris Schrift befindet sich in ACDF, Stanza storica, I 4-b, Collectanea Scripturarum ad Sanctum Officium pertinentium de anno 1557 usque ad annum 1615 praecipue quoad Inquisitionem in Regno Napolitani, 2, hier f. 4v-7r. Die Schrift wurde bislang nur von Ricci 2002, S. 54-68, untersucht. Erwähnt wird sie auch in DSI, Bd. 4, S. 1371. Eine spätere Abschrift in italienischer Übersetzung wird in BAV, Barb. lat. 4592, f. 139r, 140r-159v aufbewahrt.

166 Zur Bedeutung der Eucharistie für die römischen Bruderschaften im Cinquecento vgl. u. a. auch Marangoni, Vita Bonsignore Cacciaguerra, Appendice, S. 24: „L'anno 1548 alli 16 di agosto unitamente col suo Santo Discepolo, che era ancora Laico, ispirato da Dio, diede principio alla confraternita della SS. Trinità dei Pellegrini, e de' Convalescenti nella chiesa di San Salvatore in Campo (Marzio), chiamando seco fino al numero di quindeci compagni, tutti persone semplici e povere, ma ricche e piene di spirito, e divozione, con le quali si esercitavano in conferenze spirituali, per infiammarsi l'un l'altro col desiderio della Perfezione Cristiana. Esponevano poi ogni prima domenica del mese il Santissimo Sacramento, ove S. Filippo sermoneggiava con gran frutto [...]“. Es ist 
Der Farnese-Papst Paul III. hatte die Confraternita di Santa Maria sopra Minerva bereits 1539 mit der Bulle Dominus Noster Jesus Christus offiziell anerkannt und diese zum Vorbild für weitere Gründungen von solchen Bruderschaften in den Diözesen Italiens erhoben. Die Bruderschaften, welche zur Verehrung des Heiligen Sakraments der Eucharistie gegründet wurden, hatten schliesslich der strukturellen Verwirklichung des Tridentiner Dekrets zur Eucharistie verholfen, indem deren Verehrung die sozialen Schichten durchdrang. Die Anerkennungsbulle des Farnese-Papstes fusste auf einer besonderen Theologie der Aufbewahrung der Hostie innerhalb des Kirchenraumes, die einen ehrwürdigem Platz im Kirchenraum von Santa Maria sopra Minerva bekam und dessen Pflege (cura) den confratres der Bruderschaft zugewiesen wurde. Die Aufbewahrung des Heiligen Sakramentes wurde entsprechend auch für die Feierlichkeit des Leichnams Christi (Corpus Domini) eingesetzt. ${ }^{167}$ Die cura sacramentorum sah zusätzlich vor, dass die Hostie bei brennendem Kerzenlicht über dem Altar während der ganzen Nacht ausgestellt blieb. Dieser Forderung kamen ursprünglich auch die zeitgleich vom Architekten Antonio Sangallo il Giovane in Angriff genommenen Eingriffe im Chorraum von Santa Maria Sopra Minerva, die für die Errichtung der beiden Papstgrabmäler Leos X. und Clemens' VII. vorgesehen waren, sehr nahe. Die hierfür überlieferten Entwürfe Sangallos zur neuen Choranlage sahen die beiden Grabmäler im Vorchorjoch vor, während das Chorgestühl innerhalb einer dreiviertelkreisförmigen Apsis aufgestellt sein sollte. Diese auf das Vorhaben Clemens' VII. zurückgreifenden Umstrukturierungen des Chors zeigen ein deutliches Bestreben, diesen $\mathrm{zu}$ einer capella papalis umfunktionieren zu wollen. ${ }^{168}$ Die Florentiner Compagnia della Nunziata beseitigte dafür das Hochaltarretabel und stellte das Sakrament in einer Monstranz auf dem Hochaltar aus. Am Festtag der Santissima Annunziata wurde der Raum mit dem im

nicht schwer zu erkennen, dass Neri, der zu diesem Zeitpunkt noch keine Kirchenwürden besass, rasch unter die Beobachtung des Santo Uffizio geraten wäre, wäre die Bruderschaft nicht unter der Leitung Persiano Rosas aus San Girolamo della Carità, Neris Beichtvater, gestanden.

167 Bull. dipl. rom., VI, S. 276: „[...] quod confratres confraternitatis huiusmodi pro tempore existentes, seu ab eis per singulas regiones urbis praedictae deputati aut deputandi, diligenter ac omni cura et studio facerent et procurarent ut Sacramentum huiusmodi, tam in dicta Minerva quam singulis aliis parochialibus ecclesiis Urbis huiusmodi, ea qua decet veneratione, in loco onorifico et honesto, lampadibus accensis, die noctuque conservaretur et custodiretur. [...] Ac quod utriusque sexus personae confraternitatis huiusmodi confratres pro tempore existentes tertia quaqu die dominica cuiuslibet mensis totius anni, in dicta ecclesia de Minerva congregari, et inibi unam missam in cantu vel alias celebrari facere, ac in elevatione praefati Sacramenti faces accensas habere deberent. Necnon prima die Veneris statim post festum Corporis Christi immediate sequenti, solemnem processionem extra et circum praefatam ecclesiam de Minerva, Sacramentum praedictum honorifice, facibus, deferendo, annuatim facere“.

168 Vgl. Kleefisch-Jobst 1988, S. 528-534, sowie Frommel 1977, S. 46-51, wo deutliche Gemeinsamkeiten zwischen Sangallos Apsis und den Planungen Papst Julius‘ II. für sein eigenes Grabmal in der Peterskirche erwähnt werden. Zum Plan, den Chor zu einer capella papalis umzuwandeln, vgl. ferner Bredekamp 1998, S. 264; Frommel 2001, S. 320 und Goetzmann 2005, S. 179-180. 
Chor sitzenden Papst und dem Kardinalskollegium zu einer capella papalis umgewandelt. ${ }^{169}$ Offensichtlich musste dieser Plan während des Folgepontifikates Julius III. noch lebendig verfolgt worden sein. Er fiel aber nun zum Nutzen des Santo Uffizio und nicht mehr länger zu Gunsten der Bruderschaft des Santissimo Sacramento aus. Wie die entsprechenden Kapitel aus den Statuten der Bruderschaft zeigen, hätte die aufbewahrte Hostie am Hauptaltar bei brennendem Kerzenlicht vor dem Chorgestühl platziert werden sollen. Durch die neue Chorapsis wäre schliesslich eine ideale Nähe des Betrachters zum Sakrament sowie zum Zelebranten erreicht worden. Die Forderung, dass das Sakrament über Nacht bei brennendem Kerzenlicht aufbewahrt werden sollte, sollte jedoch weit mehr einer theologischen Überzeugung nahekommen, die den sinnlich sichtbaren Charakter des Sakramentes als ein nicht im Glauben verborgenes Geheimnis artikulierte. Es erstaunt daher nicht, dass gerade der Dominikaner und 1554 zum Bischof von Capodistria ernannte Tommaso Stella, welcher auch Mitglied der Bruderschaft von San Girolamo della Carità war und der als hauptsächlicher Gründer der Confraternita del Santissimo Sacramento von Santa Maria sopra Minerva gilt, in den Statuten und ersten Kapiteln der Bruderschaft diese Forderung der Bestätigungsbulle sogar noch stärker zu befolgen beabsichtigte, indem ,an Festtagen das Kerzenlicht verdoppelt und an den höchsten Festen sogar verdreifacht werden sollten“. ${ }^{170}$ Seit den Tridentiner Sitzungen zum Rechtfertigungsdekret befand sich Stella im engsten Umkreis von Kardinal Marcello Cervini. Insbesondere war er an der in Bologna päpstlich eingerichteten „severissima Inquisitione contra questi tristi lutherani“, wie es im bereits erwähnten Brief Lippomanos an Cervini vom November 1547 erwähnt wird, tätig. Dadurch erlangte Stella die ihm später von Papst Julius III. am 18. März 1550 verliehene Autorität, „in die Kirche zurückkehrende Häretiker“ (absolvendi haereticos revertentes

169 Zur liturgischen Nutzung des Chores AGOP, Cronica Breve dalla Chiesa e Convento della Minerva dell'Ordine dei Predicatori, Romae, lib. C, Pars prima, f. 16r: „[...] im tempo di Papa Paolo 3 essendo instituita la Compagnia del S(antissi)mo Sagramento come si dià più di sotto il Sagramento fu collocato con maggiore onore sopra l'Altare grande dietro alquale fu trasferito il Coro alla cui spesa concorse largamente la Compagnia della Nunziata massime perche in Coro doveva risiedere il Sommo Pontefice con il Colleggio dei Cardinali facendo Cappella Papale il giorno della Nunziata come (h)anno fatto molti anni [...]“. Clemens VIII. sollte diese Chorkapelle später bei seinen visite während des Jubeljahres 1600 auf der Finanzierungsgrundlage Ferdinands I. de“ Medici restaurieren lassen: Palmiero/Viletti 1989, S. 132.

170 Capitoli, statuti et oridnationi della venerabile compagnia del sacratissimo Corpo di Christo, $\mathrm{n}$. p. (Quale sia il principale carico delli Signori Administratori \& Officiali): „Che il santissimo Sacramento del Corpo di Christo sia conservato con conveniente honore \& reverentia nella Chiesa della Minerva, ove la compagnia nostra ha havuto principio, \& sempre giorno \& notte vi siano le lampadi accese dinanzi all'altare, le quali nelli giorni di festa siano duplicare, \& nelle piu solenni siano triplicate“. Dass dieser Brauch auch während des Pontifikates Julius’ III. noch lebendig war, zeigt sich in der päpstlich erlassenen Bulla piae, ac vniuersalis Societatis Sacratissimi Corporis Domini Nostri Iesu Christi, in Sacra Aede super Mineruam, Ordinis fratrum praedicatorum institutae aus BAV, Stamp. R.I.IV.1783A, c. 126v, die wahrscheinlich in das Jahr $1550 \mathrm{zu}$ datieren ist und womöglich in der Druckerei Antonio Blados herausgegeben wurde. Vgl. hierzu auch Rusconi 2008, S. 14-15. 
ad gremium Ecclesiae) absolvieren zu dürfen. ${ }^{171}$ In seiner Eröffnungspredigt zur sechsten Sitzung des Tridentinums vom 13. Januar 1547 hatte Stella das vom Konzil erlassene Rechtfertigungsdekret mit dem Festgeheimnis der Epiphanie verbunden. Die Geschenke der Magier - Gold, Weihrauch und Myrrhe - legte Stella als göttliche Geschenke der caritas aus, die Gott der düsteren Seele verliehen habe. Im Fest der Heiligen Drei Könige liessen sich diese Geschenke nun symbolhaft erschliessen. Wie die Magier, so rät Stella den Bischöfen am Konzil, den Gläubigen den Weg zu Christus durch ihre gelebte Lehre von der Gnade und der Rechtfertigung vorzuzeigen. Diesen Überzeugungen folgte auch Girolamo Seripando in seinen bereits diskutierten Predigten zum Pater noster. Die Wirkung, die Stellas Predigt zeigte, lässt sich anhand der kurzen Ansprache des Konzilsvorsitzenden nachvollziehen, in der das Rechtfertigungsdekret an das Epiphaniefest anknüpft und mit diesem die Überwindung des Dunkels durch das neue Licht feiert. ${ }^{172}$

In den Katalog der Magier-Geschenke, die nach Stella als sichtbare Zeichen der Gnade und der Rechtfertigung zu deuten sind, lässt sich auch das Aufstellen und Anzünden von Kerzen als Zeichen liturgischer Verehrung gegenüber dem Sakrament der Eucharistie einordnen. Erasmus griff in seinem Lob der Torheit von 1511 diesen Brauch bereits auf und verband ihn mit der Bilderverehrung: „Wie gross ist doch die Menge derer, die der jungfräulichen Gottesmutter ein Wachslichtlein anstecken, und noch dazu am Mittag, wenn es keinesfalls nötig ist?“173 Tommaso Stellas Forderung, dass das Sakrament der Heiligen Eucharistie auch nachts mit Kerzenlicht aufbewahrt werden sollte, findet sich in Johannes Molanus' Aussage wieder, dass „die sinnhaften Lichter, Zeichen jenes immateriellen und von Gott gegebenen Lichtes seien“. Die Bräuche der römischen Bruderschaft des Santissimo Sacramento unter der Federführung des Dominikaners Tommaso Stella nehmen bewusst eine Debatte auf, die seit der Schrift des Kirchenvaters Hieronymus gegen Vigilantius die Kontroverstheologie des Cinquecento dominierte und auf die sich auch Erasmus in seiner Kritik am Auf-

171 Buschbell 1910, S. 289; Quaranta 2010, S. 289 sowie Carcereri 1911, S. 20. Zu den Vollmachten Stellas hinsichtlich der Abschwörung von Häretikern vgl. CT, II, S. 160-161.

172 CT, V, S. 790-820. Vgl. auch Black 2003, S. 96, der sich nicht nur in der Datierung von Stellas Predigt irrt, sondern auch meint, die Sitzungsperiode zu den Sakramenten hätte in Bologna stattgefunden. Zu den weiteren Predigtzyklen Stellas in Bologna und später auch in Venedig vgl. dann CT, I, S. 663, 713, 723. Morone wird auch Stellas non placet während den späteren Konzilsdebatten um die Bischofsresidenz unterstützen, in denen die Residenzpflicht nicht als ius divinum bezeichnet wird. Vgl. diesbezüglich die Briefkorrespondenz Morones mit Stella in ASV, Conc. Trid. 42, f. 287r288v, sowie Stellas Antwortschreiben an Morone in ivi, f. 302r-303v. In dieser Hinsicht sind auch Egidio Foscararis Beobachtungen zu den Meinungsverschiedenheiten der beiden Parteien in ASV, Conc. Trid. 42, f. 255r-256v, 267r-272v, 273r-274v, zentral. Vgl. dann Jedin 1949-1975, Bd. 4/1, S. 214-215; Fragnito 1988, S. 347 und die neusten Untersuchungen bei Robinson 2012, S. 122-129.

173 Erasmus, Moriae encomium, S. 134: Quanta turba eorum, qui deiparae virgini cereolum affigunt, idque in meridie, cum nihil est opus? Zit. n. Hecht 2012, S. 148 (Anm. 125). 
stellen von Kerzen bezog. ${ }^{174}$ Folgt man der Schrift des Kirchenvaters, so lässt sich auch im Kerzenlicht der nun dargebrachte Gnadenerlass Christi zeigen, der ebenfalls in der Apostelgeschichte gemäss dem Markus- sowie Matthäusevangelium überliefert wird. Hieronymus führt die Salbung in Betanien als einen der Gründe auf, weshalb unwissenden Menschen, die Kerzen zu Ehren der Märtyrer anzündeten, derselbe Gnadenerlass zustünde, den Jesus der Frau, die ihn salben wollte, vergab. In der Auslegung Hieronymus' taucht hier eine besondere historische Dimension bezüglich der Entstehung des Christentums auf, indem „ein Christenmensch nicht geboren wird, sondern aus einer Wiedergeburt entsteht“: Non enim nascimur, sed renascimur christiani. Et quia quandam colebamus idola, nunc Deum colere non debemus; ne simili eum videamur cum idolis honore venerari? Illud fiebat idolis, et idcirco detestandum est: hoc sit martyribus, et idcirco recipiendum est. ${ }^{175}$ Das Heidentum musste somit verurteilt werden, weil es falsche Vorbilder (idola) anbetete. Im Christentum würden indessen die Zeugen des wahren Gottes verehrt.

In diesen Debatten mangelte es jedoch an einer genauen Darstellung, wie dieser liturgisch-zeremonielle Brauch innerhalb der frühchristlichen Patristik ausgelegt wurde. Anhand einer solchen Aufdeckung der liturgischen Verwendung des Kerzenlichts sollte sich der römisch-petrinische Primatsanspruch und dessen Konti-

174 Vgl. Molanus, De Picturis, c. 67r: „Sensibilia lumina, symbolum sunt immaterialis illius, \& a Deo dati, luminis [...]“. Der Bezug auf Hieronymus, Contra Vigilantium, in: PL, Bd. 23, Sp. 353-368, hier 360-361, findet sich wieder bei Erasmus, Apologia brevis, IX, S. 1156. Vgl. dann auch Minnich 1988, S. 379-413 sowie Freedberg 1971, S. 229-245. Ambrogio Catarino Politi, ein enger Mitarbeiter Stellas, führt den Brauch ebenfalls in der Ostkirche gemäss Hieronymus' Schrift durch, wo das Kerzenlicht vorerst nicht dazu diente, die Finsternis zu vertreiben, sondern als „Zeichen der Freude“ (signum laeticiae) erachtet wurde: Catharinus, De certa gloria, II, S. 81. Zur Bekanntschaft zwischen Stella und Politi vgl. die Aussagen des Theatiners Bernardino Scotti, einem weiteren engen Mitarbeiter Cervinis innerhalb des Santo Uffizio während des del Monte-Pontifkates, im Prozess gegen Kardinal Morone in Firpo/ Marcatto 2011, Bd. 1, 236-237: „[...] o da esso monsignor Catharino o veramente (il che mi pare più vero) da monsignor di Capo d'Histria, detto il Todeschino [Tommaso Stella], che il prefato reverendissimo Morone parlando col reverendissimo cardinale di Mendoza, alias di Burgos, li hebbe a dire che il [...] decreto [tridentino] de giustificatione non stava bene et che bisognava ritirarlo“. Auch zit. in Firpo 2014, S. 220. Vgl. weiter den Brief Stellas an Marcello Cervini vom 8. Oktober 1548 in Buschbell 1910, S. 275-276. Die Ergebnisse hierzu finden sich in Fragnito 2005, S. 37, und Caravale 2007, S. 57.

175 Mk 14: 3-9 und Mt. 26: 7-12. Hieronymus, Contra Vigilantium, in: PL, Sp. 345-346. Dass die Diskussion während den 1540er Jahren auch seitens der Reformatoren stark debattiert wurde, bezeugt Calvins Traité des reliques von 1543, in welcher der Genfer Reformator polemisch das Argument des Kirchenvaters umdrehte und so aufführte, dass Frauen, die Kerzen anzündeten, dies aus unverschämtem Eifer täten, woraus dann zu schliessen sei, dass dieser Brauch als Idolatrie bezeichnet werden könne. Vgl. hierzu die entsprechende Stelle in Calvin, Traité des reliques, S. 20-21: „Si l'idolâtrie n'est sinon transférer l'honneur de Dieu ailleurs, nierons-nous que cela ne soi l'idolâtrie? Et ne faut excuser que ce a été und zèle désordonné de quelques rudes et idiots ou de simple femmes. Car ce a été un désordre général, apprové de ceux qui avaient le gouvernement et conduit de l’Église“. 
nuität mit dem Frühchristentum von der protestantischen Kritik solcher caeremoniae trennen lassen. Allerdings wiesen die Tridentiner Konzilsdekrete kaum eine patristische Begründung der Liturgie auf. Anlässlich dieser Schwäche dieser Dekrete zögerten die Magdeburger Zenturiatoren nicht, den Anspruch zu erheben, dass das Anzünden von Kerzen als eindeutiger Bruch mit der alten Kirche zu betrachten sei. Cesare Baronio widmet sich im ersten Band seiner Annales Ecclesiastici somit nicht nur dem liturgischen Brauch des Kerzenlichts im Kirchenraum bezüglich der Auslegung in Hieronymus' Contra Vigilantium, sondern diskutiert dieses officium innerhalb eines mannigfachen Geflechts verschiedener spätantiker und frühmittelalterlicher Texte. Neben der Wiedergabe von Hieronymus' Interpretation findet sich in den Marginalen zum ersten, schriftlich verfassten Manuskript der Annales eine ergänzende Erläuterung zur Bedeutung dieses Brauchs und eine Erklärung, weshalb gemäss christlicher Übersetzung dies als ein heidnischer und damit abergläubiger Ritus zu betrachten sei. Baronio versteht das Anzünden von Kerzen im ersten Band seiner Annales „als ein gänzlich von einfältigen Menschen oder von solchen, die einen nichtwissenden Eifer besitzen, fernes Zeremoniell““. ${ }^{176}$ Baronio war somit bereit, dem Kirchenvater Hieronymus einen bedeutsamen Fehler zuzuschreiben, der in der Forschung bislang nur philologisch in Hinblick auf Baronios Umgang mit der Patristik untersucht wurde. Wie sich aber weiter in der Marginalie zeigt, hat vor allem der Umstand, dass der Brauch in der Ostkirche nicht mit demjenigen der römischen Kirche übereinzustimmen schien, Baronio grosse Schwierigkeiten bereitet. In der Drucklegung des ersten Bandes seiner Annales liess er daher diese Problematik aus, woraufhin ihn der damalige Maestro del Sacro Palazzo, Vincenzo Bornardo, darüber ermahnte, dass das in die Dunkelheit des Kirchenraumes strömende Licht

176 BAV, Vat. lat. 5684, f. 335r-v: „Quod vero dicat cereos non incendi solitos die, nisi in ecclesiis Orientis, quod in sup. addat de cereis honore martyrum incendi solitis, idque totum tribuat secularium hominum simplicitati, vel feminarum zelo non secundum scientiam: scabrosus plane locus est; quem non nisi levi offensa Hieronymi, quis inoffenso pede valeat penitus superare. Certe quidem perspicitur quod in fine eiusdem scriptionis habet, se tabellario properante scriptionem illam unius noctis brevi lucubratiunculam dictasse, pollitcitus nimirum si ea ad compescendum hominis procaciam non sufficissent, rursus in eundem omne studium impensurum. Quamobrem sicut properantis hominis non est omnia facile pervidere vel omnium reminisci: brevi illo temporis [...] illum multa praeterivisse oportuit. Sit in exemplum, quod in eodem libro dixit reliquias Andrea, Lucae, et Thimothei translatas esse a Constantio Constantinopolim, immemor se in libro quem antea scripserat de autoribus ecclesiasticis, id factum anno vigesimo Constantinii tradidisset. Constantinii enim ut habet verior lectio et non Constantini legenda est: nam non tantum spectum habetur, ex rei gestae historia, sed eiusdem Hieronymi testimonio, qui in appendice sui chronici ad Eusebium id factum sub Constantio manifeste testatur“. Vgl. hierzu jüngst Tutino 2014, S. 75-83. Die Zenturiatoren widmeten sich diesem Brauch nur betreffend der Märtyrerverehrung: Ecc. Hist., IV, cap. XIII, sowie ibid., V, cap. VI. Zur kirchenhistoriographischen Problematik der translatio imperii, die als Träger einer traslatio officii et caeremonii zu bezeichnen ist, vgl. infra, Kap. 2.3. 
als Metapher der Ankunft Christi im agnus dei auszulegen sei, wodurch sich schliesslich auch das nächtliche Anzünden von Kerzen über dem Kirchenaltar rechtfertigen liesse. ${ }^{177}$ In dieser überarbeiteten Darlegung des Anzündens von Kerzen im ersten Band der Annales kommt eine besondere Affinität zwischen der bruderschaftlich vorgeprägten Verehrung des Sakramentes der Heiligen Eucharistie und Baronios Auslegung der patristischen Überlieferung zum Vorschein. Die Verwandtschaft zwischen der Sakramentsverwaltung der Eucharistie und der Patristik nutzte Baronio letztlich dazu, um die Überlieferung eines römischen Ritus, der seit dem frühen Christentum bestanden hatte, historiographisch nachzuzeichnen. Diese kirchenhistoriographische Rekonstruktion sollte schliesslich die bisherige, seitens des Santo Uffizio beanspruchten Verwaltung dieser Liturgie absetzen. Die Neuorganisation sowohl des Santo Uffizio als auch der Penitenzieria Apostolica im Pontifikat Julius‘ III. hatte zur Folge, dass ein liturgisches Zeremoniell innerhalb der römischen Stadttopografie mithilfe einer Bruderschaft, die enge Beziehungen zum Maestro del Sacro Palazzo selbst gestiftet haben musste, eingeführt werden konnte. Eine solche liturgische Ausgestaltung des Santo Uffizio musste dann die weiteren Bruderschaften Roms beeinflusst haben, zumal sich am Beispiel Tommaso Stellas eine deutliche Annäherung der Confraternita di San Girolamo della Carità an die Strukturen der Confraternita del Santissimo Sacramanto von Santa Maria sopra Minerva feststellen lässt. Der Eintritt des Dominikaners Stella in die Bruderschaft von San Girolamo della Carità im Jahr 1554 führte dazu, dass die Verehrung des Heiligen Sakramentes der Eucharistie verstärkt gepflegt wurde, und zwar mittels den qua-

177 Ann. Ecc., I, S. 519: „Certe quidem testimonio etiam Vigilantiis, moles, ut ait, cereorum Sole fulgente, accendi solere in ecclesiis, satis liquet: licet ipse pium cultum derideat; perinde ac si id fideles facerent ad martyres illuminandos. In quem haec iure Hieronymus: Cereos non clara luce accendimus (sicut frustra calumniaris) nimirum ut hoc pietatis officio putemus martyres e tenebris vindicari, quorum lucerna est Agnus. Sed mysterium docet, scilicet sic facere, ut (quod sequitur) noctis tenebras hoc solatio temperemus: nempe (quod ait Apostolus) Nox pracessit, dies autem appropinquavit, abiiciamus ergo opera tenebrarum, \& induamur arma lucis. Ac proinde (quod subdit) vigilemus ad lumen, ne caeci tecum dormiamus in tenebris. Perstat enim in metaphora, qua superimus iam quorto eundem non Vigilantium, sed Dormitantium nominarat [...] Nam quonam pacto negasse potuit, interdium a fidelibus accendi lumina, qui paulo post de toto Oriente, ubi ipse agebat, haec ait: Per totas Orientis ecclesias quando legendii est Evangelii, accenduntur luminaria, iam sole rutilante, non utique, ad fugandas tenebras, sed ad signum laetitiae demonstrandum. Immo \& id ipsum factitari solitum in ecclesia Hierosolymitana, sub qua vivebat ipse Hieronymus [...]“. Vgl. zum Einspruch Bornardos dann Baronios Briefschreiben an Antonio Talpa vom 4. März 1588 in Alberici, Epistolae et opuscula., III, S. 22-26, hier 24: „Tutte simili obiettioni sono state fatte al R. P. Bernardi Compagno del Mastro Sacri Palatii, a tal fine è rimasto capace della ragione; pur mi affatigarò, se si potesse detta objetione in qualche modo mitigare, overo per dir il veri, impistrare. Che in vero non fà bon sono alle orecchie pie“. Hinsichtlich der Einschätzung des philologischen Umgangs Baronios mit der patristischen Überlieferung vgl. Zen 1994, S. 229-230, sowie die Rezension in Fubini 2003, S. 360-371. 
rant'ore, die dann auch für die Confraternita della SS. Trinità dei Pellegrini eingeführt wurden. ${ }^{178}$

Filippo Neris Vorstellung, die bruderschaftlichen Bindungen in San Girolamo della Carità möglichst unabhängig von einem regulierten Rahmen im Zusammenhang mit dem römischen Ritus zu gestalten, zielten daher darauf, möglichst nicht durch die römische Inquisitionsbehörde der Häresie angeklagt werden zu können, wie dies im Fall Kardinal Giovanni Morones geschehen war. Neri hatte nämlich in den Eingriffen der Kurie hinsichtlich der Gestaltung des bruderschaftlichen Zusammenleben selbst eine Gefahr erkannt. Die Gründung des frühen Oratoriums als eine Gemeinschaft von Priestern, die sich frei von internen Regulierungen um die Figur Neris bildete, konnte sich daher erst ab dem Pontifikat Pius' IV. tatsächlich zu realisieren begonnen haben. Im frühen Stadium der Entstehung hatte sich das Oratorium Neris nicht auf die Verehrung des Heiligen Sakramentes der Eucharistie als in bruderschaftlicher Kommunion zelebriertes officium konzentriert. Vielmehr nahm die private Beichte, die Neri selbst seinen Mitbrüdern abnahm, einen weit zentraleren Stellenwert ein. An dieser konnte Cesare Baronio nicht vor seiner Priesterweihe teilgenommen haben. Diese frühe und ausschliesslich auf die Beichte konzentrierte Oratorium begann sich in der Florentiner Nationalkirche von San Giovanni ab deren Fertigstellung im Jahr 1564 allmählich zu festigen. Daher kann erst ab diesem Zeitpunkt von einem tatsächlichen Eintritt Baronios in diese Zusammenhänge bruderschaftlicher sodalitas gesprochen werden, die ein neues Verständnis des Priesteramtes zu entfalten begann.

\subsection{Das Oratorium als neuer Priesterbund im Rom Pius’ IV}

Io me ne stò qui in S. Giovanni con molta mia maggior consolatione, che quando stava, dove era prima. Qui vivemo sei preti in vita tranquilla et attendemo alla salute dell'anime, e per gratia di Dio siamo quasi adorati per la gran riverenza et osservanza qual tutti c'hanno. ${ }^{179}$

Der Widmung an den Aldobrandini-Papst Clemens VIII. im vierten Band der Annales Ecclesiastici fügte Cesare Baronio eine weitere Widmung hinzu. In dieser zweiten Widmung, die er für den Bischof von Alessandria, Ottavio Paravicini, verfasste, ging Baronio erstmals auf die Entstehung einer Idee des Oratoriums in San Giovanni dei Fiorentini ein. Dieses erste Oratorium, das in der Nationalkirche der Florentiner eingerichtet wurde, besass eine Regola, die dem Priesterbündnis Neris erstmals eine feste, institutionelle Struktur verlieh. Das Zentrum des bruderschaft-

178 ASR, San Girolamo della Carità, 221, Liber secundus decretorum (1542-1566), f. $136 \mathrm{v}$.

179 BVR, Q 46, f. 40r, Cesare an den Vater Camillo Baronio, Rom, 24. September 1564. 
lichen Lebens dieser Oratorianerpriester in San Giovanni dei Fiorentini nahmen die nachmittäglichen Sitzungen ein, während denen Predigten zu ausgewählten Heiligenviten gehalten wurden. ${ }^{180}$ Baronio betrachtete dieses frühe Oratorium als ein auditorium, das den Weg einer erfolgreichen Kurienlaufbahn Ottavio Paravicinis ebnete. Gemäss Paravicinis eigener Zeugenaussage vom 29. November 1600 zum Heiligsprechungsprozess Neris musste das Oratorium dem späteren Bischof und Kardinal seit seiner Jugend bekannt gewesen sein, denn sein Vater war anscheinend mit Neri befreundet. ${ }^{181}$ Diese Bekanntschaft Neris mit der Familie Paravicini bleibt jedoch ungesichert und war der hauptsächliche Grund für eine hagiographische Stilisierung von Baronios frühen Jahren in Rom. Bislang ging die Forschung davon aus, dass Neri Baronio als Lehrer in den Familienhaushalt der Parravicini einbrachte. ${ }^{182}$ Dass Baronio ein Jahr nach seiner Ankunft in Rom ausgerechnet in diesen Haushalt eintrat, muss sich aus den engen Bindungen ergeben haben, welche diese Familie zum damaligen studium urbis und insbesondere zum dortigen Collegio degli Avvocati Con-

180 Ann. Ecc., IV, n. p. (Octavio Paravicino S.R.E. Presbytero Cardinali Amplissimo): „[...] discendi anumum tuum res gestas sanctorum Patrum quotidianis sermonibus instillarem, quas in nostri Oratorii auditorio mira venustate atque lepore, magna audientium voluptate ac plausu consuevisti annis pluribus recitare, admirantibus cunctis in puerili aetate senilem in dicendo maiestatem atque facundiam, iunctamque cum simplicitate prudentiam. Talibus namque tantisque primordijs tua meruit pueritia consecrari: cum \& non unius Chironis manus, sed certatim plurium sanctissimorum virorum fedulitas, summa industria, \& assidua solicitudo, longo tempore ad pulcherrimum virtutis exemplar te componere atque efformare studuerint. At cum adolevit aetas maiore incremento propagata virtutum: optime accidit, ut antequam conijcere posset in te oculos Aeqyptia petulans; virgo illa castissima non habens maculam neque ruga, Dei Ecclesia te suis praevenerit optatis amplexibus, arctoque amoris nodo devinxerit, cum sacris ordinibus obligavit; astrinxerit vero tenacius, cum ut primum per aetatem licuit, te sibi adiunxit in sponsum spiritualium foedere nuptiarum: cuius sacri connubij pronubum esse voluit magnum illum Mediolanensis Ecclesiae Archiepiscoporum, S. R. E. Cardinalem dignae memoriae, Carolum Borromaeum“. Auch abgedruckt in Alberici, Epistolae et opuscula, I, S. 359-361.

181 Primo Processo, II, S. 273: „Notus mihi divina gratia esse coepit Philippus Nereus ab anno sexto circiter aetatis meae, a quo tempore conversatione et colloquiis illius familiariter ac assidue frui datum est [...]“. Ottavio Paravicini wurde 1552 geboren, was eine Bekanntschaft mit Neris Umkreis frühestens auf ab dem Jahr 1558 vermuten lässt, da dies mit Neris offiziellem Eintritt in die Bruderschaft von San Girolamo della Carità übereinstimmt. Mit der weiteren Zeugenaussage vom 4. Januar 1611 lässt sich diese Datierung weiter bestätigen, da Paravicini anscheinend bereits mit vier Jahren Neri gekannt hatte. Baronio wird in dieser Zeugenaussage ebenfalls erwähnt: ibid., IV, S. 96. Zu Paravicini vgl. insbes. den Eintrag Tabacchis sub voce in DBI 2014, Bd. 81; Cosola 1991. Paravicini sollte unter Papst Sixtus V. die Nuntiatur für die Helvetische Republik erhalten haben, die Cosola eingehend entlang der reichen Briefkorrespondenz beschreibt. Vgl. auch Giordano 2006, S. LXXXIII, 20, 38. Neuere Untersuchungen finden sich dann bei Fattori 2004, ab indic.; Jaitner 2004, S. 322; Reinhard 2004, ab indic., sowie bei Pinto 2009, S. 153-158. Sein Vater, Giovanni Michele Paravicini, starb 1565 und wurde in Santa Maria della Pace begraben: Forcella, Iscrizioni delle chiese e d'altari, V, S. 495, Nr. 1307.

182 Calenzio, Vita, S. 22-24; Pullapilly 1975, S. 13-16; Bonadonna Russo 1984, S. 439-53. 
cistoriali pflegte. ${ }^{183}$ Es wurde bislang angenommen, dass seine Annales Ecclesiastici bereits im Umfeld der Parravicini begonnen worden seien. In seiner Widmung an den späteren Kardinal und Bischof Ottavio Parravicini verwendet Baronio die Wortwendung fructus et arbore, mit welcher er sich an seine Zeit im Haushalt der Parravicini erinnert. Diese Wortwahl kann so ausgelegt werden, dass mit Baronios Eintritt in diese Familie seine Laufbahn in den Umkreis der römischen Kurie gelangte, von wo aus sie - wie ein Baum - weiter gedeihen konnte. Baronio sprach damit ein soziales Umfeld an, dem er seine eigene erfolgreiche Karriere in der Kurie zu verdanken hatte und das der junge Ottavio Parravicini über den Vater Giovanni Michele seit seiner Jugend gekannt haben musste. Dieses soziale Umfeld im Rom der Mitte des Cinquecento lässt sich einerseits aus seiner Beteiligung an der Einsetzung einer Heilig-GeistBruderschaft in seiner Heimatstadt Sora rekonstruieren. Die institutionellen Strukturen dieser Bruderschaft leiteten sich nämlich von denjenigen des römischen Hospitals von Santo Spirito in Sassia ab. Andererseits konstituierte sich dieses Netzwerk Baronios auch aus seiner Bekanntschaft mit dem Juristen Cesare Costa, welcher in der von Pius IV. eingesetzten Kommission zur Verbesserung des Corpus Iuris Canonici tätig war. Zunächst soll die Bedeutung des Hospitals von Santo Spirito in Sassia und der dortigen Bruderschaft für das Rom des ausgehenden Carafa-Pontifikates erläutert werden. Baronio erwähnt in seiner überlieferten Briefkorrespondenz mit seinem Vater sowohl das Hospital als auch die Bruderschaft von Santo Spirito mehrmals. Auf den Stellenwert, welcher den Correctores Romani in Baronios Laufbahn zukam, soll hingegen erst später eingegangen werden. Die Bedeutung dieser Kardinalskommission, die ein neues Corpus Iuris Canonici herausgeben sollte, für Baronios Werdegang hängt mit einer richtungsweisenden Veränderung, die innerhalb der Kurie nach dem Tod Papst Pauls IV. stattfand, zusammen. Sie begann sich mit der Freilassung Morones aus Castel Sant' Angelo anzubahnen, zeigte sich aber vor allem im ersten Romaufenthalt des Papstneffen Carlo Borromeo. Die Anwesenheit des zuvor zum Kardinal ernannten Papstneffen hat die weitere Entwicklung von Neris Beichtkreis nachhaltig beeinflusst.

In einem langen Briefschrieben vom 16. Dezember 1560 teilt Cesare Baronio seinen Eltern die Entscheidung mit, dass er die Weihen zum Subdiakonat anstreben wolle. 1558 hielt sich Baronio für kurze Zeit bei seinen Eltern in Sora auf, vermutlich wegen des Konflikts zwischen den sbirri und den Apostaten. Ein Jahr danach kehrte er wieder nach Rom zurück, wo ihn sein padre spirituale, den Baronio in seinem Brief an die Eltern aber nicht bei Namen nennt, davon überzeugen konnte, die erste der höheren Weihen anzustreben. „Seit drei Jahren“ dachte Baronio darüber nach, „entweder dem Orden der Kapuziner oder einem anderen Orden der Observanten

183 BAV, Ott. lat. 2552, f. 369r-374r. Zum Collegio degli Avvocati vgl. Adorni 1995, S. 294. Zu dessen weiterer Entwicklung insbes. unter dem Chigi-Pontifikat Alexanders VII. zuletzt Pampalone 2014, S. 15-22. Folgt man der frühen Briefkorrespondenz Baronios, so musste der Haushalt der Paravicini einen reichen Eindruck hinterlassen haben. Vgl. hierzu Baronios Briefschreiben vom 5. Juni 1558 an den Onkel Don Marco Barone in BVR, Q 46, f. $4 \mathrm{v}$. 
beitreten zu wollen“ - Neris Priesterbund wird in diesem Briefschreiben nirgendwo erwähnt. ${ }^{184}$ Baronio teilt seinen Eltern in demselben Brief auch den vorgesehenen Verlauf des Weihezeremoniells zum Subdiakonat mit. Kardinal Giacomo Savelli, der damalige vicarius des Papstes, hatte Baronio bereits die Erlaubnis erteilt, die höheren Weihen zu empfangen:

[...] et quanto io me ne compiaccia, che forsi il veder me cosi disposto ve indurresti a conformarvi con la volunta mia, e di Dio. Resta dunque Patre, et Madre che ve ne contentiate per li sopradetti rispetti. Et vi s'aggiunge, che in questo stato megli porto restorarvi di tante e tante fatighe et pener, quale havete per me patite, che essendo io assunto in tal stato Ecclesiastico sarro intercessore per voi, et in vita et in morte, et questo vi apportera piu giovamento, che non haveria portato qual altro stato si vogli. Io fin ad hora ho pigliato li quattro ordini minori: sabato prossimo che sarà il giorno di S. Thomaso, et che si faranno le ordinationi sarro ordinato da Subdiacono, che gia ho havuto la licentia dal Vicario del Papa di promovere alli sacri ordini con titolo di patrimonio, et si faranno le veste, cioè un gabano, et una settana fin alli piedi, che così vol la nuova bolla che si vadi in habito et tonsura [...] e staro qui in Casa come prima fin tanto che sarro habile a dir messa, e poi quando che vi piaccia mi ridurro in vostra Casa, dove che viveremo in santa pace questi pochi giorni della nostra peregrinatione [...]. ${ }^{185}$

In diesem Brief treten zwei entscheidende Aspekte hervor, die seitens der Forschung bisher nicht ausreichend erklärt wurden. Einerseits wird in diesem Schreiben deutlich, dass sich Baronio über die Bedingung, ein liturgisches Dienstamt bekleiden zu können, bewusst war. Dies schliesst bereits die Annahme, dass es sich beim ungenannt gebliebenem padre spirituale um Filippo Neri gehandelt haben könnte, aus. Andererseits wusste Baronio ebenfalls davon, dass der Nachfolger Pauls IV. diese Bedingungen zum Empfang der höheren Weihen massgeblich änderte. Damit lässt sich Baronio schon 1560 in einem kurialen Prälatenkreis lokalisieren, dem Filippo Neri bewusst fernbleiben wollte. Die Vorkehrungen des vicarius urbis waren spezifisch gegen Neris Beichtkreis gerichtet. Nachdem nämlich Paul IV. mit seiner bereits erwähnten Verordnung gegen Mönche ohne Ordensangehörigkeit vorzugehen beabsichtigte, hatte er den 1555 zum Kardinalvikar ernannten Virgilio

184 BVR, Q 46, f. 6: „[...] per il che gia da tre anni in quà, che in tal via persevero per sua gratia, non hò cessato mai, e con orationi, gemiti, e sospiri pregare la sua maesta, che poi che da fango del mondo tratto m'haveva, ch'insieme ancora mi insegnasse per qual via piu secondo il suo volere, lo havrei possuto servire, et non essendo mai risoluto del suo beneplacito, tal volta anzi piu volte io prcipitoso con indescreto fervore ho voluto ingerirmi nella religione, hora de Capuccini, hora d'altri Osservanti. Ma perche sua divina Maiesta non si voleva servir di me in tale stato, dava lume e spirito al mio R.do Padre spirituale che tali pensieri, et ispirationi non erano dal spirto di Dio, ma che era inganno del nemico; per il che il predente, e benacorto Padre sempre mi ha ritenuto la briglia di non lassarmi trascorrere così precipitosamente, le parole del quale sempre poi mi sino ritrovato, atteso che ben poi ho cognosciuto quella non esser stata la vocazion mia [...]“.

185 BVR, Q 46, f. $7 v$. 
Rosario mit der Aufgabe, reformandi quicquid necessarium fuerit in utroque officio, betraut. $^{186}$

Rosarios Vorkehrungen zur Verbesserung der Apostasie in Rom betrafen auch Neris Bruderschaft in San Girolamo della Carità. In mehreren Zeugenaussagen des ab 1595 begonnenen Heiligsprechungsprozesses wird davon berichtet, dass Neri vom vicarius urbis verfolgt worden sei. Der Florentiner Bürger Simone Grazzini erinnert sich in seiner Aussage vom 8. August 1595 beispielsweise daran, dass ,während des Pontifikates Pauls IV., Neri unter Verfolgung durch den Kardinalvikar von Spoleto (Virgilio Rosario) stand, der diesem verbat, sich mit einer Gruppe von Anhängern in Rom bewegen zu dürfen“. Dieses Verbot betraf auch den von Neri einge-

186 ASV, Arch. Concist., Acta Vicecanc., 8, f. 149r: „Apud Sanctum Petrum [...] octava Mensis Novembris 1558 fuit Consistorium in quo SANCTITAS SUA proposuit [...]. Item eadem auctoritate statuit et ordinavit ut Officium Vicariatus reducatur in Collegium Cardinalium et deputavit Referendissimum Cardinalem Virgilium [...]“. Am 27. August 1554 wurde Rosario von Papst Julius III. zum Bischof von Ischia ernannt, nachdem er ein Doktorat utroque iure abgeschlossen hatte und der Pfarrei von Santa Maria Rotonda in Neapel zugeordnet wurde, wodurch er in eine enge Zusammenarbeit mit Gian Pietro Carafa eintrat. Irrtümlicherweise hat die frühere Forschung die Pfarrei Rosarios in Neapel mit Santa Maria Rotonda in Rom, dem Pantheon, verwechselt, so insbes. Buonocore 1926, S. 25. Vgl. hierzu auch Cardella 1793, IV, S. 356, sowie Moroni, Dizionario, Bd. 59, S. 158. Nach der Kardinalsernennung vom 15. März 1557, während welcher Paul IV. auch den Inquisitor und späteren Papst Pius V., Michele Ghislieri, zum Kardinal erhob, trat Rosario am 11. Juni desselben Jahres mit den Kardinälen Ghislieri, Giovanni Reumano und Scipione Rebiba in die durch den Papst einberufene Kommission gegen Kardinal Morone ein. Vgl. diesbezüglich insbes. Pastor 1893-1933, Bd. 6, S. 530531, und Firpo/Marcatto 1984, Bd. 2, S. 30: ,[...] tutti uomini schierati sulle sue posizioni intransigenti e da lui stesso insigniti della porpora cardinalizia, personaggi lontanissimi dal Morone per sensibilità culturale ed esperienze umane e religiose, scegliendo con cura all'interno del Sacro Collegio coloro nei quali sapeva di poter trovare dei fedeli esecutori delle sue direttive“. Das avviso vom 5. Juni 1557 berichtet bereits über die am Donnerstag, dem 3. Juni, üblich stattfindende Sitzung des Santo Uffizio, bei welcher der Prozess gegen Morone entschieden wurde: BAV, Urb. lat. 1038, f. 234r. Vgl. auch die Berichterstattung Bernardo Navageros bei Santarelli 2011/12, Bd. 2, S. 745. Zur Beurteilung der Kardinalsernennung vom März 1557 dann auch das avviso in BAV, Urb. lat. 1038, f. 204v, in welchem berichtet wird, dass „die Mehrheit (seien) [...] Theatiner mit wenig Ansehen“ (la maggior parte [...] chietini di poca considerazione) ausmachten. Vgl. dann Antonovics 1972, S. 301-328; Simoncelli 1988, S. 72-73, und Firpo 2005, S. 360-361. Bereits die Bulle Pauls III., Licet Ecclesiarum omnium, statten den vicarius, formulierte die Befugnis, die Orden verteilen und über alle anderen Sakramente verwalten zu dürfen: ASV, Reg. Vat. 1710, f. 436r sowie Bull. dipl. rom., V, S. 202. Wie der Konzilssekretär Massarelli in seinem Tagebuch festhielt, sollten gemäss dem Willen des Papstes solche Ämter in Zukunft nur durch Kardinäle besetzt werden. Dieses Bestreben des Carafa-Papstes schlug sich vor allem auch in der Bulle Super erectione officii S. R. E. Camerae apostolicae Regentis von Ende November 1558 nieder, die das Kardinalskollegium strenger an die Obrigkeit des Papstes band und diesem besondere funktionale Ämter, wie dasjenige des Auditor Curiae causarum Camerae apostolicae, übertrug. Hierzu das bereits von Massarelli erwähnte Konsistorium vom 28. November, während welchem Rosario zum vicarius papae wiedergewählt wurde, in CT, II, S. 327. Die Bulle befindet sich in BAV, Stamp.R.G.Dir.Can. IV.1267. Vgl. auch die Konsistorialakten vom 6. März 1559 in ASV, Arch. Conc., Acta Vicecanc., 8, f. 163r. Zu den neuesten Untersuchungen vgl. Brunelli 2011, S. 46-49. 
führten Brauch des Besuchs der sieben Kirchen Roms. ${ }^{187}$ Als am 19. Januar 1560 der Kardinal Giacomo Savelli zum Nachfolger Rosarios gewählt wurde, hatte ihm Pius IV. auch die Vollmachten des judex ordinarium übertragen. Während des Carafa-Pontifikates fielen diese Vollmachten noch in den Zuständigkeitsbereich des Regentis Camerae apostolicae. ${ }^{188}$ Zwischen dem Zeitpunkt, an dem sich Cesare Baronio für den Empfang der höheren Weihen entschied, und seiner Priesterweihe, die am 27. Mai 1564 stattfand, arbeitete der vicarius urbis Savelli weitere Anordnung aus, die nicht nur die Priesterordinationen betrafen, sondern auch vom Kirchenschmuck und der Beachtung des Gottesdienstes handelten. Savellis Edikte, die 1566 fertiggestellt wurden, fallen somit zeitlich mit Baronios Priesterordination zusammen. Weil sich Savelli in diesen Verordnungen hauptsächlich mit der Priesterordination auseinandersetzte, können seine Edikte als Produkt der Tridentiner Dekrete zur Priesterausbildung und -ordination während der dritten und letzten Sitzungsperiode betrachtet werden. ${ }^{189}$

187 Primo Processo, I, S. 24: „Nel pontificate di Paolo Quarto, li fu levata una persecutione dal card. di Spoleti vicario, quale li prohibì che non dovesse andare in comitiva; et lui commisse a tutti li suoi figlioli, che non le andassero dietro, perchè voleva obedire [...]“. Vgl. auch die Aussagen Giacomo Crescenzis vom 15. November 1595 in ibid., S. 361-362, und diejenige Monte Zazzaras vom 22. November desselben Jahres in ibid., S. 374. Als Rosairo am 22. Mai 1559 durch Bluthusten (sbocca di sangue) starb, sahen viele Anhänger Neris die mögliche Ursache in seinem Vorgehen gegen Pippo buono. Hierzu insbes. Primo Processo, I, S. 49-50: „[...] comparse un prete incognito lì a l'Oratorio, qual era sacerdote, et io l'ho visto dir Messa, et portava una cintura de corda; era homo iusto, de barba negra, magro et brunetto. Questo prete disse a m.s Filippo, quale stava lì a S. Hieronimo, che non dubitasse, che Iddio lo voleva consolare et voleva che seguitasse l'opera cominciata et che, fra quindeci dì, seria morto il cardinale et l'haveria liberato da questi travagli. Et in questo tempo de quindeci giorni, il card. de Spoleti morse de morte subitanea; et il prete che haveva predetta la sua morte non fu visto più“. Vgl. auch Marcello Ferros Aussage vom 23. August 1595, in welcher der Besuch der sieben Kirchen Roms direkt mit den Verfolgungen Rosarios in Zusammenhang gebracht wird: ibid., S. 80-81. Zu Rosarios Tod vgl. den Nachruf Gallettis in BAV, Vat. lat. 7871, f. 182r. Für weitere Zeugenaussagen vgl. Del Re 1991, S. 164-165.

188 ASV, Reg. Vat. 1918, f. 170r: „[...] de Fratrum Nostrorum consilio officiu praedictum sic vacans per te quoad vixeris aut Vicesgerentem et Suffraganeum ac Locumtenentem tuum exercendum, cum omnibus et singulis privilegiis, facultatibus praerogativis, immunitatibus, exemptionibus et jurisdictionibus necnon honoribus, oneribus, juribus et emolumentis cnsuetis ac quibus alii in Urbe, suburbiis et Districtu praedictis Vicarii in Spiritualibus Romanorum Pontificum et Praedecessorum Nostrorum qui pro tempore fuerunt, uti, potiri et gaudere potuerunt seu etiam debuerunt, auctoritate praedicta concedimus et assignamus, ac te in Nostrum et Urbis ac suburbiorum ac Districtuum praedictorum Vicarium necnon Romanae Curiae Judicem Ordinarium assumimus, constituimus et deputamus, curam regiminis et administrationibus liberumque exercitium officii huiusmodi tibi plenarie committendo“. Zu den administrativen Verfügungen des Regentis Camerae apostolicae während des Carafa-Pontifikates vgl. Brunelli 2011, S. 46-47; Cuggiò 2004.

189 Savellis Anordnungen finden sich in ASVR, Bandimenta, Editta Vicarii Urbis, 1566-1609, cc. 154r-155r, 187r, 234r-235v, 229r-230v. Vgl. hierzu auch DSI, Bd. 3, S. 1384-1385. Zu einer historischen Entwicklung des Amtes des vicarius papae nach 1558 vgl. insbes. Micheletii 1988. 
Baronio musste daher seine Entscheidung, die Priesterweihe anzustreben, unabhängig von Filippo Neri und dessen Beichtkreis getroffen haben. Das Verhältnis zwischen Neris Oratorium und dem neuen vicarius urbis war immer noch von gegenseitigem Misstrauen geprägt. Baronio entschied sich für den Empfang der höheren Weihen ein Jahr bevor er sein Doktorat in utrusque iure erwarb. Dieser Tatbestand lässt vermuten, dass Baronio womöglich eine Karriere als avvocato concistoriale innerhalb der Kurie anstrebte. Sein Onkel Paolo überwies noch vor dem 1. April 1561 achtzehn scudi an die Schatzkammer des Collegio degli Avvocati, was als Hinweis darauf verstanden werden kann, dass Baronio beim Rechtswissenschaftler Cesare Costa studiert haben musste. ${ }^{190}$ Aus einem weiteren Briefschreiben vom 21. Mai 1561 lässt sich ein kurialer Prälatenkreis feststellen, in welchem Baronio zu verkehren anfing:

Heri a sera per gratia del Signore compitte il mio debito, et ho satisfatto al vostro desiderio, e fu' addottorato in civile et canonico; dove forono molti dottori, et scolari, e ci forno tutti questi scolari del paesi, vi fu in detto loco il mastro di Casa di S. Fiore, et il R.do Monsignor Cirillo; et furno fatte le solite ceremonie con assai bel ordine, e Dio mi dette gratia di portarme assai meglio, che forsi altru non pensava [...]. ${ }^{191}$

Bislang wurde dieses Schreiben in Bezug auf eine Widerlegung oder Bestätigung der Frage, ob Baronio ab 1558 schon Kontakte zu Filippo Neris Oratorium gehabt haben könnte, nicht beachtet. Anscheinend kannte Baronio zum Zeitpunkt, als er das Doktorat beider erwarb, sowohl Bernardino Cirillo, der seit 1556 commendatore von Santo Spirito in Sassia war, als auch den Kardinal von Santa Fiore, Guido Ascanio Sforza, der 1560 Bischof von Parma wurde. Dieser Brief ordnet sich in eine Reihe weiterer Briefe Baronios an seinen Vater ein, die Baronios Ehrgeiz, die Priesterordination anzustreben, weiter verdeutlichen. Nachdem sich Baronio wieder für einige Tage in Sora bei seinen Eltern aufgehalten hatte, entschloss er sich im April 1561 nämlich, dem studium der Theologen und Kanoniker beizutreten. Das Studium der Theologie beabsichtigte er gleichzeitig mit seiner Teilnahme an Messgesängen zu absolvieren. Baronio fügte dann noch an, dass die Priester in Rom nun vom Volk grössere Anerkennung bekämen. ${ }^{192}$ Einen weiteren Grund, die Priesterweihe erlangen zu wollen, sah Baronio darin, dass er dadurch das Privileg erwerben konnte, um Lossprechungen reservierter Beichtfälle (casi riservati) selber erteilen zu können. Die Vergabe dieses Privilegs oblag dem damaligen sommo penitenziere, dem Papstneffen Carlo Borromeo. Im siebten Kapitel zum Busssakrament legten die Tridentiner Konzilsväter fest, dass dieses Recht nicht „beliebigen, sondern nur oberen Priestern“ (non a quibusvis, sed a summi dumtaxat sacerdotibus) zugesprochen werden dürfe. ${ }^{193}$ In Sora wurde zu diesem Zeitpunkt eine

190 BVR, Q 46, f. 10r; Carafa, Professoribus Gymnasii, II, S. 412.

191 BVR, Q 46, f. $11 r$.

192 BVR, Q 46, f. 10v: „[...] donando l’ordinarsi in Roma da Messa al sacerdote maggiore autorità“.

193 BVR, Q 46, f. 11r. Das Briefschreiben kann auf den 5. Mai 1561 datiert werden. Zum Kapitel über die Reservation von Beichtfällen in COD, S. 708. Für einen Überblick vgl. Prosperi 1997, S. 266-267. 
Kommende des Hospitals von Santo Spirito frei, die nun Baronio als Subdiakon übernehmen und später als Diakon verwalten durfte. Diese Kommende erhielt er direkt vom bereits erwähnten commendatore des römischen Ospedale di Santo Spirito in Sassia, Bernardino Cirillo. Aus durch Eintritte in sein Hospital angesammeltes Geld beabsichtigte Cirillo, die Reparaturen des Hospitals in Sora finanzieren zu wollen. Das Vorbild zu diesen Restaurationsmassnahmen waren Cirillos Eingriffe in den Kirchenraum des römischen Hospitals. Cirillos Massnahmen zur Gestaltung von Santo Spirito in Sassia hatten nämlich die Entwicklung der Kirchenraumarchitektur im Rom der 1560er Jahre nachhaltig beeinflusst. Die Briefkorrespondenz Baronios während seinen ersten Jahren in Rom stand demnach in einem Gegensatz zum Bericht in Francesco Zazzaras Memorie, die der bisherigen Baronio-Forschung als Grundlage dienten. Zazzara zufolge habe sich Baronio gewünscht, „aus Liebe zu Christus unbekannt und sogar verschmäht zu werden“. Das „Privileg eines Juristen beider Rechte“ hätte er danach "zerrissen“, woraufhin er in Filippo Neris Beichtkreis eingetreten sei. ${ }^{194}$ Um Baronios Eintritt in Neris Oratorium präziser datieren zu können, muss seine frühe Briefkorrespondenz im Lichte einer Bildproduktion beleuchtet werden, die sich funktionell dem Dienst am Kirchenraum verschrieb. Der Kirchenraum selbst wurde im Pontifikat Pius' IV. als ein vorbildhafter Raum verstanden, in welchem die apostolische Versammlung um die Gottesmutter Maria im Pfingstwunder vergegenwärtigt werden konnte. Die römische Bildproduktion begann sich somit wieder verstärkt der Bildtradition des Pfingstfestes zuzuwenden und sie für programmatische Dekorationsschemata von Kirchenräumen zu nutzen.

Der Künstlerbiograph Giorgio Vasari erwähnt in der zweiten Ausgabe seiner Vite den Architekturkomplex von S. Mariae alias S. Spiritus in Saxia de Urbe im Zusammenhang mit den Restaurationsmassnahmen, die Papst Paul III. nach den verheerenden Folgen des Sacco di Roma ergriff. ${ }^{195}$ Eine anonyme Zeichnung aus der

Im Besonderen für Carlo Borromeo und seinen Avvertenze vgl. dann De Boer 2008, S. 348-354; Bossy 1975, S. 29; Prosperi 1968, S. 137-168.

194 Zit. n. Calenzio 1907, S. 60: „Mi scordai scriver sopra, che quando Sua Signoria s'addattorò poco di poi desiderando d'essere disprezzato per amor di Christo, et non esser conosciuto, stracciò detto suo privilegio, et ne fece tanti segnacoli di libri“. Dies kommt einer weiteren Aussage in BVR, O 7, f. 51r, erstaunlich nahe: „Ma poi abbandonando il diritto civile, lacerò le lettere patenti contenenti il privilegio conseguito, e fattone brandelli se ne servì di segni nel Breviario“. Dass Baronio aber eine besondere Nähe zum zivilen und insbesondere zum kanonischen Recht nach seiner Erlangung des Subdiakonats und der Doktorwürde weiterhin pflegte, zeigen zwei bislang ignorierte Inventare in der Biblioteca Vallicelliana, nämlich die Handschriften BVR, P 206, f. 109v-116v und BVR, Q 72, f. 435r. Ein weiteres im römischen Staatsarchiv aufbewahrtes Inventatium bonorum et singulorum librorum repertorum in hereditate q. bo. mem. Ill.mi Cardinalis Baronij präsentiert einen Index juristischer Publikationen, die Baronio gekannt haben musste: ASR, Auditor Camerae, notaio Domenco Amadeo, prot. 89, f. 2r-7r. Zu diesem Index vgl. zuletzt Lanza 2008, S. 193-196.

195 Vasari, Vite, I, S. 227-278: ,[...] a' giorni nostri era in piedi la chiesa antica, quando fu rifatta alla moderna, con maggiore ornamento e disegno, da papa Paolo III di casa Farnese“. Der Architekt Andrea Palladio, der während seines Romaufenthaltes ab 1554 ebenfalls einen zentralen Beitrag 
Biblioteca Vaticana zeigt weiter, wie sich das Hospital mit seinem Kirchenbau in die Projekte Antonio Sangallos d. J. für die Sanierung der Aurelianischen Mauer ab 1542 und in ein Projekt zur Errichtung der heutigen Porta Santo Spirito eingliederte. Diese Eingliederung konnte aber erst unter der Komtur Cirillos fertiggestellt werden. ${ }^{196}$ Bereits unter Alessandro Guidiccioni, Cirillos Vorgänger, wurde gegenüber der 1546 angebrachten Orgel über dem Seiteneingang in der dritten Kapelle links die Cappella del Crocifisso als Grabkapelle für den commendatore errichtet. Der spanische Künstler Pedro Roviale (Pedro Rubiales) begann ein Jahr später, diese Grabkapelle auszumalen. Der commendatore Guidiccioni eiferte mit seiner Grabkapelle der Cappella di San Giovanni Evangelista seines Vorgängers Farncesco Landi nach, indem er seine Kapelle ebenfalls mit reichem Stuck und Malereien ausstattete. Um diese Dekorationen finanzieren zu können, verwendete Guiddicioni die Gelder des Hospitals. Dadurch erregte er den Neid der Bruderschaft des Hospitals, woraufhin ihn Papst Julius III. denunzierte. Da seine Kappellenausstattung mit viel zu hohen Kosten verbunden war, entzog der del Monte-Papst Guidiccioni auch seine Würde als commendatore. Dadurch wurde er auch der Verwaltung des Ospedale enthoben. ${ }^{197}$

zur Innenausstattung des Kirchenraumes beisteuern sollte, präzisiert die Renovationsbestrebungen Pauls III. und hält fest, dass der damalige commendatore, Francesco Landi, „da fondamenti una bellissima chiesa" erbaute: Palladio, Guida, S. 35. Noch vor den Eingriffen unter dem Farnese-Pontifikat wurden bereits am 18. Februar 1520 fünf Altäre eingeweiht, nämlich diejenigen der Jungfrau Maria, des San Giovanni Battista, der Heiligen Martha, des Sant' Antonio Abate sowie des San Nicola prope Campanile dudum impensa Johannis de Gonfaloneriis mantuani Magisteri stabuli Domus hospitalis S.ti Spiritus in Saxia de Urbe erectum fuit consecratum. Hierzu ASR, Ospedale Santo Spirito, b. 1444, f. 231 r.

196 BAV, Barb. lat. 4391B. Vgl. dazu Bianchi 1993, S. 243-277; idem 2001, S. 61-72. Als Architekt der Festungen des römischen Borgo war Antonio Sangallo il Giovane bis zu seinem Tod am 3. August 1546 tätig. Jacopo Meleghino trat ab 1547 bis 1549 als Sangallos Nachfolger ein. Unter seiner Leitung liessen sich in der Kirche weitere vier Kapellen realisieren: ASR, Ospedale Santo Spirito, b. 233, f. 102r-103v. Am 27. Februar 1546 ging eine Zahlung an mastro Nicolò de Telami da Cremona für die Installation einer Orgel in der chiesa nuova del detto Hospitale, welche auf der rechten Seitenwand über dem dortigen Eingang angebracht wurde: ASR, Ospedale Santo Spirito, b. 236, f. 39r, sowie ivi, b. 237, f. 5v-6r. Vgl. diesbezüglich auch Melella 1994, S. 507-519.

197 Vgl. Alveri, Roma in suo stato, II, S. 263. Bezüglich der Zuschreibung der Dekoration der Cappella Guidiccioni an Roviale Spagnolo vgl. Bologna 1959, S. 38-39, sowie die neueren Untersuchungen bei Michaus 2007, S. 71-72, und Agosti 2012, S. 259-265. Zum Maler Rubiales, der eng mit Vasari auch an der Ausschmückung der Sala dei Fasti Farnesiani im Palazzo della Cancelleria zusammenarbeitete, vgl. Vasari, Vite, VII, S. 43-44. Die Ausstattung der Cappella Guidiccioni lässt sich in eine Konstellation weiterer Kappellendekorationen des Pontifikats Julius‘ III. rücken, die um Vasaris eigene Cappella Del Monte in San Pietro in Montorio entstanden. Zur Del Monte-Kapelle vgl. Nova 1984, S. 150-154; Cantatore 2007, S. 115-117 und Conforti 2011, S. 183-203. Bislang wurde allerdings seitens der kunsthistorischen Forschung bewusst darauf verzichtet, die Forderungen auf minimale Ornamentierung von Kappellenausstattungen im Zusammenhang mit einer Neuausrichtung der Verwaltungspraxis der Sakramente zu verstehen. Für erste Ansätze vgl. Hall 1999, S. 172-173. 
Mit der Ernennung Bernardino Cirillos zum commendatore von Santo Spirito in Sassia wurde der bildprogrammatische Einsatz solcher Dekorationsmuster und grotesker Schmuckdetails neu bewertet. Dieses Neuverständnis lag der Ausschmückung der Cappella Gonzaga zu Grunde. Durch seinen engen Kontakt zum Conte Alfonso Gonzaga beauftragte Cirillo den Maler Livio Agresti mit der Dekoration dieser Kapelle. Sie stellt in ihrer Architekturordnung sowie ihrer malerischen Ausstattung einen Bruch mit den vorangehenden Kapellendekorationen in Santo Spirito dar. Der Bilderschmuck nimmt nun deutlich mehr Raum als die Stuckdekoration in diesem Kapellenraum ein. Dadurch werden andersartige Formen des Stuckdekors eingesetzt. Bislang blieb die Frage, wie ein solcher Dekorationsbruch überhaupt zu Stande kommen konnte, unbeantwortet. Diesem Einschnitt in der bildprogrammatischen Dekoration lag ein theologisches Verständnis darüber, wie das Amt des commendatore von Santo Spirito in Sassia aufgefasst werden sollte, $\mathrm{zu}$ Grunde, das erst mit Bernardino Cirillo formuliert werden konnte und sich in der Wahl der Bildsujets für die Kapelle niederschlug. ${ }^{198}$ Das in der Cappella Gonzaga aufgestellte Altarbild der Beweinung Christi wird von zwei Malereien flankiert, der Anbetung der Hirten links und einer Wiederauferstehung Christi rechts. Zwei überlebensgrosse Tugenden, Iustitia und Misericordia, trennen nicht nur das Mittelbild von den beiden Seitenbildern in Hinsicht auf die Anordnung im Kapellenraum, sondern verbinden diese miteinander durch ihre Armbewegungen. Die beiden Marmorskulpturen vermitteln bereits einen zentralen Gedanken räumlicher Einheitlichkeit. Der Stuckanteil in der Kapelle verbindet daher die Bildtafeln miteinander, wie dies auch in der Apsiskalotte beobachtet werden kann. Bis zum Gebälk ziehen sich aufstuckierte Halbkreisbögen über die beiden Seitenbilder und scheinen somit wie ergänzende Bildrahmen zu wirken. Die dadurch entstandenen Lünetten werden durch vollplastische Putti - ebenfalls stuckartige Kompositionen Agrestis - besetzt. Sie präsentieren dem Betrachter ovale Spiegel mit der Darstellung der Mariä Verkündigung. Indem Agresti seine Bildtafel der Beweinung Christi mit einem gesprengten Dreiecksgiebel krönte, erhob er dieses unmittelbar zum Altarbild. Auf dem Giebel lasten Engelsgestalten, die über ihren Zeigegestus auf die Bildfelder der Kalotte zeigen. Hier demonstriert Agresti seine Anlehnung an die männlichen Liegefiguren Perino del Vagas über den Wandbildern der Sala Regia. ${ }^{199}$ Der Verweisgestus dieser aus Stuck gefertigten Engelsfiguren erfüllt eine zweifache Funktion. Einerseits dient er dazu, dem Betrachter die sich in den Bildfeldern vollziehende Passion Christi anzuzeigen. Andererseits werden

198 Vgl. Bross 1993, S. 338-343; eadem 1994, S. 216-217. Ausführliche kunsthistorische Anmerkungen insbes. bei Kummer 1987, S. 41-50. Für die Ausmalung Agrestis 1557 vgl. dann ASR, Ospedale di S. Spirito, b. 1895 sowie Vasari, Vite, VII, S. 421. Neuere Untersuchungen kunsthistorischer Art dann bei Ganz 2003, S. 293-312. Zur Entstehungsgeschichte der Dekoration Agrestis bleiben die in Campori 1855, S. 2-3, publizierten Briefe aus dem Jahr 1557, auf die erstmals Spazzoli 1972/75, S. 73-74, sowie Strinati 1977, S. 69, 72, aufmerksam machten, wichtig.

199 Davidson 1976, S. 411-413; Kummer 1987, S. 45. 
dadurch die einzelnen Bildfelder zwischen den Darstellungsfeldern der Kapellenwand und der Kalotte in ihrer materiellen Beständigkeit miteinander vereint.

Dieser Paradigmenwechsel, der sich in der Cappella Gonzaga gegenüber früheren Kapellendekorationen aus den 1540er Jahren vollzog, konnte dadurch erreicht werden, dass die bereits durch die Apsis vorgegebene Raumkomposition mit dem Bilderschmuck verbunden wurde. Das Zentrum dieser bildprogrammatischen Verbindung nahm die Bilderzählung ein. Die Stuckdekoration gliedert sich damit reibungslos in den Erzählzyklus der Bildtafeln ein. Solche Stuckdekorationen, die nicht - wie im Falle der Cappella Guidiccioni - in ein Spannungsverhältnis mit dem malerischen Anteil der Bildprogrammatik standen, wurden erstmals in der Sala Regia von Perino del Vaga entworfen und später von Daniele da Volterra realisiert. Sie gehörten aber, wie es die Innendekoration sowohl des Palazzo Ricci-Sacchetti als des Palazzo Capodiferro-Spada zeigt, zum festen Bestand des römischen Palastschmucks. ${ }^{200}$ Am 21. März 1571 verfasste Bernardino Cirillo seine Relazione della fabrica e casa di Santo Spirito di Roma. Aus dieser geht hervor, dass der commendatore für die Sakristei Altäre, Kreuze, Kelche, Tabernakel und verschiedene Paramente einrichten liess. Dieser Schmuck der Sakristei in Santo Spirito steht nicht nur symbolisch für die wichtige Bedeutung, die der Verehrung des Heiligen Sakramentes der Eucharistie zukam, sondern ist vor allem im Zusammenhang mit Cirillos Bestimmungen zur Aufnahme von Novizen in den Orden von Santo Spirito zu betrachten. Cirillo fand nämlich zum Zeitpunkt seines eigenen Beitritts „die Kirche und das Haus mit Brüdern und Kappellanen vor, die fast alle Apostaten und sfratati waren“.201

Bernardino Cirillos Berufung zum commendatore ging somit mit dem Vorgehen Papst Pauls IV. gegen die Apostaten einher. Diese Übereinstimmung musste auch Livio Agrestis Ausschmückung der Cappella Gonzaga beeinflusst haben. Die Kapelle

200 Vgl. zur Sala Regia Davidson 1976, S. 412, sowie Pugliatti 1984, S. 61. Es bleibt in der Forschung noch ungeklärt, in welcher Weise die private Palastausschmückung mögliche Auswirkungen auf die Ausstattung von Kapellenräumen um die Mitte des Cinquecento hatte. Zum Palazzo Ricci-Sachetti vgl. für einen Überblick zu dessen Bildprogramm von Francesco Salviati Hall 1999, S. 162-169. Bezüglich einer Kontextualisierung dieser Problematik in einen künstlerischen Diskurs um den Begriff der maniera vgl. Mendelsohn 1982; Williams 1997, S. 36-39.

201 BLR, Cortelli, VII, f. 29r: „[...] trovò la Chiesa e la Casa con frati et cappellani quasi tutti apostati e sfratati“. Vgl. Vanti 1936, S. 158. Zu Cirillos Wahrnehmung der Bruderschaft von Santo Spirito vgl. auch das Briefschreiben in der Biblioteca Nazionale di Firenze, Fondo Capponi, 78, f. 312v: „I frati sono frati e tanto basti!“ Über die bruderschaftliche Entwicklung v. a. während des Quattrocento geben die Bullen der Päpste Eugen IV. Licet vigilis Pastor vom 13. Oktober 1444, Cum nos anno vom 4. Februar 1446, Salvator Nostri vom 25. März 1446, diejenigen Pauls II. Propter commune debitum vom 16. Nov. 1465 und Sixtus' IV. Etsi ex debito vom 31. Aug. 1473 in BLR, Bull. S. Spir., f. $185 r-209 v, 254 r-v, 266 r-v$, Auskunft. Neue relevante Untersuchung finden sich für Santo Spirito bei Rehberg 2007a, S. 15-70; idem 2007b, S. 225-260. Cirillos Relazione befindet sich in BAV, Ott. lat. 2473, f. 179r-184v. Vgl. weiter Alloisi/Cardilli 2002, S. 46-47. 
wurde nicht nur als Familiengrablege der adeligen Gonzagas genutzt, sondern war auch als Cirillos Privatkapelle gedacht. Deshalb musste die Cappella Gonzaga im Zeremoniell der Aufnahme neuer Novizen eine wichtige Rolle gespielt haben. Der commendatore verlieh in diesem Zeremoniell den Bittstellern das Habit des Ordens vom Heiligen Geist, auf dem ein Gemmenkreuz (cum geminato signaculo Sanctae Crucis) aufgetragen war. Danach legten die Neueintretenden ein Gehorsamsgelübde gegenüber dem commendatore ab. Nach ihrem Eintritt in den Orden waren die Novizen für ein ganzes Jahr in der karitativen Krankenfürsorge tätig. Diese Krankenfürsorge blieb seit der ersten Regula des Ordens erhalten. Die endgültige Aufnahme in den Orden erfolgte dann anlässlich eines öffentlichen Zeremoniells, bei welchem sich die Novizen vor dem Altar präsentierten und auf ihren Knien vor dem commendatore um ihre Aufnahme in den Orden baten. Nachdem der Zelebrant ebenfalls dem Eintritt der Novizen zustimmte, wurden sie auf ihre Kenntnis der Riten hin befragt. Darauf folgte der Gesang des Veni Creator. Zum Abschluss las der Bewerber mit der Hand auf dem Evangelium eine formula vor, in welcher er sein Gehorsamsgelübde gegenüber dem Ordensoberen Cirillo ablegte. Gemäss diesem Gelübde stimmte der commendatore der definitiven Aufnahme zu und verpflichtete die neuen Ordensbrüder zur regelmässigen Messzelebration sowie zur Verteilung des bruderschaftlichen Brotes (panem). ${ }^{202}$

In diesem Zeremoniell der Aufnahme von Neueintretenden war ein theologisches Verständnis des Pfingstwunders enthalten, wonach die Apostel den Heiligen Geist über die Gestalt der Gottesmutter Maria empfangen hätten. Das Gleichnis zwischen der zeremoniellen Aufnahme von Novizen und der Theologie des Pfingstfestes war ein zentraler Gedanke für die bildprogrammatische Ausstattung des Kirchenraumes von Santo Spirito in Sassio unter der Komtur Cirillos. In der zweiten Ausgabe seiner Vite erwähnt Vasari eine Tafel Girolamo Siciolantes, die der Maler für die Sakristei von Santo Spirito in Sassia ausführte und auf welcher das Pfingstwunder dargestellt ist. Die Tafel Siciolantes wird heute im Hospital des Ordens aufbewahrt. Ein im römischen Staatsarchiv aufbewahrter und erstmals von Antonella Pampalone aufgefundener Zahlungsbeleg an den Maler erlaubt eine Datierung der Fertigstellung der Tafel auf den 31. August 1564. ${ }^{203}$ Im Département des arts graphiques des Musée du Louvre wird eine Vorzeichnung Siciolantes aufbewahrt. Hunter bezeichnete Siciolantes Dar-

202 ASR, Ospedale Santo Spirito, b. 1: Ord. S. Spir. e Commend., Modus suscipiendi novitium ad professionem.

203 Vasari, Vite, VI, S. 220: „[...] per la sagrestia della chiesa di Santo Spirito di Roma,in un'altra tavola a olio, la venuta dello Spirito Santo sopra gl'Apostoli, che à molto graziosa opera“. Der Zahlungsbeleg zit. n. Pampalone 1995, S. 279: „A messer Jeronimo da Sermoneta dipintore scudi quarante di moneta sono per ragione di scudi ottanta che dovea avere da noi per il quadro dipinto che è al altare della sagrestia“. Vgl. auch Hunter 1996, Dok.-Nr. XIII: Testi e atti notarili 1543-1818. Obwohl Hunter die Tafel als verschollen deklarierte, fand Roberto Canatà eine sich im Hospital befindende Tafel auf, die zumindest der Beschreibung Vasaris entspricht. Vgl. hierzu Canatà 1991, S. 120. Heute schmückt Jacopo Zucchis Tafelbild der Erscheinung Christi vor den Heiligen Helena, Hieronymus, Petrus und Paulus den Altar der Sakristei: Pillsbury 1974, S. 441-442. 
stellung des Pfingstwunders noch als „konventionell“. ${ }^{204}$ Die Bildtafel nimmt Jacopo Zucchis spätere Komposition der 1580er Jahre für die Apsiswand der Kirche von Santo Spirito in Sassia vorweg, indem sie die Apostel um die Zentralfigur der Gottesmutter Maria anordnet. Über dem Kopf Mariens ereignet sich das Wunder der Ankunft des Heiligen Geistes. Während aber in der konventionellen Bildtradition die Taube und die Gottesmutter die Zentralachse des Bildaufbaus bilden, liess Siciolante in seiner Vorzeichnung die göttliche Taube bewusst weg (Abb. 6). Dadurch hat der Maler das in der Apostelgeschichte überlieferte Pfingstwunder (Apg. 2, 1-5) neu gedeutet. Der wundersame Empfang des Heiligen Geistes wird in der Vorzeichnung sowie in dem für die Sakristei von Santo Spirito vorgesehenen Altarbild als Versammlung der Jünger unter der Obhut der Gottesmutter Maria gedeutet. Ähnlich wie die Apostel sollten die Novizen des Ordens als spirituelle Führer der neuen christlichen Gemeinde wirken. Ihr Gehorsamsgelübde gegenüber dem commendatore bei ihrer zeremoniellen Aufnahme in den Orden bestätigt Cirillos spirituelle Führung in der karitativen Krankenfürsorge. Diese den Kranken erwiesene caritas wird daher als apostolische Aufgabe aufgefasst und gilt als Preisgabe der Ordensnovizen an die Gottesmutter Maria. ${ }^{205}$ Siciolantes Komposition zeigt in der Anzahl der Apostelfiguren eine weitere Abweichung von der Bildtradition des Pfingstwunders. Die in der Apostelgeschichte überlieferte Zahl von sieben Figuren erhöhte der Maler auf zwanzig. Hunter deutete diese höhere Apostelanzahl als ein Indiz dafür, dass die übrigen dreizehn Figuren - gemäss den Passagen in der Apostelgeschichte - die betende Gemeinde im Zusammenhang mit der Berufung Matthiä darstellten. Die zusätzlichen Figuren könnten aber auch Bildnisse zeitgenössischer Kirchenprälaten zeigen. ${ }^{206}$ Diese Deutung, dass Siciolante in seinem Altarbild für die Sakristei von Santo Spirito in Sassia auch zeitgenössische Persönlichkeiten einfügte, lässt sich jedoch nicht aufrechterhalten. Erst in der um 1575 ausgeschmückten Cappella della Trinità fügte Livio Agresti auf seinem Ölgemälde der Heiligung eines Paralytikers am linken Bildrand die Figur des commendatore Cirillo ein. Agresti hatte dieselbe Figur bereits in einer Vorzeichnung, die sich heute im Gabinetto Disegni e Stampe der Uffizien befindet, verwendet und sie entspricht dem Porträt Cirillos im Palazzo del Commendatore (Abb. 7). ${ }^{207}$ Dass Agresti die Figur Cirillos in die Bildkom-

204 Für die Vorzeichnung, welche 304 x 190 mm (Inv. 10197) misst, vgl. Gere/Pouncey 1983, Bd. 1, S. 161; Hunter 1988, S. 22-23.

205 ASR, Ospedale di Santo Spirito, Ord. S. Spir. e Comm., b. 1: Modus suscipiendi novitium ad professionem: „Ego N. N. offero et trado me ipsum Deo et Beatae Mariae et Sancto Spiritui ac Dominis nostris infirmis ut omnibus diebus vitae meae sim servus illorum“. Zit. n. Vanti 1938, S. 160. Vgl. bezüglich einer solchen Auslegung des Pfingstwunders auch Philippou 1964, S. 70-97.

206 Hunter 1988, S. 24. Zur betenden Gemeinde und der Berufung des Matthias zum Apostel vgl. die Stelle in Apg. 1, 12-26.

207 Petroli Tofani 2005, S. 400 und zuletzt Raimondo Sassis Eintrag im Kat. Ottawa 2009, S. 330-331, Nr. 102. Vgl. auch Bross 1994, S. 341-342. Zum Bildnis Cirillos im Palazzo del Commendatore vgl. dann Colonna 1995, S. 178, 197. Fabrizio Biferali schlug jüngst sogar die These vor, dass die am linken Bildrand des Pfingstwunders sitzende, bärtige und sich schielend dem Betrachter zuwendende Figur einem Bildnis 
position seines Altarbildes einfügte, lässt sich dadurch erklären, dass der commendatore diese Kapelle als seine Grabkapelle auswählte. Ein Epitaph am Sockel des rechten Kapellenpfeilers stützt diese Vermutung. ${ }^{208}$

Die Einbindung zusätzlicher Figuren in das Altarbild Siciolantes für die Sakristei muss daher im Zusammenhang des ab 1561 wieder aufgenommenen Trienter Konzils erklärt werden. Die Konzilsväter entwickelten während dieser letzten Sitzungsperiode ein neues Verständnis des Priesteramtes. Cirillo legte während seiner gesamten Amtszeit als commendatore von Santo Spirito grossen Wert auf die Ausbildung von Priestern, welche die wiederversammelten Konzilsväter in Trient ebenfalls ansprachen. Die Neuauslegung des Priesteramtes geschah als eine Fortführung der bereits erwähnten Dekrete zum Predigtwesen aus der ersten Sitzungsperiode. Die Konzilsväter sahen im Predigt- sowie Priesterwesen eine Möglichkeit, den Opfercharakter der Messe neu zu verstehen. In ihrer Gnadenwirkung nahm die Heilsbotschaft der Messe am Altar eine sichtbare Gestalt an. Im Dekret über das Weihesakrament wurde diese Sichtbarkeit der Messe wieder aufgegriffen und auf das Priesteramt übertragen. Das Priestertum zeichnete sich dadurch ebenfalls als sichtbare Gestalt aus:

Opfer und Priestertum sind durch die Anordnung Gottes so miteinander verbunden, dass jedes von beidem im gesamten Gesetz existiert. Da also im Neuen Testament die katholische Kirche das heilige Opfer der Eucharistie aufgrund der Einsetzung des Herrn als sichtbares empfangen hat, muss man auch bekennen, dass es in ihr ein neues sichtbares und äusseres Priestertum gibt, in das das alte (Priestertum) überführt wurde. ${ }^{209}$

Den Tridentiner Konzilsvätern gelang es dadurch, die einzelnen Zuständigkeitsbereiche innerhalb des Kirchenkorpus in Bezug auf die cura animarum klar aufzuteilen.

des Kardinals Giovanni Morone entspräche: Biferali 2011, S. 199. Biferali sieht in ihr Gemeinsamkeiten mit einem Porträt Pulzones aus der Galleria Corsini. Vgl. hierzu Dern 2003, Nr. 84; Kat. Trento 2009, Nr. 5 sowie Pancheri 2010, S. 263. Eine Kopie des Bildnisses, welches auf das 18. Jahrhundert zu datieren ist, befindet sich heute in der Quadreria der Universität Bologna. Die Vorzeichnung Siciolantes erlaubt allerdings keine solche Deutung, da sowohl im Altarbild als auch in der Vorzeichnung ein Kardinalshut fehlt. 208 Forcella, Iscrizioni, VI, S. 398, Nr. 1220.

209 Zit. n. Wohlmuth 2002, Bd. 3, S. 742. Vgl. COD, S. 742: „Sacrificium et sacerdotium ita Dei ordinatione coniuncta sunt, ut utrumque in omni lege existerit. Cum igitur in novo testamento sanctum eucharistiae sacrificium visibile ex Domini institutione catholica ecclesia acceperit: fateri etiam oportet, in ea novum esse visibile et externum sacerdotium, in quod vetus translatum est“. Zum Messopferdekret der 22. Sitzung vom 17. September 1562 vgl. ibid., S. 732-737; CT, VIII, S. 751-755; Jedin 1949-1975, Bd. 3, S. 39-44. Es ist als Verdienst des Tridentinums gegenüber der scholastischen Theologie des Mittelalters anzusehen, dass es die drei Aspekte des Heiligen Sakramentes der Eucharistie - nämlich Opfer, Realpräsenz und Kommunion - miteinander in einer Einheit verbinden konnte. Dies lag auch am Umstand, dass das Tridentiner Dekret nun den regelmässigen Empfang der Kommunion wiedereinführte, und zwar als zentralen Bestandteil der Messe. Während des Mittelalters hingegen ereignete sich der Empfang der Kommunion ausserhalb der Messefeier. Vgl. dazu Duval 1985, S. 61-150; Sesboüé 1995, S. 158-170; Buzzi 1995, S. 136-145; McHugh 1991, S. 157-181; Iserloh 1979, S. 341-381; Palmer Wandel 2006, S. 219-225; O’Malley 2013, S. 189-195. 
Allerdings blieb die Frage, wie die Priester ihrem Dienst liturgisch nachkommen sollten, weiterhin unbeantwortet. Das Priestertum wurde allein im Zusammenhang mit der Messe verstanden. Um liturgisch im zeremoniellen Gefüge des Kirchenkorpus eingeordnet werden zu können, musste das Priesteramt über die Grenzen der Messzelebration hinaus verstanden werden. Deswegen muss ein liturgisches Verständnis des Priestertums in einem engen Zusammenhang mit der Einrichtung von Priesterseminaren in Rom betrachtet werden. Der Jesuitenorden hatte mit seinem Seminario Romano ein Vorbild zur Errichtung weiterer solcher Ausbildungsstätte von Priestern geschaffen. Die Konzilsväter hielten in ihrem am 15. Juli verabschiedeten Reformdekret fest, dass zur Ausbildung des Klerus Seminare eingerichtet werden sollten und deren Verwaltung unter die Obhut des zuständigen Diözesanbischofs fallen sollte. In diesem Kanon des Reformdekrets wurde daher die „angemessene Unterweisung in der kirchlichen Disziplin“ durch das Tragen der Tonsur und des klerikalen Gewandes festgehalten. Das Erlernen der Grammatik, des Gesangs und der kirchlichen Zeitrechnung gehörten ebenfalls zur Priesterausbildung. Ferner beschlossen die Konzilsväter, dass Priester die Heilige Schrift, die kirchlichen Bücher, die Heiligenpredigten sowie die Formen der Sakramentsspende auswendig lernen sollten. Die Priesteranwärter, die ihre Priesterausbildung an einer solchen „Pflanzstätte“ (seminarium) aufnahmen, verpflichteten sich auch an Festtagen der jeweiligen Diözesankathedrale oder -kirche zu dienen. ${ }^{210}$ Noch bevor die Jesuiten ihr Seminario Romano am 1. Februar 1565 eröffneten, galt dieses Seminar für die übrigen Diözesen bereits als institutionelles Vorbild. Der General und Nachfolger Ignatius von Loyolas im Jesuitenorden, Diego Laínez, teilte am 12. Juli 1562 in seinem Briefschreiben an Francisco Borja mit, dass sich die Konzilsväter - unter seiner Leitung - mit der Gründung eines römischen Priesterseminars auseinandersetzten. Dieser Plan zur Errichtung eine Ausbildungsstätte für Priester in Rom sollte der Kardinal Morone Papst Pius IV. vorlegen. Das Priesterseminar sollte dem Collegio Germanico des Ordens ähnlich sein, da sich dieses bezüglich der Ausbildung von Priestern, die in Deutschland ihre Missionstätigkeit aufnahmen, bereits bewährt hatte. Auch aus diesem Grund sollte die Leitung dieser römischen Ausbildungsstätte für Priester den Jesuiten unterstehen. ${ }^{211}$ Die Konzilsväter sahen in diesem Priesterseminar ein Vorbild, an-

210 COD, S. 751: „Ut vero in eadem disciplina ecclesiastica commodius instituantur, tonsura statim atque habitu clericali semper utentur, grammatices, cantus, computi ecclesiastici aliarumque bonarum artium disciplinam discent; sacram Scripturam, libros ecclesiasticos, homilias sanctorum, atque sacramentorum tradendorum, maxime quae ad confessiones audiendas videbuntur oppurtuna, et rituum ac caeremoniarum formas ediscent. [...] cathedrali et aliis loci ecclesiis diebus festis inserviant".

211 MHSJ, Monumenta Lainii, VII, S. 138: „El legado Morón ha tomado cardo de scriuir después a su Sandidad lo que instan mucho destos perlados principales, y entre ellos el cardenal de Lorena, que su Santidad haga ay en Roma un gran seminario come a todos que tienen hazerse en sus yglesias [...]“. Vgl. Paschini 1958, S. 4; Testa 2002, S. 23. Ein weiterer Brief Laínez’ vom 8. Juli 1563 an Cristoforo in Madrid berichtet ebenfalls über den Entschluss der Konzilsväter, ein solches Seminar in 
hand dem alle nationes in Rom ihre eigenen Seminare gestalten konnten. Durch diese weiteren Seminare wurde den Diözesanbischöfen versichert, dass Priester eine ordentliche Ausbildung erfahren konnten. Aufgrund seiner Kenntnisse der bereits bestehenden Seminare in Rom warnte der Kardinal Giovanni Morone die Konzilsväter aber schon früh vor einem grundsätzlichen Widerspruch zwischen der Errichtung „nationaler“ Priesterseminare und dem Tridentiner Reformdekret. Die Errichtung von Priesterseminaren in den Diözesen sollte nicht Aufgabe der Jesuiten sein, denn dafür waren die Bischöfe zuständig. Deswegen hatte sich Morone auch aktiv an der Gründung des Collegio Germanico in Rom beteiligt und orientierte sich dabei am Vorbild des Diözesankollegiums in Dillingen, das der Kardinal Otto Truchsess von Waldburg gegründet hatte. ${ }^{212}$ Wie Guasco bereits beobachten konnte, hatten die Konzilsväter die Bischöfe wohl nur dazu verpflichtet, Priesterseminare in ihren eigenen Diözesen zu gründen. Was den Besuch von Studenten dieser Diözesanseminare betraf, darüber schwiegen die Konzilsväter. Angehenden Bewerbern war es daher immer noch auf traditionellem Weg möglich, die höheren Weihen zu erlangen. Vorzugsweise besuchten sie das Studium Urbis und bereiteten sich auf ein Examen vor, das ihnen ihr zuständiger Diözesanbischof abnahm. ${ }^{213}$ Dieser Weg scheint besonders dem Fall von Cesare Baronios Laufbahn zu entsprechen. Auch wenn der spätere Oratorianer wahrscheinlich eine Karriere als Konsistorialadvokat vorhatte, konnte er die Priesterwürde auch abseits dieser engen Grenzen kurialer Laufbahnen erlangen. Die Bestimmungen der Konzilsväter in Trient zeigen deutlich, dass die Ausbildung von Priestern noch nicht in einem festen institutionellen Rahmen begriffen war.

Cesare Baronios Weg zu seiner Priesterweihe muss daher in einem bislang noch kaum berücksichtigten Zusammenhang mit der Rolle, welche die Oratorien einzelner Bruderschaften in Rom bei der Ausbildung von Priestern spielten, erläutert werden. Vorreiter solcher Ausbildungsorte für angehende Priester, die keine Seminarien waren, stellten die beiden römischen Bruderschaften des Gonfalone und des Santissimo Crocifisso dar. Die Baugeschichte des Oratoriums, das die Confraternita del Santissimo Crocifisso nahe ihrer Kirche von San Marcello al Corso errichtete, setzte im Pontifikat Pius` IV. an. Der Papst erhob in einem 1563 erlassenen breve diese Bruderschaft zur Arciconfraternita. ${ }^{214}$ Eine Untersuchung bruderschaftlicher Oratorien kann darüber Aufschluss

Rom einzurichten: ibid, S. 183: „[...] no le paroció al dicho legado Morón, diziendo que ya auia seminario en Roma, id est, de nuestra Compañia y del collegio germánico“.

212 Zur Gründungsgeschichte des Collegio Germanico in Rom vgl. O’Malley 1993, S. 234-235; Bitskey 1996; Schmidt 1984; Pellicia 1946, S. 323-337.

213 Guasco 1986, S. 644; Testa 2002, S. 24.

214 ASV, Arciconfraternita del SS. Crocifisso di San Marcello, E-II-20. Ein auf den 26. Februar 1563 datiertes und in ASR, Archivio dei 30 Notai Capitolini, off. 24 (Tarquinius Caballutius), 78, f.57r-v, aufbewahrtes Dokument nennt dieselbe Bruderschaft bereits als arciconfraternita. Der Mailänder Bischof und Kardinal Carlo Borromeo musste diese Entscheidung des Papstes stark beeinflusst haben, zumal er selbst in seiner Diözese solche Kreuzesbruderschaften einrichtete. Vgl. zu diesem Aspekt v. a. Giuliani 2011, S. 323-350; Zardin 1998, S. 235-263; idem 2009, S. 167-213. 
geben, wie die Priesterausbildung im nachtridentinischen Rom abseits der Jesuitenseminare geprägt war. Diese Oratorien haben letztlich zur Entstehung von Filippo Neris eigener Versammlung von Priestern in San Giovanni dei Fiorentini geführt. Die beiden Bruderschaften des Gonfalone und des Santissimo Crocifisso zeichneten sich durch das päpstliche Privileg aus, am Gründonnerstag ihre Besucher abends zur Cappella Paolina im Apostolischen Palast in einer Bussprozession führen zu dürfen und dort das ausgestellte Heilige Sakrament der Eucharistie zu verehren. Bis zu diesem Zeitpunkt stand allein der Santissima Trinità dei Pellegrini e Convallescenti dieses Privileg zu. Nach einem gemeinsamen Abendessen, auf das der Ritus der Fusswaschung folgte, betraten mehr als 260 confratelli der Bruderschaften des Gonfalone und des Santissimo Crocifisso den Palazzo Apostolico bei einer Kerzenlichtprozession. Dort angekommen, schritten sie durch die Sala Regia bis zur Cappella Paolina, wo sie dem Kurienzeremoniell zum Fronleichnamsfest beiwohnten. ${ }^{215}$ Obwohl mit einem Oratorium eine Raumarchitektur bezeichnet wird, war dieses mit der bruderschaftlichen Zusammenkunft von Priestern gleichgesetzt. Daher spiegelt sich in der architektonischen Ordnung eines Oratoriums eine zeremonielle Ordnung anlässlich solcher Zusammenkünfte innerhalb der Bruderschaften. Ferner dienten diese Versammlungen zur rituellen Vorbereitung auf die alljährlichen Bussprozessionen während der Osterwoche. Die Confraternita del Santissimo Crocifisso hatte daher bereits ab 1549 mit einer steigenden Mitgliederzahl zu kämpfen, unter denen sich auch Namen prominenter römischer Familien fanden. Damit dieses Wachstum auch beibehalten werden konnte, beschloss die Bruderschaft ein Oratorium zu errichten, das sie für ihre Versammlungen nutzen wollte. ${ }^{216}$ Das Oratorium als Architekturordnung ist ein rechteckiger Bau mit Kassettendecke. In diesem Raum ist eine eingezogene Nische für den Altar eingerichtet. Entlang der beiden Seitenwände sind Sitzplätze für die Mitglieder der Bruderschaft installiert, die zusammen mit dem Altar eine räumliche Einheit bilden. Diese Einheit kommt vor allem bei gemeinsamen Messzelebrationen zum Tragen. Der Kardinalprotektor der Bruderschaft, Ranuccio Farnese, legte am Festtag der Kreuzauffindung vom 3. Mai 1562 den Grundstein zu dem Oratorium bei San Marcello al Corso. Damit wurde die Bruderschaft mit der Legende der Kreuzauffindung verknüpft, der die posttridentinische Kontroverstheologie einen zentralen Stellenwert zuschrieb. In der wundersamen

215 ASV, Archivio della Arciconfraternità del Gonfalone, 1219 (Inventario di Scripture e Robe dal 1553 al 1558 [1533-1577]), f. 26v. Vgl. auch Wisch 2011, S. 212 und Partridge/Starn 1990, S. 25-26. Auch prominente Vertreter der Carafa-Familie waren Mitglieder der Bruderschaft des Santissimo Crocifisso, nämlich die beiden Kardinäle Carlo und Alfonso Carafa sowie der Graf von Montorio, Giovanni Carafa. Vgl. hierzu Delumeau 1951, S. 294.

216 Für eine Rekonstruktion der Baugeschichte dieses Oratoriums, welche eine andere Entwicklung aufzeigt als diejenige der Gonfalone-Bruderschaft, ist Fabio Landos Trattato come fu fatto l'oratorio della Compagnia del Santissimo Crocifisso in ASV, Archivio della Confraternita di San Marcello, P.XIX.51, unablässig. Vgl. dazu v. a. Henneberg 1974, S. 15-16. 
Kreuzauffindung wird eine christozentrische Thematik evoziert, auf die in den Bussprozessionen der Bruderschaft während der Karwoche Bezug genommen wird. ${ }^{217}$ Damit praktizierte die Bruderschaft des Santissimo Crocifisso seit ihrer Gründung eine auf die Kreuzes- und Opfercharakteristik ausgerichtete Messliturgik, die mit den Tridentiner Bestimmungen übereinstimmte. Die Gonfalone-Bruderschaft hingegen übte zuerst eine Marienfrömmigkeit aus, die sich erst später zu einer ähnlich christozentrischen Andacht der Messefeiern ausbildete. Die Gonfalone-Bruderschaft war seit dem Quattrocento für die Versorgung der Marienikone in Santa Maria Maggiore zuständig, die jedes Jahr am 15. August - dem Festtag der Himmelfahrt Mariens - in einer Prozession zum Lateran geführt wurde, wo sie zusammen mit der Christusikone ausgestellt wurde. ${ }^{218}$ Nach einem Brand im Jahr 1555 musste die Bruderschaft ihr zwischen der Via Giulia und dem Tiber gelegenes Oratorium erneuern. Zwei Jahre später ersetzte Pietro Roviale Spagnuolo das ursprüngliche Altarbild der Pietà durch ein neues Gemälde der Kreuzigung Christi (Abb. 8). Pietro Roviale, der in Juan de Valverde de Hamuscos Historia de la composición del cuerpo humano als ein Michelangelo ebenbürtiger Maler gerühmt wird, scheint sich aber nicht vollständig vom vorherigen Bildsujet abgewandt zu haben. Für das neue Altarbild der Kreuzigung hatte der Maler am rechten Bildrand unten eine liegende Marienfigur eingesetzt. Damit betonte er eine liturgische Abhängigkeit der christozentrischen von der zuvor praktizierten marianischen Andacht der Gonfalone-Bruderschaft. Barbara Wisch argumentierte, dass das neue Altarbild den Paradigmenwechsel von der Marienfrömmigkeit zu einer Christozentrik unterstütze. ${ }^{219}$ Sie formulierte jedoch keine Erklärung, weshalb Roviale eine Marienfigur einfügte. Pietro Roviales Bildlösung verweist auf den Umstand, dass im Rom des Carafa-Pontifikates im liturgischen Leben römischer Bruderschaften zwei, wenn nicht sogar mehrerer Riten gleichzeitig bestanden. Da die Gonfalone-Bruderschaft ihr Oratorium an der Via Giulia hatte, war sie stark an die

217 Die Kontroverstheologie des 16. Jahrhunderts zur Kreuzauffindung basierte v. a. auf Luthers im Jahr 1522 gehaltener Predigt am Festtag der Kreuzerhöhung, in welcher er sein Verständnis einer rechtgläubigen Auffindung folgendermassen erläuterte: „Nun wellen wir die rechte erfyndung und erhebung des heiligen creütz auch suchen. Nun Christus hat befolhen das yetlicher sein aigen creütz sol erfinden und erhebn, wie er seins erfunden hat, das soltu hailgen wie er seins geheiligt hat mit flaisch und blut, wa fynsts aber? du darffst nit ayn spaden in die hand nemen und tieff graben, nit reyten gen Jerusalem, sondern erfinden ist erkantnus. [...] das recht creütz muess mit im eingeschlossen haben schmach und spot mit dem leiden, das leyt tief dynn, das grebt man rauss allain mit dem hertzen, das findt man aber, wann man erkent das es got aufgelegt hat. [...] Darnach folgt die erhebung des creütz: wann es nun funden ist, das mans erhebt, nit wie Heraclius ader stacionarij die die leüt mit kressen, sonder erkennen jm hertzen dass got hat auss gnedigem willen aufgelegt, und unbillich tragen und got darumb dancken und preysen. [...] Darum ist das das recht hailig creütz erfundne und erhaben [...]“. Zit. n. WA, 10/3, S. 335-337. Vgl. auch Richter 2009, S. $181-185$.

218 Esposito 1984, S. 91-136; Wisch 1985, S. 6-59; Randolfi 1999, S. 9-25; Richter 2009, S. 208.

219 Wisch 2000, S. 210. 
seit Anbeginn des Cinquecento von Papst Julius II. geförderte urbane Ideologie des römischen Stadtraumes angebunden. ${ }^{220}$ Damit musste sie zwangsläufig eine grössere Bandbreite ritueller Frömmigkeitsansprüche erfüllen, welche die römische Stadtgesellschaft an die Gonfalone-Bruderschaft hatte.

Die Wende von der Marienfrömmigkeit hin zu einer Christozentrik kann erst mit der Ausmalung des Oratoriums zwischen 1568 und 1571 mit Episoden aus der Passionsgeschichte Christi festgestellt werden. Bevor ein neues Missale und ein neues Breviarum Romanum im Ghisleri-Pontifikat Pius‘ V. herausgegeben wurden, waren die Bestimmungen darüber, wie die Messe als sichtbares Kreuz und Opfer zeremoniell gefeiert werden sollte, nur in den Beobachtungen zur Messfeier (De observandis et vitandis in celebratione missarum) festgelegt worden. Die Konzilsväter in Trient konnte es nicht erreichen, ein allumfassendes und allgemeingültiges Reformdekret bezüglich der Messefeier herauszubringen. In den Tridentiner Beobachtungen wurde ein Katalog aufgestellt, wodurch die Bischöfe ,die geschuldet kultische Verehrung zum Ruhme Gottes und zur Erbauung des christlichen Volkes“ in ihren Diözesen wiederherstellen konnten. Damit hatten die Konzilsväter allerding den Bischöfen nur angeordnet, dass sie keinen „Weltleuten oder Regularen“ die Messzelebration erlauben dürften. ${ }^{221}$ Während des Tridentinums entwickelte sich die Dominanz einer spezifisch christozentrischen Thematik des Messopfers, die dann in Rom sowohl die Marien- als auch die Heiligenfrömmigkeit allmählich verdrängte. Cesare Baronios Briefe an seine Eltern berichten ebenfalls von einem solchen Wandel, der anscheinend schon 1563 einzusetzen begann. In Baronios Briefen lässt sich eine profunde Kenntnis sowohl der Heilige Schrift als auch des Tridentiner Messopferdekrets beobachten. Diese Kenntnis der Tridentiner Beschlüsse musste sich Baronio über seine Bekanntschaft mit dem Bischof von Parma und dem Kardinal von Santa Fiore, Guido Ascanio Sforza, angeeignet haben, und zwar als er in dessen Haushalt wohnte. Kurz vor seiner Priesterweihe befand sich Baronio somit in der

220 Vgl. dazu Temple 2011, S. 43-46.

221 COD, S. 736-737: „Deinde, ut irreverentia vitetur, singuli in suis diocesibus interdicant, ne cui vago et ignoto sacerdoti missas celebrare liceat. Neminem praeterea, qui publice et notorie criminosus sit, aut sancto altari ministrare aut sacris interesse permittant, neve patiantur, privatis in domibus atque omnino extra ecclesiam et ad divinum tantum cultum dedicata oratoria, ab eisdem ordinariis designanda et visitanda, sanctum hoc sacrificium a saecularibus aut regularibus quibuscumque peragi [...]“. Hier scheint die bereits diskutierte Bulle Papst Pauls IV. gegen die Apostaten einen wichtigen Einfluss ausgeübt zu haben: supra, Kap. 1.2.1. Dieses zusätzliche Dekret wurde von einer Deputation unter der Leitung des Bischofs von Ragusa, Ludovico Beccadelli, verfasst. Ein erster Entwurf wurde von den Konzilslegaten aus Angst vor zu langen Debatten, welche die Sitzung vom 17. September 1563 weiter aufgeschoben hätten, abgelehnt: CT, VIII, S. 916-924. Vgl. hierzu auch Monson 2002, S. 1-37, hinsichtlich des im ersten Entwurf enthaltenen Verbotes polyphoner Musik, was möglicherweise ein Indiz für die Kenntnis von Palestrinas polyphon komponierter Missae Papae Marcelli durch einzelne Prälaten im Umkreis Beccadellis auf dem Tridentinum sein könnte. Zum Dekret vgl. auch O’Malley 2013, S. 191-193. 
Nähe zu einem prominenten Mitglied des Santo Uffizio. Die Entscheidung Baronios, eine Laufbahn als Kleriker führen und „das nackte Kreuz zusammen mit Christus tragen“ zu wollen, muss im Zusammenhang mit diesem engen Kontakt zum Kardinal verstanden werden. ${ }^{222}$ In einem weiteren Brief vom 23. Februar 1563, den Baronio an seine Mutter adressierte, erläutert er die Thematik des perfetto cristiano und Diener Gottes. In Baronios Verständnis hat sich ein „vollkommener Christenmensch“ nicht der Ausübung von Tugenden zu widmen. Sein oberstes Ziel solle es vor allem sein, die Vollkommenheit anzustreben, indem er regelmässig die Sakramente empfange und über die Passionsgeschichte Jesu meditiere. ${ }^{223}$

Damit spricht Baronio die Problematik des „rechtmässigen Unterrichts der christlichen Lehre“ in den jeweiligen Diözesen an, was auch ein Anliegen der in Trient versammelten Konzilsväter war. Die dottrina cristiana hatte schon in Baronios eigener Heimatstadt und Diözese von Sora an Stellenwert eingebüsst. Diese Vernachlässigung der christlichen Lehre sollte für Baronio anhand der vorbildhaften Rolle, welche die dottrina cristiana in Rom spielte, überwunden werden. Dafür sah Baronio die Einsetzung einer Bruderschaft in seiner Heimatstadt vor, deren Mitglieder sich ausschliesslich dem rechtmässigen Unterricht der christlichen Lehre widmen sollten:

\footnotetext{
Non accade ch'io racconti le miserie della nostra Diocesi, circa del culto divino; come non solo le pecore, ma ne gli pastori loro sanno quel che conviene ad un Christiano: il che meglio che me sapete: one considerando io tal cosa, mi parse di cercar di provederci per questa via. Qui in Roma, et in altre città vicine, e nella Lombardia, è una compagnia d'huomini da bene, e spirituali, quali fanno questa professione d'insegnare la dottrina Christiana summariamente; e questi nelli giorni festivi nella Chiesa; e fanno gran frutto, et è molto commendata tal opera da tutti: tantopiu, quanto che gli ministri son buoni: ne solo pigliano, ma danno del loro, come son corone, santi, e dottrine christiane; et alcune volte sono andato io ad aiutargli in opera si meritoria, e sono molto miei amici. ${ }^{224}$
}

Aus diesem Briefschreiben lässt sich vermuten, dass Baronio noch vor seinem Eintritt in das Oratorium Filippo Neris eine besondere Nähe zu derjenigen Kardinalskommission gepflegt haben musste, die der Medici-Papst noch während der letzten

222 Kardinal Sforza hatte Baronio sogar mehrmals Benefizien in seiner Diözese von Parma angeboten. BVR, Q 46, f. 35v: „[...] che il Sign. Maestro di Casa di Monsign. R.mo di Santa Fiore piu volte m'haveva offerto beneficij in Parma, e ch'io sempre gl'havevo risposto di non volermi lontanare da Roma. [...] deliberai di farmi clero, insieme con li capelli posi da banda ogni pensier terreno, e deliberai portar la nuda croce, insieme con Christo, il che di nuovo confermo, e dico con David: Dominus portio mea, dominus pars haereditatis mea, tu es qui restitues haereditate mihi [...]“. Zur Biografie Sforzas vgl. zuletzt Schwedt 2013, S. 240.

223 BVR, Q 46, f. 37r: „Qui iustus est, iustificetur adhuc; cioè, colui ch“è giusto, cerchi di diventar ancora piu giusto; poi che è pericolosa cosa di fermarsi in un segno, e misura di vivere, senza haver desiderio ogn'hora di maggior perfettione; essendo che nella via di Dio, il non andar innanzi, e tronare in dietro; e chi si contenta di una mediocre perfettione non è degno di veder Iddio, essendo egli infinita perfettione“.

224 Briefschreiben Baronios an den Vater vom 1. November 1563 in BVR, Q 46, f. 38 r. 
Tridentiner Sitzungsperiode zur Ausarbeitung des Catechismus Romanus eingesetzt hatte. ${ }^{225}$ Dieser kuriale Arbeitskreis sollte einen neuen Katechismus herausgeben, in dem auf die von den Reformatoren ausgesprochene Verurteilung von Messen zu Ehren der Heiligen als Götzendienst eingegangen werden sollte. Die Konzilsväter antworteten in ihrem Messopferdekret auf diese Verurteilung dahingehend, dass das Opfer nur Gott dargebracht werde. Indem nur einem Gott geopfert werde, danke ihm der Priester für den Sieg der hochseligen Märtyrer und bitte um ihren Schutz, damit sie für die Gläubigen im Himmel Fürsprache einlegen könnten. ${ }^{226}$ Tommaso Gigli - der damalige Bischof von Sora - versuchte sogar, Baronio selbst für eine solche Unterweisung von Klerikern zu gewinnen, wie es auch ein auf den 9. April 1564 datierbarer Brief Baronios an den Vater bezeugt. Bis zu diesem Zeitpunkt hatte Baronio allerdings die Priesterweihe noch nicht empfangen. Erst am 27. Mai 1564 wurde Baronio zum Priester ordiniert. Deshalb sandte er an seiner statt einen gewissen Pensabene, der sich dieser Aufgabe Giglis widmen sollte, nach Sora. Derselbe Pensabene scheint dann auch im Elternhaus Baronios Unterkunft gefunden $\mathrm{zu}$ haben:

Il Pensabene sarra costì fra dieci giorni, gli farete ogni carezze, e fate conto d'alloggiare un santo, qual meglio conoscerete con gli effetti, che con le mie parole: qui è quasi adorato: lui riforma le cose di Mastro Marco; fategli fare qualche sermone nella vostra Congregatione della Charità: il suo procedere é con semplicità, ancor che sia litteratissimo, e di gran spirito. ${ }^{227}$

Dieses Briefschreiben widerlegt die von Pullapilly vertretene Meinung, dass Baronio Giglis Angebot deshalb ablehnte, weil er ,der Niederlegung seiner Annales Vorrang“ gab. ${ }^{228}$ Baronios Brief zeigt jedoch, dass er sich nach seiner Diakonatsweihe zuerst im Umkreis des Mailänder Bischofs Carlo Borromeo bewegt haben muss. Dies würde die Vermutung nahelegen, dass es sich beim genannten Pensabene um Pensabene Turchetti gehandelt hat. Turchetti war für die Gründung von sogenannten „Schulen zum Unterricht der christlichen Lehre“ in Rom federführend. Die Gründung solcher Schulen geschah nach dem Vorbild der bereits 1536 in Mailand

225 Zur Kommission vgl. CT, IX, S. 1106, 10-17; ibid., I, S. 720, 21-24; ibid., VI, S. 602, 10-20. Vgl. dann auch Bellinger 1987, S. 26-38. Der „Vater der Katechismusidee“ war gemäss Boesch 1956, S. 75-76, der bereits erwähnte Kardinal Seripando: supra, Kap. 1.2.1.

226 CT, VII, S. 157 (II, 4, 73): „[...] dum uni Deo immolat, gratias illi agit pro beatissimorum martyrium insigni victoria; eorumque patrocinium ita implorat, ut ipsi pro nobis intercedere dignentur in caelis, quorum memoria agimus in terris“. Hier verwendet der römische Katechismus den Begriff der Märtyrer, während das Konzil noch die Wendung der illorum victoriis gebrauchte. Zur Formulierung der Konzilsväter vgl. COD, S. 734: „Et quamvis in honorem et memoriam sanctorum nonnullas interdum missas ecclesia celebrare consueverit, non tamen illis sacrificium offerri docet, sed Deo soli, qu illos coronavit“. Darüber hinaus auch O’Malley 2013, S. 189; Malesevic 2015, S. 26.

227 BVR, Q 46, f. 40r-v.

228 Pullapilly 1975, S. 25: „Predictably, this offer was turned down because his prior commitment to write the Annales was more important to him“. 
eingesetzten Compagnia della Dottrina Cristiana. Damit liesse sich auch die bislang seitens der Forschung wohl kaum wahrgenommene Figur des Maestro Marco, die Baronio ebenfalls in seinen Briefen erwähnt, als der in Rom ab 1560 ansässige Mailänder Marco de Sadis Cusani identifizieren. Cusani richtete zusammen mit Henrico de Pietra in Sant' Apollinare die erste Schule für den „Unterricht der christlichen Lehre“ ein. ${ }^{229}$ Turchetti erwähnt in einem Briefschreiben vom 5. Juli 1562 an Borromeo die Gründung weiterer solcher Schulen in Rom. ${ }^{230}$

Pensabene Turchetti pflegte ebenfalls enge Verbindungen mit dem Oratorium von San Giovanni dei Fiorentini. Er verfasste nämlich die erste Regola der Oratorianer, die er 1566 niederschrieb. In diese erste Regola des Oratoriums fügte Turchetti ein Kapitel über die „geistlichen Übungen“ (Essercizii Spirituali) ein, aus dem sich die spirituelle Charakteristik der Oratorianer ableiten lässt. Neben der Bedeutung des Busssakraments wurde der Marienfrömmigkeit ein ebenso großer Stellenwert zugesprochen, indem „,jeden Morgen ein Mysterium des Rosenkranzes rezitiert“ werden sollte. Turchettis Regola lässt auch erkennen, dass die Oratorianer in San Giovanni dei Fiorentini das traditionelle Totengebet De profundis praktizierten. Diese Gebetsform für Verstorbene lehnte sich an den gängigen Begräbnisritus an. Diesbezüglich liegt die Vermutung nahe, dass einige Priester aus Neris Oratorium auch der Confraternita della Morte e Orazione angebunden sein mussten. ${ }^{231}$ Turchettis Regola enthält jedoch kein Indiz, ob innerhalb der Priesterversammlungen in San Giovanni dei Fiorentini Vorträge zur Kirchengeschichte gehalten wurden. Cesare Baronios Eintritt in Filippo Neris Beichtkreis musste daher durch die Vermittlung des commendatore von Santo Spirito in Sassia zu Stande gekommen sein, zumal es Bernardino Cirillo selsbt war, der Neri davon überzeugen konnte, die Leitung der Florentiner Nationalkirche zu übernehmen. ${ }^{232}$ Dies geht auch mit der Tat-

229 Moroni 1834, S. 246 und Marangoni, Vita, App., S. 21-23, wo auch eine Biografie Pietras abgedruckt ist.

230 Castiglione, Istoria delle scuole di dottrina cristiana, S. 220.

231 Die Regola befindet sich in einer Abschrift in Marangoni, Vita, app., S. 100-104, hier S. 102: „Ogni mattina si reciti un Mistero del Rosario; cercando di meditarlo fin che si può, o pur la Corona della Madonna, o del Signore, e di più cinque Pater, \& altretrante Ave per la conversione de' Peccatori, \& un De profundis per li Morti [...]“. Zur Confraternita della Morte e Orazione, die unter Pius IV. mit der Bulle Divina disponente clementia vom 17. November 1560 zur Erzbruderschaft erhoben wurde, vgl. Serra 2007, S. 75-108, sowie infra, Kap. 2.1.2.

232 Vgl. hierzu die Zeugenaussage Giovanni Manzolis vom 5. Oktober 1595, zentral aus Primo Processo, I, S. 241-242: „Poco dopoi il p. m.s Filippo fu ricerco di andare al governo di S. Giovanni dei Fiorentini, et se ne fece pregare un pezzo. Finalmente, per compiacere alla natione et a mons. Cirillo, vi andò, ma non per questo abbandonò S. Hieronimo, che tornava sempre a dormire a S. Hieronimo, et confessava nell'uno et nell'altro luogo“. Diesen Vorschlag unterbreiteten allerdings bereits 1563 die beiden Florentiner Pier Antonio Bandini und Giovanni Battista Altoviti. Hierzu die weiteren Zeugenaussagen in ibid., III, S. 279 (Germanico Fedeli, 8. Juni 1610) und ibid., IV, S. 115-116 (Kardinal Ottavio Bandini, 8. August 1611). 
sache einher, dass Baronio unmittelbar nach seiner Priesterweihe am 27. Mai 1564 seine erste Messe in derselben Kirche hielt. Da diese Messe auf den vierten Sonntag nach Pfingsten fiel, leitete sie Baronio mit den Worten Dominus illuminatio mea ein. ${ }^{233}$ Unmittelbar danach verlieh Tommaso Gigli, der vorhin genannte Bischof von Sora, dem neuen Mitglied der Oratorianer ein Kanonikat in seiner Heimatstadt Sora. Damit beabsichtigte Gigli, Baronio wieder stärker an diese Diözese anzubinden. Ebenso wie die Einladung Giglis, in Sora für den rechtmässigen Unterricht der dottrina cristiana $\mathrm{zu}$ sorgen, lehnte Baronio auch dieses Kanonikat ab. ${ }^{234}$ Filippo Neri ergriff nach dieser Ablehnung Baronios sofort die Möglichkeit, seinem neuen Mitglied und den beiden Familiaren des Papstneffen Borromeo - Francesco Maria Tarugi und Alessandro Fedeli - in San Giovanni dei Fiorentini eine Unterkunft zur Verfügung zu stellen. ${ }^{235}$ Dadurch konnte Neri einen für ihn günstigen Abstand zur administrativen Leitung und der liturgischen Ausgestaltung seiner Priesterversammlungen in San Giovanni dei Fiorentini gewinnen, da er immer noch in San Girolamo della Carità wohnte. Aus einem bislang undatierten Briefschreiben Baronios an seine Eltern in Sora können seine ersten Tätigkeiten für die Priesterversammlungen in San Giovanni dei Fiorentini rekonstruiert werden. Baronio war primär für die Predigten aus der Heiligen Schrift zuständig. ${ }^{236}$ Ein weiteres Briefschreiben vom 5. Mai 1567 an seinen Vater gibt Aufschluss darüber, dass diese Priesterversammlungen in San Giovanni dei Fiorentini in einem problematischen Spannungsverhältnis mit Giacomo Sa-

233 BVR, Q 63, f. 291v: „Eodem anno, dominica quarta post pentecostem, cuius introitus, Dominus illuminatio mea, dixi in ecclesia S. Ioannis Florentinorum Romae primam missam". Ein Briefschreiben an seinen Vater vom 1. Juni 1564 in BVR, Q 46, f. 40r, enthält eine Einladung an seine Eltern, an dieser ersten Messe Baronios teilzunehmen. Die Priesterweihe vom 27. Mai 1564 kann durch ein weiteres Schriftstück in BVR, Q 63, f. 291v, nachgewiesen werden.

234 Vgl. neben Baronios Briefschreiben an den Vater, das zwischen Juni und August verfasst wurde, in BVR, Q 46, f. 40r-43v, auch BVR, Q 56, f. $14 r-v$.

235 Primo Processo, III, S. 325: „Et là, a S. Giovanni dei Fiorentini, vi mandò ad habitare alcuni delli suoi figliuoli spirituali, fra li quali vi fu Baronio, il Tarugi, il Bordino, il p. Angelo Velli, il p. Alessandro Fidele, il p. Camillo et alcuni altri [...] et la Nation Fiorentina gli dava alcuni scudi il mese per ciascuno prete [...]“. Dass der Familienkreis Borromeos einen zentralen Anteil an der Bildung dieser sodalitas hatte, lässt sich anhand eines am 9. November 1562 erstellten Testamentes Neris ableiten, welches er aufgrund einer schweren körperlichen Krankheit anfertigen liess und welches sich befindet in ASR, Collegio dei Notari Capitolini, 622, 1556 ad 1563. Bernardinus de Comitibus Not., f. 515r. Eine deutsche Übersetzung dieses Schriftstücks liegt vor in Wick-Alda/ Wodrazka 2011, S. 196-200. Zu diesem Testament vgl. auch Incisa della Rochetta 1973/72, S. 65-68.

236 BVR, Q 43, f. 43v: „Dirrete a mia madre, che attenti a star sana, et allegra, che se lei vedesse il bel frutto, che si fà nell'anime; e come a me peccatore Dio mi ha dato in governo persone sante, certo ne haveria grandissima consolatione e tutte l'altre consolationi del mondo, a comparatione di questa [...] Non posso esprimere quanto sia la mia allegrezza delli miei figlioli spirituali, quali sono vostri nepoti, quali di tante sopra humane gratie da Dio sono donate. Onde in me si verificano le parole della Scrittura, che dice: Laetare sterilis, quae non paris, quia plures erunt filii sterilis, quam virum habentis“. 
vellis Edikten standen. Der vicarius urbis verfügte nämlich darüber, dass Priester, die später der Diözesanverwaltung eines Bischofs unterstehen sollten, auf deren Kenntnisse über die Heilige Schrift sowie über die Patristik geprüft werden sollten. Das Briefschreiben an den Vater berichtet darüber, dass Baronio vom vicarius Savelli über seine Kenntnisse zu den Kirchenvätern Ambrosius und Augustinus geprüft wurde:

Essendo sinistramente informato il Cardinal Savello Vicario del Papa, fece intendere al Santo Padre, che mandasse i suoi, che raggionavano e confessavano, all'esame, perchè voleva, che fossero interrogati alla sua presenza dagl'esaminatori. Obbedì il Santi, e vi mandò il P. Cesare Baronio, il P. Francesco Bordini, il P. Francesco Bozzio, et il P. Antonio Carli, che poi si fece Religioso. Se n'andarono dunque questi à presentarsi al Cardinal Vicario, dove si ritrovarono gli esaminatori [...] cominciarono ad interrogare il primo, ch'era il P. Cesare Baronio, al quale fù domandato, che avesse studiato; e rispondendo esso, ch'havea studiato legge, e che in quella s'era addottorato: altro che legge vi vuole, soggiunse uno degl'esaminatori, per sermoneggiare: se non havete studiato altro che questo, non basta. Havete mai letto i Padri le disse un altro esaminatore; a cui esso rispose: un poco; replicò esso: havete voi letto S. Agostino? L'ho letto tutto, soggiunse; le disse quello: giacché l'havete letto tuttoo come voi dite, dove dice esso la tal e la tal altra cosa? Rispose il P. Cesare Baronio: la dice nel tale e tal luogo, nella tale e tale occasione, e riferi le parole ad verbum del Santo con una gran franchezza [...] Le domandoó poi un'altra dottrina di S. Agostino, al che esso rispose molto aggiustamente. Le dimandó poi che altro havea veduto di S. Agostino, a cui rispose, che haveva letto tutte le opere [...] e domandandogli se havea vedute altre opere; rispose: S. Ambrogio. ${ }^{237}$

Die patrischen Schriften dieser beiden Kirchenväter mussten daher den Kern von Baronios Predigten in San Giovanni dei Fiorentini gebildet haben. Im Verlauf dieser Studie konnte gezeigt werden, dass der Eintritt Cesare Baronios in Filippo Neris Oratorium sich zu einem Zeitpunkt vollzogen haben muss, als sich die städtischen Normen der Sakramentsverwaltung mit einem Neuverständnis des Priesteramtes gemäss den Tridentiner Beschlüssen überschnitten. Diese Überschneidung kam am deutlichsten im Zusammenhang mit Frage der Priesterausbildung zum Vorschein. Während seiner ersten Jahre in Rom musste Baronio demgemäss zuerst einem kurialen Prälatenkreis begegnet sein, bevor er dem Beichtkreis von Priestern in Filippo Neris Oratorium beitreten konnte. Mit diesen ausgewählten Kurienprälaten

237 BVR, Q 58, f. 77r- $v$. Dieses Examen war auch von den Konzilsvätern in Trient im Reformdekret der 24. Sitzung vom 11. November 1563 bestimmt wurden: COD, S. 761-763. Entsprechend findet sich in ASVR, Bandimenta, Editta Vicarii Urbis (1566-1609), f. 229r-230v, ein vom Vikar Savelli herausgegebenes Edikt vom 24. August 1566 über die „Beobachtung des Heiligenkultes“ (Osservanza del culto divino). Vgl. diesbezüglich auch Baronios Briefschreiben vom 5. Mai 1567 in BVR, Q 46, f. 44v: „Ci sono sopragiunte fatighe, che gia per ordine di superiori da loro esaminati a predicare, siamo tre per invicem. Per gratia di Dio le cose riescono megli che non pensava, e tuttavia moltiplica l'odientia: a ciascuno tocca la sua festa. A me tocca la festa di san Filippo et Jacobo; e mi tocca la festa la predica dell'Ascentione, alla quale hora mi preparo. Spero in Dio le cose riusceranno da bene in meglio, mediante l'orationi delle molte persone devote: pensate che bisogna stare in cervello, predicando in un loco, come questo, dove è la nobilità di Banchi [...]“". 
begann Baronio bis zu seiner Priesterweihe 1564 enge Beziehungen zu stiften, auf die er in seiner fortgeschritteneren Laufbahn zurückgreifen konnte. Als dann Filippo Neri die administrative Leitung der Florentiner Nationalkirche von San Giovanni übergeben wurde, bot sich für Baronio ein günstiger Zeitpunkt, einer Priesterversammlung beizutreten, innerhalb der er seine Tätigkeit als Messner aufnehmen konnte. Baronios Eintritt in Neri Oratorium ist somit als das Ergebnis eines intensiven Dialogs zwischen einer sich in der Beichte zusammenschliessenden Priesterversammlung und einzelner Kurienorgane, denen die Stadtverwaltung Roms anvertraut wurde, zu betrachten. Auch wenn dieser Dialog nicht reibungslos verlief, konnte sich Baronio nichtsdestotrotz zum Zeitpunkt seines Examens vor dem vicarius urbis als ordentlicher sowie kenntnisreicher Priester behaupten. Giacomo Savellis Prüfung der Priester von San Giovanni dei Fiorentini erlaubte es dem Oratorium schliesslich, neue Priester aufzunehmen und selbst als Ausbildungsstätte künftiger Seelenhirte zu wirken. Filippo Neris Priesterversammlungen präsentierten daher ein alternatives Modell der Priesterausbildung gegenüber den Jesuiten- und Diözesanseminaren. Diesen alternativen Weg der Priesterausbildung hat auch der Jesuit Giovanni Polanco in einem am 10. August 1560 verfassten und an die Ordensoberen adressierten Schreiben festgehalten:

Et così essendovi, generalmente parlando, due maniere di aiutar li prossimi: una nelli collegii con la institutione della gioventù nelle lettere, dotrrina et vita christiana; l'altra con aiutar universalmente tutti con le prediche et confessioni, et altri mezzi conformi al nostro solito modo di procedere [...]. ${ }^{238}$

Filippo Neris Oratorium kann daher zu den römischen Seminaren gezählt werden, die zur Ausbildung von Priestern eingerichtet wurden. Der Erläuterung Polancos kommt eine im Art Institute of Chicago aufbewahrte Vorstudie zu Livio Agrestis Disputation der Heiligen Katharina mit Philosophen sehr nahe. Das Blatt zeigt einen Entwurf für ein Altarbild, das ursprünglich den Hochaltar der Kirche von Santa Catherina dei Funari zieren sollte (Abb. 9). ${ }^{239}$ In der Bildmitte sitzt die Heilige Katharina in dramatischem contraposto auf einem Sockel. Sie wird von fünfzig heidnischen Philosophen, die ebenfalls in bildrhetorischen Figurenstellungen dargestellt sind, umgeben. Oben links thront Kaiser Maxentius. Im Bildvordergrund setzte Agresti eine eingerahmte Szene, welche die Erscheinung eines Engels vor der Heiligen Katharina zeigt. Zwei michelangeske Figuren flankieren diese Verkündigungsszene, die sich hinter einem Gitter abspielt. Agresti musste sich dabei an Raffaels Befreiung Petri aus der Stanza d'Eliodoro angelehnt haben. Die Szene der Verkündigung ist ferner als ein bildsprachliches Mittel gedacht, um mit ihr den Anschein zu erregen, dass sich unterhalb des Hauptaltars eine mit Gittern ab-

238 MHSI, Monumenta paedagogica, III, S. 304-306, 305. Vgl. diesbezüglich dann auch O’Malley 1993, S. 200, 206-208.

239 Bross 2000, S. 280-297; Bolzoni 2010, S. 40-49. 
gesperrte confessio befindet. Die Figur der Heiligen Katharina inszeniert Agresti aber nicht als Rednerin, sondern stellt sie als Erzieherin dar, indem er sie inmitten mehrerer offenliegender Bücher auf der eingerahmten confessio zeigt. Die pyramidale Anordnung der Figuren führt den Blick des Betrachters zur Heiligen hinauf. Ihr Streitgespräch mit den Philosophen lässt zusammen mit der angeschlossenen Engelserscheinung in der confessio an die theologische Überzeugung denken, dass sich die Glaubensabkehr vom Heidentum hin zum Christentum im rituellen Empfang der Heiligen Kommunion vollzieht - ein Gedanke, der nicht nur bei den Jesuiten, sondern auch im Beichtkreis Filippo Neris stark vertreten wurde. Cesare Baronios Annales Ecclesiastici sprechen ebenfalls diese neue theologische Einstellung gegenüber der Wirkung, welche die Predigt im Zusammenhang mit der dottrina cristiana besitzt, an. Dieses neue Verständnis des Predigtwesens, welches allen voran der vicarius urbis Savelli und der Papstneffe Carlo Borromeo förderten, verbreitete sich im römischen Stadtraum unmittelbar nach dem Abschluss des Tridentiner Konzils. Abgesehen von den Jesuiten war es allen voran die Priesterversammlung in San Giovanni dei Fiorentini, die am stärksten von dieser Entwicklung betroffen war. Die Entstehung von Cesare Baronios Monumentalwerk ist jedoch nicht - wie im folgenden Kapitel gezeigt werden soll - aus dem Umstand, wie Filippo Neris Oratorium seine anfänglichen Schwierigkeiten mit der römisch-kurialen Stadtverwaltung bewältigte, zu erklären. Die Annales Ecclesiastici entstanden viel mehr aus einem spezifischen Bedürfnis der Kurie, eine allgemeingültige Kirchengeschichte vorzulegen, die auch mit den zeremoniellen Bestimmungen zur Liturgie übereinstimmte. Noch während der letzten Sitzungsperiode des Tridentinums hatte die Kurie versucht, diesen Wunsch anhand der Konzilsdekrete zu erfüllen. 